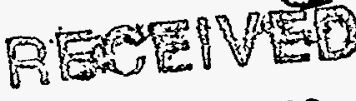

$$
\begin{aligned}
& \text { SEP } 03 \text { 19S8 } \\
& \text { OSTI } \\
& \text { DOE/mC/32260--4 }
\end{aligned}
$$

\title{
A Robotic Inspection Experimental System (ARIES) And BOA
}

\section{Topical Report \\ February 1998}

Work Performed Under Contract No.: DE-FC21-95MC32260

For

U.S. Department of Energy

Office of Environmental Management Office of Technology Development 1000 Independence Avenue Washington, DC 20585
U.S. Department of Energy Office of Fossil Energy Federal Energy Technology Center P.O. Box 880 Morgantown, West Virginia 26507-0880 By

DHSTRIBUTION OF THS DOCLAENT IS LNULAMTED

Operating Engineers National HAZMAT Program

1293 Airport Road

Beaver, West Virginia 25813 


\section{Disclaimer}

This report was prepared as an account of work sponsored by an agency of the United States Government. Neither the United States Government nor any agency thereof, nor any of their employees, makes any warranty, express or implied, or assumes any legal liability or responsibility for the accuracy, completeness, or usefulness of any information, apparatus, product, or process disclosed, or represents that its use would not infringe privately owed rights. Reference herein to any specific commercial product, process, or service by trade name, trademark, manufacturer, or otherwise does not necessarily constitute or imply its endorsement, recommendation, or favoring by the United States Government or any agency thereof. The views and opinions of authors expressed herein do not necessarily state or reflect those of the United States Government or any agency thereof. 


\section{DISCLAIMER}

Portions of this document may be illegible in electronic image products. Images are produced from the best available original document. 


\section{CARNEGIE MELLON UNIVERSITY \\ BOA \\ HUMAN FACTORS ASSESSMENT}

\section{SECTION 1 - SUMMARY}

\section{Technology Description}

BOA is a self-propelled automated minienclosure, able to remove insulation from installed pipes, primarily of 4 " nominal outside diameter. The system is designed for two operators: one oversees the abatement head operation from a distance of 10 or 15 feet using a pendant control and the other bags the debris at a cyclonic bagging station that is attached by a vacuum hose to the cutting head. Since the abatement head is its own enclosure, there may be no need for further enclosures to be built. The system wets and removes asbestos insulation automatically, cutting the debris into consistent "chunks" and moving the waste under a strong vacuum to a bagging machine. Prior to reaching the bagging operation, the material passes through a water separator which greatly reduces the weight of the debris and allows recirculation of water, after sufficient filtration.

\section{Key Results}

The safety and health evaluation, during the human factors assessment, focused on: noise, dust concentrations, ergonomics, and computer software. Industrial hygiene sampling indicated that worker exposures may be kept low enough during normal operation of BOA to eliminate the need for respiratory or hearing protection while working around the cutting head and bagging operation. Airborne particulate measurements showed a slight rise over background levels during the operation of $\mathrm{BOA}$, but the average of all the readings during operation was 1.6 percent of the OSHA respirable dust standard. Air sampling and noise monitoring showed dust to be negligible. Noise was shown to be a potential exposure hazard depending on worker location.

\section{SECTION 2 - HEALTH AND SAFETY EVALUATION}

General Safety and Health Concerns

Safety and health issues of concern with BOA included tripping hazards, lockout/tagout, ergonomics, electrical hazards, working at heights, and struck-by hazards.

\section{Industrial Hygiene Monitoring}

During the assessment, sampling was conducted for dust, noise, and ventilation flow. Observational evaluation and the NIOSH lifting equation were used for ergonomic evaluation.

Ergonomically there is potential for muscle/back, knee, leg, ankle, shoulder, and neck stress and/or injury due to the lifting, twisting, bending, stooping, and kneeling required during set up, operation, and tear down of BOA. Calculations based on the NIOSH lifting equation indicate that the bags of insulation should be kept at 30 pounds or less as the job is currently conducted.

Ventilation measurements documented strong air flow into the cutting head when the main vacuum unit was operating and acceptable levels when only the auxiliary vacuum was working.

Air sampling was conducted throughout the area where $B O A$ was operating. All dust sampling showed results below the limit of detection for the analytical method and therefore, below the OSHA PEL and the ACGIH TLV. An MIE realtime particle counter showed a slight rise above the background level but this was still only 1.6 percent of the OSHA respirable dust standard. 
Area noise monitoring conducted during the operation of BOA showed noise levels ranging from 80-89 dBA inside the work area and 96$103 \mathrm{dBA}$ outside the work area in the vicinity of the vacuum unit. This shows noise to be a potential exposure hazard, especially for anyone working in the area of the vacuum unit. Noise monitoring will need to be conducted on a jobby-job basis to determine the levels of exposure.

\section{Software and Hardware Considerations}

The primary missing item is diagnostic software to help computer maintenance personnel locate faults within the system. The exception handling design and implementation appears to be adequate to provide fail safe systems under any unusual failure within the software and/or hardware. System valves and motors fail in a "safe" deactivated condition. For example, if power or computer failure occurs, the robot will remain securely clamped to the pipe and requires manual power to be applied to move it.

\section{Human Factors Interface}

The computer system responsible for operating $B O A$ provides an important human factors interface. A Heartbeat Card in the system basically performs a dead-man switch function to disable the system in a fail-safe mode. The E-Stop buttons located on several system components (pendant, control box, etc.) activates a heartbeat failure.

System operation from the pendant is simple and straight forward. The BOA pendant control consists of simple, single actions, i.e. open clamp, close clamp. Full control by the operator is via this operator pendant. The pendant has a message display panel which displays

operational and fault information to the operator. The Manual Button Box provides simple controls and power to the robot, if the unit has to be removed from the pipe due to computer system failure. In addition, BOA has a bumper tactile sensor and a pipe hanger detection IR sensor.

\section{SECTION 3 - TECHNOLOGY APPLICABILITY}

On observation the technology did not generate visible dust and air monitoring did not show a significant dust level. Noise measurements, also, were acceptable for the new technology. The need to work only on 4" O.D. pipe runs that do not have many bends limits the applicability of the technology. The time needed to physically move the head around a pipe bend may negate the savings associated with the unit automatically operating on a straight run.

\section{SECTION 4 - REGULATORYIPOLICY ISSUES}

The site safety and health personnel where BOA is being used need to be concerned with safety and health regulations applicable to the issues discussed above. Regulations that will apply may include but not be limited to the following areas: housekeeping; machine guarding; lockout/tagout; toxic and hazardous substances; asbestos; scaffolding; cranes, derricks, hoists, elevators, and conveyors; noise and respiratory protection; TSCA; PPE; HAZCOM; and HAZWOPER.

\section{SECTION 5 - OPERATIONAL CONSIDERATIONS \& RECOMMENDATIONS}

Recommendations for improved worker safety and health include good housekeeping, PPE compatible with the level of exposure, ergonomic training and awareness, using a more stable wheel base on the cyclonic bagger, designing an adequate lift to install BOA on elevated pipe runs, and limiting the bags of insulation to 30 pounds or less.

Research supported by the U.S. Department of Energy's Federal Energy Technology Center, under cooperative agreement DE-FC21-95MC32260 with the Operating Engineers National HAZMAT Program, 250 Airport Circle, Beaver, WW 25813, phone 304-258-8674, fax 304-253-7758. This report was prepared with the support of the US DOE; however, any opinions, findings, conclusions, or recommendations expressed herein are those of the author(s) and do not necessarily reflect the views of the DOE. 


\section{CYBERMOTION \\ A ROBOTIC INSPECTION EXPERIMENTAL SYSTEM (ARIES) \\ HUMAN FACTORS ASSESSMENT}

\section{SECTION 1 - SUMMARY}

\section{Technology Description}

ARIES consists of a 6-wheeled K3A mobile platform, a compact subturret, a sonar imaging system, a laser-based light detection and ranging (lidar) navigation beacon system, and a camera positioning system. It has a sonar imaging system used in navigation and collision avoidance and an automatic docking/charging system. Drum-referencing algorithms and camera-positioning algorithms have been included in the primitive instruction set for the robot. The robot's navigation is based on "Synchro-Drive", a patented design that utilizes concentric shafts to distribute drive and steering power to the six wheels simultaneously. ARIES uses a virtual path concept in which only a limited amount of information needs to be provided to the control computer in order to get the vehicle moving.

\section{Key Results}

The safety and health evaluation, during the human factors assessment, found several areas of concern including ergonomics, laser hazards, tripping hazards, fall-from-above and struck-by hazards, electrical hazards, and decontamination of the system.

\section{SECTION 2 - HEALTH AND SAFETY EVALUATION}

\section{General Safety and Health Concerns}

Safety and health issues of concern with ARIES included tripping hazards, lockout/tagout, ergonomics, electrical hazards, fall-from-above and struck-by hazards, and laser hazards.

\section{Industrial Hygiene Monitoring}

Exposure monitoring requirements will be dependent on the environment where ARIES is operating. This will be determined by the site characterization and air monitoring plan. Other areas of concern include lasers, lead-acid batteries, and ergonomics.

The batteries used to power the base of the robot are 12 volt 85 amp. sealed lead-acid. Under normal circumstances there should not be any exposure to the hazardous constituents of the battery but the potential for exposure to lead and lead contaminated sulfuric acid must be realized and proper precautions must be used.

ARIES uses a Class Illb (less than) $100 \mathrm{~mW}$ $600-1550 \mathrm{~mm}$ wavelength diode laser. The laser is mounted on the mast and is used in the laser-based lidar navigation beacon system. Direct viewing as well as diffuse reflections of the beam of the Class IIIb laser used on ARIES is hazardous to the eye, in particular to the retina. The laser should never be viewed directly or with any type of telescopic device.

There are ergonomic stressors associated with the set up and tear down of the system. There is the potential for severe back injury when lifting and carrying the mast that weighs approximately 300 pounds. There is also the potential for strain/sprain to the shoulders, arms, hands, legs, and knees due to the lifting, bending, twisting, stooping, and kneeling required to unload, load, crate, and uncrate other components of ARIES.

\section{Software and Hardware Considerations}

The robot has internal default values, such as motor speed, which can be set using the 
software, Site Manager. This however, does not provide an easy way to either view the default settings or modify them. During the human factors assessment, it was indicated that there has not been any analysis, design, testing, or other architecture diagrams and documentation conducted for the internals of the Site Manager software.

\section{Human Factors Interface}

From the perspective of software usage and the human interface with the operation of ARIES, three levels of users have been identified and suggested by the current human factors assessment. The three suggested levels are (1) the expert who knows the details of the operation of the robot, its programming, and the internal hardware; (2) the programmer who programs the aisle paths, location of the fiduciaries, etc.; and (3) the operator who starts the robot operation for each mission. An additional area of concern with the system software and human factors interface issues involves the analysis, design, testing, and architecture diagrams and documentation. These have not been developed and there is concern that this could lead to human error which may result in a safety/hazard situation.

ARIES is capable of being manually controlled should the need arise. A manual control pendant can be attached to the base of the robot that is then controlled by a "joy-stick" type control lever. An issue of importance for manual operation is that the sonar capabilities for sensing obstructions are disabled. The operator manually moving ARIES needs to be aware of this and take proper precautions to avoid obstacles.

Several maintenance tasks were conducted during the human factors assessment. Several of the tasks were impossible for the operator to perform while wearing chemical protective gloves due to the added bulk, the loss of dexterity, and the loss of tactile sensation.

\section{SECTION 3 - TECHNOLOGY APPLICABILITY}

ARIES mission involves navigating through narrow aisles (typically 36 inches) to inspect drums stacked three high. This does not allow much room for collision avoidance maneuvers. Collision with an object has the potential to stall or tip the robot or the robot may run over the object. This in and of itself, the robot striking a drum, or the object striking a drum has the potential to cause a release and therefore, a spill and/or exposure to contaminants. Additionally, injury may be caused by workers being struck by falling objects.

\section{SECTION 4 - REGULATORYIPOLICY ISSUES}

Safety and health personnel where ARIES is being used need to be concerned with safety and health regulations applicable to the issues discussed above. Regulations that will apply may include but not be limited to the following areas: housekeeping, machine guarding, lockout/tagout, toxic and hazardous substances, electrical, non-ionizing radiation, materials handling, PPE, HAZCOM, and HAZWOPER.

\section{SECTION 5 - OPERATIONAL CONSIDERATIONS \& RECOMMENDATIONS}

Recommendations for improved worker safety and health include good housekeeping, developing lockout/tagout procedures, laser safety training, appropriate PPE, training in the hazards associated with lead acid batteries, calculating the center of gravity for the robot, engineering controls for tip angle cut off, ergonomics training and awareness, and always using mechanical materials handling devices to lift and carry the mast.

Research supported by the U.S. Department of Energy's Federal Energy Technology Center, under cooperative agreement DE-FC21-95MC32260 with the Operating Engineers National HAZMAT Program, 250 Airport Circle, Beaver, WW 25813, phone 304-258-8674, fax 304-253-7758. This report was prepared with the support of the US DOE; however, any opinions, findings, conclusions, or recommendations expressed herein are those of the author(s) and do not necessarily reflect the views of the DOE. 


\section{UNIVERSITY OF SOUTH CAROLINA CYBERMOTION, INC. A ROBOTIC INSPECTION EXPERIMENTAL SYSTEM (ARIES) TABLE OF CONTENTS}

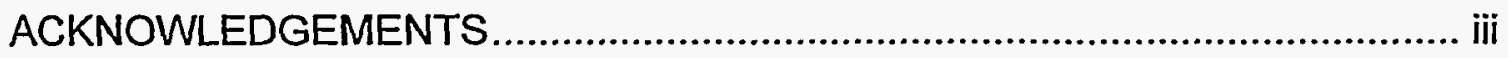

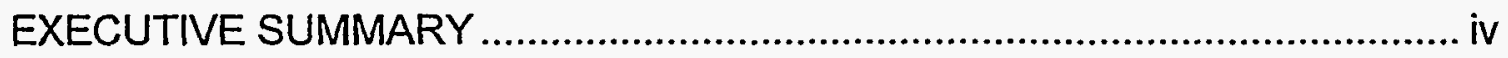

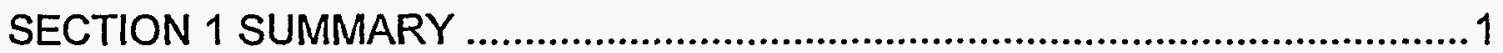

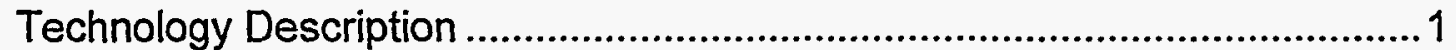

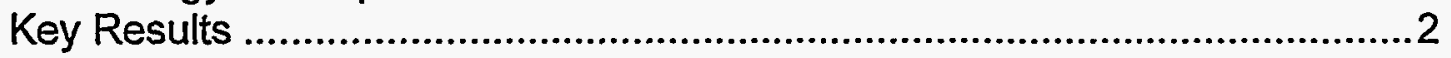

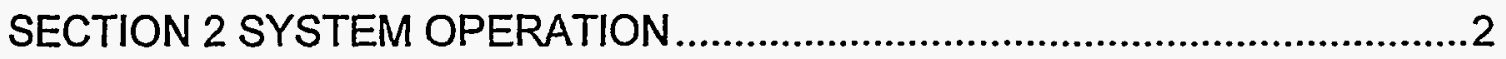

SECTION 3 HEALTH AND SAFETY EVALUATION ....................................5

General Health and Safety Concerns ......................................................5

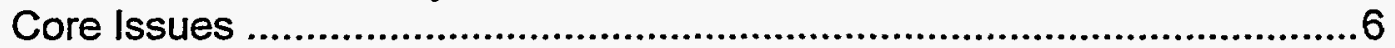

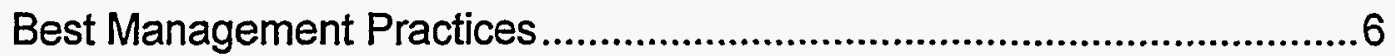

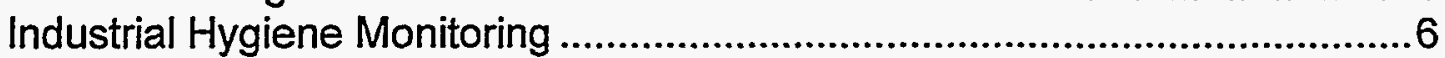

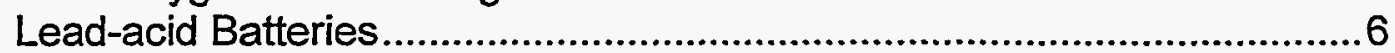

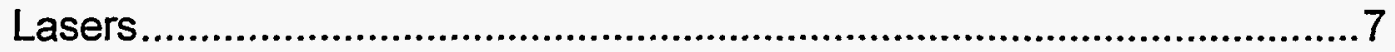

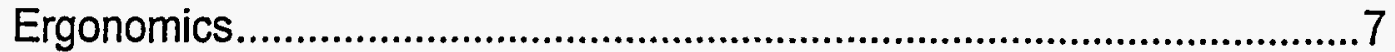

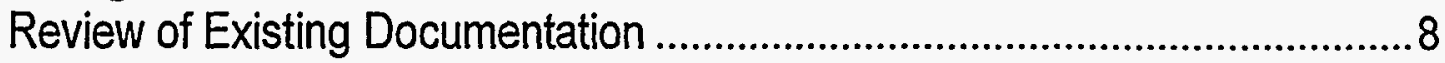

Software and Hardware Considerations .......................................................

Human Factors Interface ........................................................................ 10

Technology Applicability ................................................................. 12

SECTION 4 JOB SAFETY ANALYSIS (JSA) .............................................15

SECTION 5 FAILURE MODES AND EFFECTS ANALYSIS (FMEA) .................21

SECTION 6 TECHNOLOGY SAFETY DATA SHEET (TSDS) …....................22

SECTION 7 EMERGENCY RESPONSE/PREPAREDNESS …......................35

SECTION 8 REGULATORY POLICY ISSUES................................................35

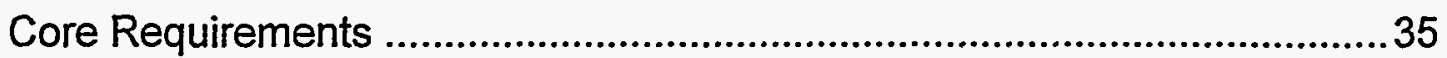




\section{TABLE OF CONTENTS (CONTINUED)}

Technology Specific Requirements ............................................... 36

Special Requirements ................................................................. 37

Best Management Practices................................................................. 37

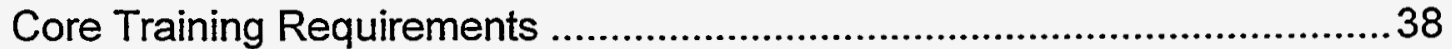

Technology Specific Training .......................................................... 38

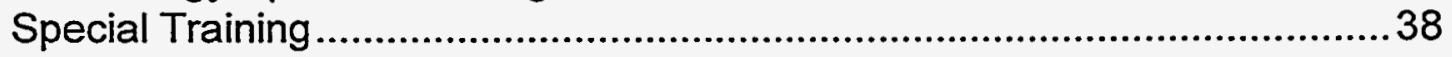

Best Management Practice Training ...................................................38

SECTION 9 OPERATIONAL CONSIDERATIONS AND

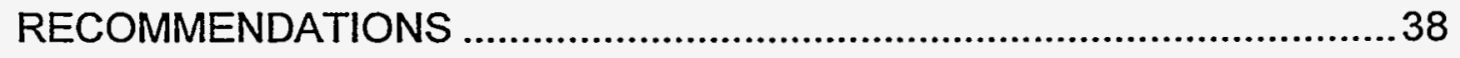

APPENDIX A - REFERENCES ........................................................44

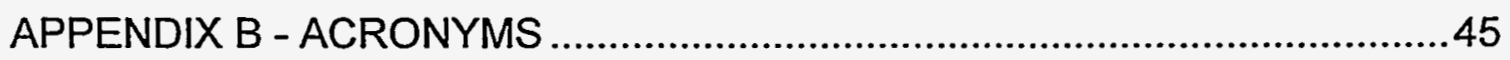




\section{ACKNOWLEDGEMENTS}

The human factors assessment of Cybermotion, Inc. A Robotic Inspection Experimental System (ARIES), was conducted under support of the U.S. Department of Energy's Federal Energy Technology Center, under cooperative agreement DE-FC2195MC32260 with the Operating Engineers National Hazmat Program. The Operating Engineers National Hazmat Program would like to thank the following people for their participation on the "research action team" and the professional expertise they provided for this assessment:

Barbara McCabe

Pat Bell

Robert Harrold

David Mullins

Tony Szwiliski

Aktar Lodger

Tracy Smith
Operating Engineers National Hazmat Program Operating Engineers National Hazmat Program Operating Engineers National Hazmat Program Operating Engineers Local Union 132 Contractor to OENHP (Marshall University) Contractor to OENHP (Marshall University) Contractor to OENHP (Marshall University) 


\section{EXECUTIVE SUMMARY}

The ARIES robotic drum inspection robot designed by Cybermotion, Inc. was assessed for "human factors" by a team from the Operating Engineers National Hazmat Program. ARIES was developed for the Department of Energy (DOE) to remove the worker from the potentially hazardous environment encountered during the routine inspection of drums used to store radioactive waste. There are currently over 315,000 drum equivalents of Mixed, Tru-Mixed, and Low-Level waste accumulated at DOE sites. Mixed waste, due to its hazardous constituents, is covered under the Resource Conservation and Recovery Act (RCRA) regulations which outline a requirement for a weekly inspection of drums and facilities. In addition, DOE and Environmental Protection Agency (EPA) requirements mandate regular inspections.

At the present time, workers walk through the aisles where the drums are stored and visually inspect the drums for discoloration, paint blisters, dents, bulging, and rusting. This is a less than efficient method to conduct inspections and creates the potential to expose workers to radioactive waste. The robot will roam the aisles of 55-gallon drums, stacked three high, making decisions about the surface condition of the drums and maintaining a database of information about each drum. The robot will locate and identify each drum, characterize relevant surface features, and update a database containing inspection information. A camera positioning system positions the vision camera and any other required instrumentation packages (bar-code reader, etc.) to perform the inspection process for each drum. It is anticipated that the mobile robot system will improve the quality of inspection and generate required reports in addition to relieving workers from potential low-level radioactive exposure and contamination hazards. Workers will be required for computer operations, maintenance of the system and its components, and decontamination, when necessary.

The robot itself does not generate any airborne hazards that require exposure monitoring. Exposure monitoring requirements will be dependent on the environment where ARIES is operating. This will need to be determined by the site characterization and air monitoring plan.

The use of sealed lead-acid batteries to power the robot presents an exposure potential for workers. Under normal circumstances there should not be any exposure to the hazardous constituents of the battery but the potential for exposure to lead and lead contaminated sulfuric acid must be realized and proper precautions must be used. This may include handling the batteries utilizing personal protective equipment (PPE), when appropriate, training personnel in the hazards associated with lead-acid batteries, and proper storage and waste disposal. Additionally, there is the possibility of the production of hydrogen gas during the charging of lead-acid batteries. Due to the flammable and explosive properties of hydrogen, this needs to be taken into consideration when the location of the charging station is chosen. 
ARIES uses a Class IIlb (less than) $100 \mathrm{~mW} 600-1550 \mathrm{~mm}$ wave length diode laser. The laser is mounted on the mast and is used in the laser-based lidar navigation beacon system. Direct viewing as well as diffuse reflection of the beam of a Class IIlb laser such as the one used on ARIES is hazardous to the eye, especially to the retina. The laser should never be viewed directly or with any type of telescopic device.

Ergonomic stressors are associated with the crating, uncrating, unloading, and loading of the components for ARIES. Of particular concern is the robot mast. The mast weighs approximately 300 pounds. This has the potential to cause severe back injury to workers from lifting, bending, and carrying the mast. A crate or container or a transport vehicle needs to be developed that will allow the mast to be lifted, carried, and set on the robot base strictly by mechanical means, such as a forklift.

Cybermotion has not completed the minimal amount of documentation on ARIES that is recommended by the Robotic Industries Association (RIA). Critical documents, such as standard operating procedures (SOP's) and maintenance procedures, will enlarge the understanding of worker risks and protection.

The computer system used to operate the robot and the associated software does not distinguish between types of users or levels of security levels. Three user levels are recommended: 1. the expert, who is the person that knows the details of the operation of the robot, its programming, and the internal hardware; 2. the programmer, who.is the person that programs the aisle path, location of the fiduciaries, etc.; and 3 . the operator, who will start the robot operation for each mission, after which the robot will perform its tasks. Additionally, analysis, design, testing, and other appropriate architecture diagrams and documentation need to be developed for the internals of the Site Manager software.

During the human factors assessment, the collision avoidance system was assessed. It was found that the system works adequately as long as the obstacle is not too short or too far off to the side. It needs to be assured that workers in the area are aware of the "blind spots" for the collision avoidance system and that they. take appropriate precautions.

There are decontamination issues with ARIES that may keep it from being "clean" enough to be removed from the area. Areas of concern on the base include the cooling fan for the on board computers and the access doors for areas such as the on board computers and the batteries. Due to the design of the mast and its camera payload arm, it appears to be virtually impossible to decontaminate this section of the robot. Water cannot be used to decontaminate this part of the robot because of all of the open electrical connections and wiring. Where the wiring, chains, and belts run through conduit, the conduit is an open design. 
The robot has a current limit and stall servo kickout feature if it runs into an object and cannot continue forward. It does not have a similar feature for tipping avoidance. The center of gravity for the robot is not known and therefore, there is not enough

information to determine when the robot could tip and thereby cause injury to workers or damage to the drums. The center of gravity needs to be calculated and a stall servo kickout feature for angle of operation needs to be incorporated. 


\section{UNIVERSITY OF SOUTH CAROLINA CYBERMOTION, INC. A ROBOTIC INSPECTION EXPERIMENTAL SYSTEM (ARIES)}

\section{SECTION 1 - SUMMARY}

\section{TECHNOLOGY DESCRIPTION}

A team from the Operating Engineers National Hazmat Program (OENHP) conducted a human factors assessment of A Robotic Inspection Experimental System (ARIES ${ }^{1}$ ), a robotic technology developed by Cybermotion, Inc. The main focus of the assessment was the human factors issues associated with the installation, operation, maintenance, and decontamination of this robotic equipment developed to inspect drums.

Currently, there are over 315,000 drum equivalents of Mixed, TRU-Mixed, and LowLevel waste accumulated at Department of Energy (DOE) sites. Most of this waste is stored above ground in drums or other containers stacked in rows in warehouses at DOE facilities. Mixed waste, due to its hazardous constituents, is covered under the Resource Conservation and Recovery Act (RCRA) regulations which outline a requirement for a weekly inspection of drums and facilities. In addition, DOE and Environmental Protection Agency (EPA) requirements mandate regular inspections.

The development of a mobile robot system, such as ARIES, for the automation of visual inspection provides several benefits. These benefits include a decreased risk, a decreased radiation dose to workers, and increased consistency of inspections.

The mobile robot inspection system, ARIES, has been developed for the DOE to remove workers from the potentially hazardous environment encountered during the routine inspection of drums used to store radioactive waste. The robot will roam the three-foot wide aisles of 55-gallon drums, stacked three high, making decisions abut the surface condition of the drums and maintaining a database of information abut each drum.

\footnotetext{
'ARIES is the commercialized product of a three-phase contract, No. DE-AC21-92MC29115, awarded by FETC to SCUREF (South Carolina Universities Research and Educational Foundation). This project team involved the University of South Carolina, Clemson University, and Cybermotion, Inc.
} 
The robot system will locate and identify each drum, characterize relevant surface features (such as paint blisters, dents, rusted areas, etc.), and update a database containing inspection information. A camera positioning system (CPS) positions the

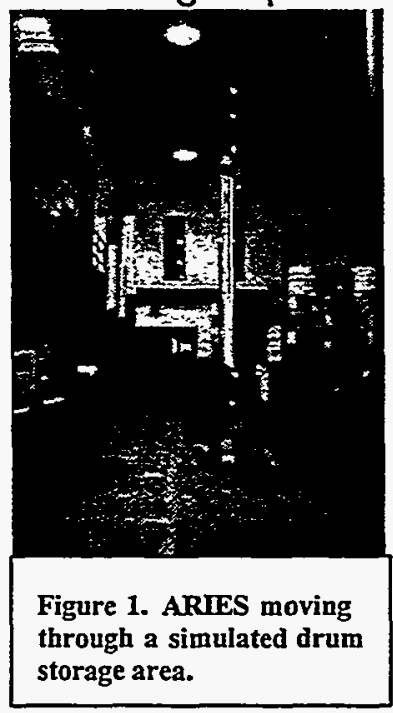
vision camera and any other required instrumentation packages (bar-code reader, etc.) to perform the inspection process for each drum. It is anticipated that this mobile robot system, based on a commercial mobile platform, will improve the quality of inspection, generate required reports, and relieve workers from potential lowlevel radioactive exposure and contamination hazards. Workers will be required for computer operations, maintenance of the system and its components, and decontamination, when necessary.

\section{KEY RESULTS}

The safety and health evaluation during the human factors assessment found several areas of concern. These areas, which will be discussed in detail in later sections of this report, include issues related to ergonomics, laser hazards, tripping hazards, fallfrom-above hazards, struck-by hazards, electrical hazards, and decontamination of the system.

\section{SECTION 2 - SYSTEM OPERATION}

The mobile robot inspection system, ARIES, has been developed for the DOE to remove workers from the potentially hazardous environment encountered during the routine inspection of drums used to store radioactive waste. The robot will roam the three-foot wide aisles of 55-gallon drums, stacked three high, making decisions about the surface condition of the drums and maintaining a database of information about each drum. The robot system will locate and identify each drum, characterize relevant surface features (such as paint blisters, dents, rusted areas, etc.), and update a database containing inspection information. The CPS positions the vision camera and any other required instrumentation packages (bar-code reader, etc.) to perform the inspection process for each drum. It is anticipated that this mobile robot system, based on a commercial mobile platform, will improve the quality of inspection, generate required reports, and relieve workers from potential low-level radioactive exposure and contamination hazards. Workers will be required for computer operations, maintenance of the system and its components, and decontamination, when necessary. 
Cybermotion developed a new version of their commercial Navmaster Series vehicle for ARIES. The robot consists of a 6-wheeled K3A mobile platform, a compact subturret, a sonar (sound navigation and ranging) imaging system, a laser-based lidar (light detection and ranging) navigation beacon system, and a camera positioning system. It has a sonar imaging system used in navigation and collision avoidance and an automatic docking/charging system. Drum-referencing algorithms and camerapositioning algorithms have been included in the primitive instruction set for the robot. The vehicle for the mobile autonomous robot is commercially available, and is capable of unsupervised navigation in a variety of semi-structured environments. The robot's navigation is based on "SynchroDrive," a patented design that utilizes concentric shafts to distribute drive and steering power to the six wheels simultaneously. This gives the

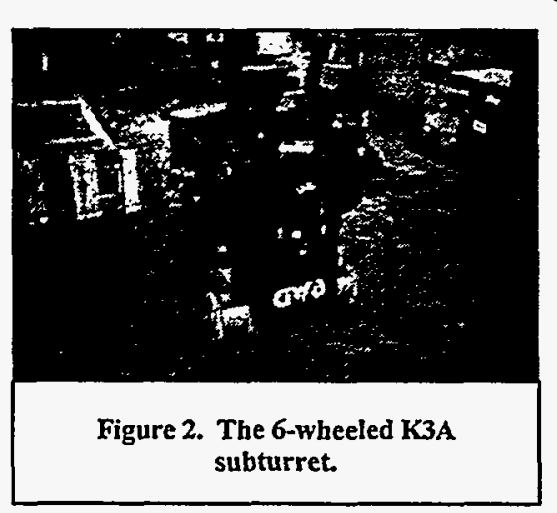
vehicle an ability to dead-reckon its navigation with good accuracy to any given locale over rough and dynamic indoor terrain. The K3A platform is equipped with several onboard and offboard computers. The navigation computer is located in the vehicle base and manages the drive and steering functions. The collision avoidance computer resides in the movable turret and oversees the

data acquisition from eight ultrasonic transducers (also located in the turret). ARIES uses a virtual path concept in which only a limited amount of information needs to be provided to the control computer in order to get the vehicle moving. Low-level, real-time control algorithms perform dead-reckoning navigation with relatively low-cost sensor and computing hardware. The vehicle updates its estimated position in a Cartesian coordinate plane with every 0.07 inches that it travels regardless of how locomotion is obtained. While navigating a path, the PID drive and steering controllers are initiated every 0.1 seconds to correct any perceived errors accumulated as the vehicle travels. Referencing instructions provide dynamic navigational corrections to the vehicle by referencing the system to walls, halls, doorways, etc.

The additional special computer systems for ARIES consist of an onboard management system and an offboard supervisory system. The onboard system, housed in the robot subturret, provides control of the inspection processes and manages other onboard activities. Low-level primitive instructions used by the drum navigation algorithms have been added to the instruction set of the K3A. The onboard computers are essentially transparent to the operator during autonomous operations. Standard UNIX workstations are used for the offboard supervisory computers. The software is written to be portable across most UNIX systems and currently runs on Silicon Graphics, DEC, $H P$, and Sun workstations. Silicon Graphics systems are used for development purposes and some 3-D features require this system for acceptable performance. Provisions have been made for alternative representations in other systems. The 
offboard system provides three primary functions: (i) functional compatibility with the PC-based software provided by Cybermotion for control and programming of the basic robot, (ii) programming tools for creating the mission program, and (iii) the ability to monitor and control the robot during the inspection process. An assembler for the virtual path language of the robot has been provided. This assembler operates in the DOS and UNIX environment. The offboard computers are used by operators for mission setup, monitoring, and control when human interaction is necessary.

Offboard computers networked via wireless Ethernet with onboard computers provide the high-level planning, monitoring, reporting, and general supervision of ARIES.

Multiple control and monitoring stations may be employed. Planning the inspection task (the mission) begins with the implementation of a world representation of the robot's environment (the Robot World).

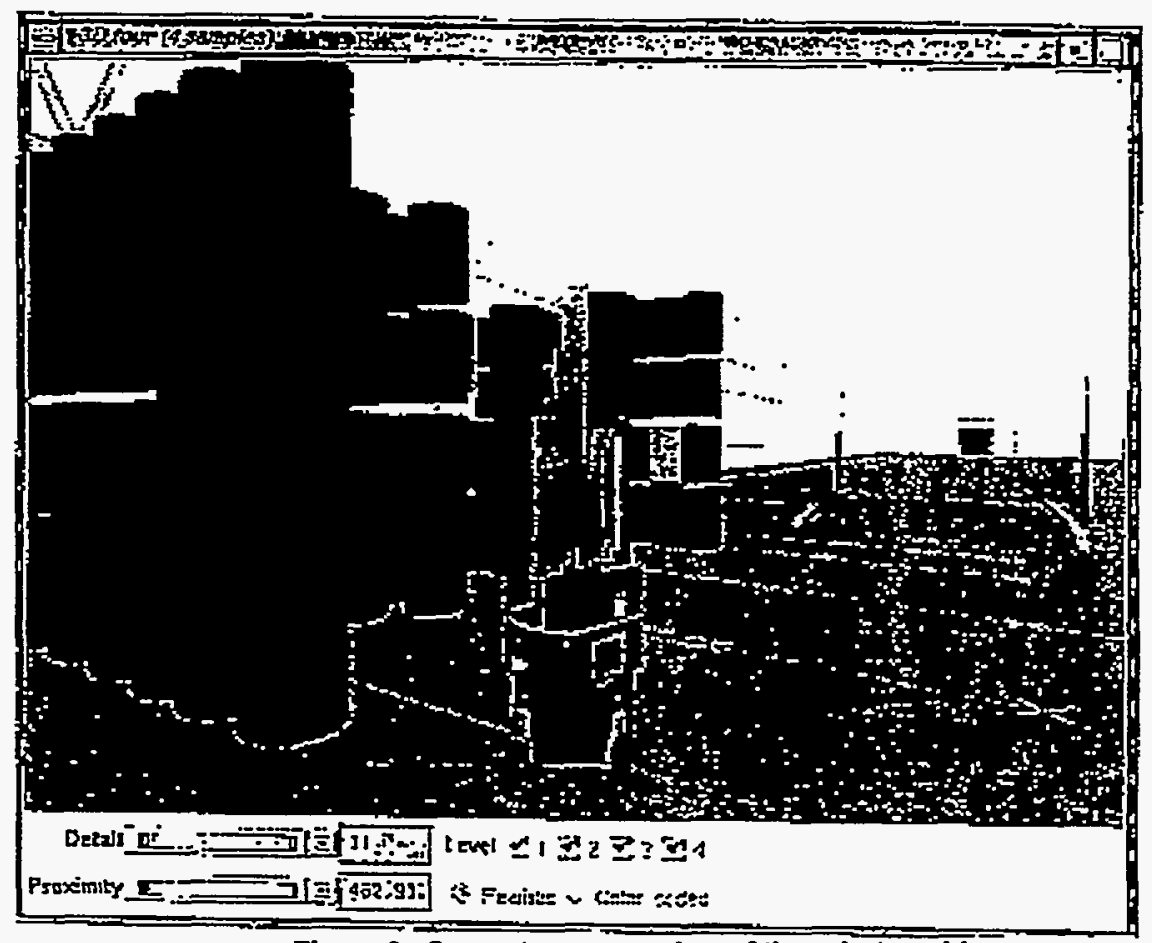

Figure 3. Computer screen view of the robot world.

A path planner automatically generates robot path programs for user-specified paths, based on the site description contained in the robot world. The mission program, used to control the inspection process, is downloaded from the offboard system to the onboard computer where it is executed. The offboard systems may be used to monitor and control the system during the inspection process.

The mission represents the system description of the tasks to be performed by the robot. The mission is created by the Site Manager (mission planning), down-loaded to 
the robot (mission assignment), and executed by the onboard Mission Controller. The Site Manager may be used off-line to plan and create a mission or on-line to control and/or monitor the operation of the robot. It is the user's primary access to the system at the task level. The Mission Controller is charged with the task of carrying out the mission. It is a peer of the Site Manager in that it receives the mission from the Site Manager. However, it is primarily a real-time program, since it directly controls the robot during the survey. The mission consists of (i) the mission script, a high-level description of the mission used by the onboard Mission Controller; (ii) the Path Library, a set of path programs that may be used to travel between the nodes included in the survey area; and (iii) a local copy of the drum list.

The mobile platform transports an inspection application payload that includes a mechanical fixed-mast deployment system, the CPS. The inspection payload consists of color and black and white cameras, bar-code scanner, and strobe lighting. For the drum inspection process, at each stack of drums (three drums in height) the CPS deploys the inspection module at various heights on the drums required by the vision system. A major component of the inspection module is the vision system. It is used to analyze the drums' external and visible conditions and to determine their structural integrity. The overall function of the vision module is to locate suspect drums and to report their condition. Once drums have been located by the robot's navigation system, visual assessment of drum condition is primarily an autonomous assessment of visible and quantifiable surface characteristics. The visible surface blemishes which indicate the possibility of drum failure are rust patches of approximately $0.5 \times 0.5$ inch size and paint blisters indicating internal surface rust. These inspection criteria were developed for ARIES by a task specific work group of the DOE Mixed Waste Focus Area (MWFA).

\section{SECTION 3 - HEALTH AND SAFETY EVALUATION}

\section{GENERAL HEALTH AND SAFETY CONCERNS}

Personnel where ARIES is being used need to be concerned with safety and health issues. Issues that personnel need to be cognizant of may be divided into two categories. Core issues are those that are based on current safety and health regulatory requirements. Best management practices are related to issues that are not based on current safety and health regulations but are key elements in preventing worker injury and illness on the job. 
Safety and health issues of concern with ARIES included:

\section{Core Issues:}

Tripping hazards - The fiduciaries used for robot navigation are tripping hazards. In addition, they are easily moved, by tripping on them, which could cause navigational problems for the robot.

Electrical hazards - There are electrical hazards associated with the charging station and the lead-acid batteries. Proper lockout/tagout procedures need to be applied before any maintenance activities are performed.

\section{Best Management Practices:}

Laser - There are hazards associated with the Class Illb laser used on ARIES.

Tipping hazards - There is the potential for the robot to tip and fall on or strike personnel or strike a drum of waste.

Fall-from-above hazards - There is the potential for fall-from-above hazards from the robot striking an object and knocking it onto personnel or other drums.

Struck-by hazards - There is potential for struck-by hazards from the robot running into personnel in the area as well as running into other objects which may then become a struck-by hazard for personnel.

Ergonomics - There is the potential for severe back injury during the loading and unloading of the ARIES system from the transport vehicle. This will be discussed in greater detail in the Industrial Hygiene section of this report.

\section{INDUSTRIAL HYGIENE MONITORING}

Exposure monitoring requirements will be dependent on the environment where ARIES is operating. This will be determined by the site characterization and air monitoring plan. There are however, areas of concern that are directly related to ARIES itself. This includes lead-acid batteries, lasers, and ergonomics.

\section{Lead-acid Batteries}

The batteries used to power the base of the robot are 12 volt 85 amp. sealed lead-acid. Under normal circumstances there should not be any exposure to the hazardous 
constituents of the battery but the potential for exposure to lead and lead contaminated sulfuric acid must be realized and proper precautions must be used. Proper precautions may include handling the batteries utilizing personal protective equipment (PPE), when appropriate, training personnel in the hazards associated with lead-acid batteries, and proper storage and waste disposal. In 1985, the EPA declared lead-acid batteries to be hazardous waste. Therefore, these batteries must be disposed of using the proper procedures for the disposal of hazardous waste. The lead-acid batteries need to be stored in a water tight, impermeable, curbed surface area. Additionally, there is the possibility of the production of hydrogen gas during the charging of leadacid batteries. Due to the flammable and explosive properties of hydrogen, this needs to be taken into consideration when the location of the charging station is chosen. There should be no open flame or external ignition sources in the area of the charging station.

\section{Lasers}

Lasers are classified to describe the capabilities of the laser system to produce injury to personnel. This classification rates lasers from Class I lasers (no harm) to Class IV lasers. ARIES uses a Class $11 \mathrm{lb}$ (less than) $100 \mathrm{~mW} 600-1550 \mathrm{~mm}$ wavelength diode laser. The laser is mounted on the mast and is used in the laser-based light detection and ranging (lidar) navigation beacon system. Direct viewing as well as diffuse reflections of the beam of the Class IIIb laser used on ARIES is hazardous to the eye, in particular to the retina: The laser should never be viewed directly or with any type of telescopic device. Persons working in an area where there is the potential to be in direct view or reflected view of the laser beam need to use goggles developed specifically for laser use. In addition, all persons working with or performing any type of maintenance activities on the laser must be trained in laser safety.

\section{Ergonomics}

General observational techniques were used to assess the ergonomic stressors associated with ARIES. The observations included:

- The robot, including the base with subturret and mast, and the associated system components must be loaded and unloaded from the transport vehicle. The base of the robot with the subturret can be manually "walked" off of or on to the vehicle but the mast and all other components must be hand-carried. The main concern is the mast. The mast, which weighs approximately 300 pounds, is contained in a wooden crate-like structure which is used to carry it. Although there are handles located on the crate for carrying, there is a great potential for severe back injury and/or injury to the shoulders/arms/hands from workers having to lift and carry this amount of weight. A crate or container or a transport vehicle needs to be developed that will 
allow the mast to be lifted and carried strictly by mechanical means, such as a forklift.

There is also the potential for ergonomic stressors to the back and shoulders/arms/hands from lifting and carrying other system components. Placing these components on pallets to facilitate lifting and moving them with a forklift would alleviate many of these stressors.

- Uncrating/crating the mast may require bending, lifting, stooping, and/or kneeling. These activities increase the ergonomic stressors placed on the back, legs, knees, shoulders, and arms. Additionally, uncrating/crating requires the crate to be disassembled from around or assembled around the mast. This requires removing/placing of screws and nails, which at times are in difficult to reach locations. Bolts with wing nuts would be easier to reach and maneuver. A system that would allow the crate be raised and/or lowered would eliminate the need for all of the bending, stooping, kneeling.

\section{REVIEW OF EXISTING DOCUMENTATION}

The Robotic Industries Association (RIA) has identified the following as important documents from the manufacturer. The following review was conducted during the human factors assessment of ARIES.

\section{Document}

1. Function and location of all controls

2. Robot specifications, including range and load capacity

3. Limiting device information

4. Number, location, and degree of adjustment of hard stops

5. Number and location of control reliable limiting means

6. Lifting procedures and precautions

7. Precautionary information

8. Operating instructions

9. Maintenance and repair information, including preventive maintenance schedules

\section{$\underline{\text { Available }}$}

Yes No N/A Under development

口

口

口

口

口

口 $\boldsymbol{\square}$

口

区

叫

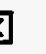

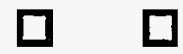

$\square \square$

$\square$

$\square \square$

$\square \quad \square$

$\square \quad \square$

$\square \quad \square$

$\square \quad \square \quad \square$

] 
10. Information required for installation

11. Special environmental requirements

12. Electrical requirements

13. Lockout procedures

14. Failure mode analysis information

15. Hazard analysis and description of all hazard controls

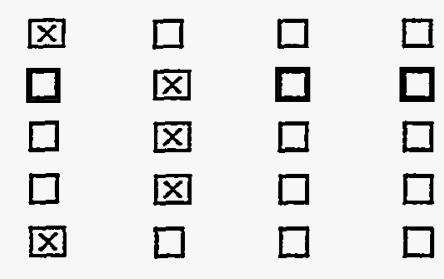

The OENHP evaluations of Type III, robotic technologies requires the following be reviewed in addition to the previous list.

1. Training manuals and training requirements

2. Health and safety plan

3. Job Safety Analysis

4. Operations Manual

5. Maintenance Manual

6. Software listing

\begin{tabular}{|c|c|c|}
\hline$\square$ & 狂 & $\square$ \\
\hline$\square$ & 凶 & $\square$ \\
\hline ] & 凶 & $\square$ \\
\hline$\square$ & 凶 & $\square$ \\
\hline$\square$ & 区 & $\square$ \\
\hline 冈 & $\square$ & $\square$ \\
\hline
\end{tabular}

\section{SOFTWARE AND HARDWARE CONSIDERATIONS}

During the human factors assessment, the software and hardware required for the operation of ARIES was assessed. The following comments and recommendations are made with regard to this:

- From the perspective of software usage, it was evident that three types of users will exist for the system: (1) the expert, who is the person that knows the details of the operation of the robot, its programming and the internal hardware. This may be a representative of the developer; (2) the programmer, who is the person that programs the aisle paths, location of the fiduciaries, etc. This person must have the knowledge (training) required to use the "Site Manager" and other software provided by the developer to program the path and normal operational features of the robot. This person may have limited knowledge of the internal workings of the robot, internal programming details such as UNIX codes; and (3) the operator, who will start the robot operation for each mission, after which the robot will perform its tasks. If the robot stalls, the operator would take it out to a safe location and report the incident to the supervisor. The operator would not be required to have any knowledge of the software/hardware aspects of the robot.

The programs (Site Manager) did not distinguish between users and there was not any "levels of security " feature in the software. This would allow anyone logging into the system to have access to all features with the possibility of 
someone changing/modifying data inadvertently. This could lead to the robot functioning differently than expected and the results could lead to events with the potential for causing accidents and worker injury. It is recommended that the different user levels be defined, either as above or otherwise, and appropriate levels of security be provided for each.

- During the human factors assessment, the Site Manager was demonstrated to the research action team. It was evident that many of the features of the user interface were not very "user friendly". For example, the process of entering the robot path points and fiducial points, the inability to see the path sequence, and the inability to conduct a simulated (computer generated) run. Due to this, several tasks conducted by the user (programmer level, as described above), were tedious. As a result of this tedium, there is the potential for the user to make mistakes, resulting in a possible incorrect path for the robot, resulting in a safety/hazard situation. It is recommended that a careful analysis of the user interface be conducted to increase its "user-friendliness" from an operational perspective.

- The robot has internal default values, such as motor speed, which can be set using the software, Site Manager. However, Site Manager does not provide an easy way to either view the default settings or modify them. This may cause incorrect paths for the robot which may result in safety/hazard situations. It is recommended that the software be programmed to allow viewing of the appropriate robot default settings and/or modifications.

- During the human factors assessment, it was indicated that the robot hardware, through its internal software, has many "lockout" features and is not dependent on external software for safety lockouts. Some of these features were demonstrated during the human factors assessment, stalling when encountering an object too small for the sonar to recognize but too large for the robot to go over and speed control during path movements. Other lockout features need to be assessed before ARIES is deployed at a facility.

- During the human factors assessment, it was indicated that there has not been any analysis, design, testing, or other architecture diagrams and documentation conducted for the internals of the Site Manager software. It is recommended that design and testing documentation be created for future use.

\section{HUMAN FACTORS INTERFACE}

From the perspective of software usage and the human interface with the operation of ARIES, three levels of users have been identified and suggested by the current human factors assessment. The three suggested levels are (1) the expert who knows the 
details of the operation of the robot, its programming, and the internal hardware; (2) the programmer who programs the aisle paths, location of the fiduciaries, etc.; and (3) the operator who starts the robot operation for each mission.

The Site Manager software, which was demonstrated during the human factors assessment, was not considered to be very "user friendly". For example, the process of entering the robot path and fiducial points, the inability to see the path sequence, and the inability to conduct a simulated run prior to the actual event increased the level of difficulty of using the software to operate ARIES. In addition, this caused several of the tasks to be tedious. This tedium increases the potential for the user to make mistakes which could result in a safety/hazard situation.

An additional area of concern with the system software and human factors interface issues involves the analysis, design, testing, and architecture diagrams and documentation. These have not been developed and there is concern that this could lead to human error which may result in a safety/hazard situation.

ARIES is capable of being manually controlled should the need arise. A manual control pendant can be attached to the base of the robot which is then controlled by a "joystick" type control lever. This is a basic operation for moving the robot forward/backward/side-to-side in case of computer operation shutdown. An issue of importance for manual operation is that the sonar capabilities for sensing obstructions in its path is disabled. The operator manually moving ARIES needs to be aware of this and take proper precautions to not run into anyone or anything. The operator must assure he/she has clear visibility of the robots path as it is being removed from one area to another area. Additionally, it may be necessary for the operator to enter the area where ARIES has stopped. This area may be contaminated and therefore, the operator will need to enter utilizing the proper PPE. This has the potential to cause a decrease in visibility due to the use of a full face respirator and a decrease in dexterity and tactile sensation due to the use of radiation/chemical protective gloves. This needs to be taken into consideration and proper precautions used. If ARIES is used in an area where the site characterization has shown chemical protective garments, including gloves to be necessary upon entering the area, consideration should be given to a design change for the manual operating pendant. This should include a larger "joystick" control to accommodate the decrease in dexterity and tactile sensation caused by wearing the gloves.

Several maintenance tasks were conducted during the human factors assessment. This included changing the filter on the charging station, changing the prong on the charging station, and changing the lead-acid batteries in the robot base. These activities were conducted with the operator wearing no gloves (Level D protection), gloves commonly used with an Anti-C (radiation protection) ensemble, and gloves 
commonly used with a Level $B$ (chemical protection) ensemble. Changing the filter on the charging station and changing the lead-acid batteries was not a problem with any of these types of protection. Although changing the lead-acid batteries was not difficult, there were other concerns. These concerns were with electrical hazards and ergonomics which will be discussed in greater detail in other sections of this report. Changing the prong on the charging station was difficult without any gloves and with the Anti-C gloves, and impossible with the Level B gloves. The space to reach into to unscrew the nuts (which were small) is very tight. This, in addition to the decrease in manual dexterity and tactile sensation, made the task impossible. Replacing the nuts with a wing-nut would make the task easier regardless of the type of glove that must be worn.

\section{TECHNOLOGY APPLICABILITY}

ARIES' mission involves navigating through narrow aisles (typically 36 inches) to inspect drums stacked three high. This does not allow much room for collision avoidance maneuvers. Collision with an object has the potential to stall or tip the robot or the robot may run over the object. This in and of itself, the robot striking a drum or the object striking a drum, has the potential to cause a release and therefore, a spill and/or exposure to contaminants. Additionally, injury may be caused by workers being struck by falling objects.

During the human factors assessment the collision avoidance capabilities of ARIES were assessed by placing objects of various size and shape in the robot's path. The collision avoidance was assessed in both the manual mode and autonomous mode of operation. The objects placed in the path and the robot's reaction to these during autonomous operation are as follows:

\begin{tabular}{|c|c|c|}
\hline Object & Object Dimensions & Robot Action \\
\hline traffic cone & $3^{\prime}$ high with $16^{\prime \prime}$ wide base & saw the cone and stopped \\
\hline delineator pole & $3^{\prime} 9^{\prime \prime}$ high with $41 / 2^{\prime \prime} \times 6^{\prime \prime}$ base & saw the delineator and stopped \\
\hline wooden peg & $6 "$ high & hit and pushed \\
\hline brick (lying flat) & $23 / 16^{\prime \prime} \times 7^{\prime \prime} \times 3 \frac{1}{2}$ & hit and stalled \\
\hline delineator pole base & $41 / 2^{n} \times 6^{\prime \prime}$ & hit and stalled \\
\hline $\begin{array}{l}\text { delineator pole (sticking } \\
\text { perpendicularly into aisle } \\
\text { at } 38^{\prime \prime} \text { from floor) }\end{array}$ & & did not see, ran into \\
\hline legal pad & $81 / 22^{n} \times 113 / 4^{n} \times 1 / 2 n$ & did not see, ran over \\
\hline
\end{tabular}




\begin{tabular}{|l|l|l|}
\hline wooden base & $1 / 2^{\prime \prime}$ high & hit and stalled \\
\hline brick (standing on end) & $23 / 16^{\prime \prime} \times 7^{\prime \prime} \times 31^{\prime \prime}$ & hit, pushed brick over then stalled \\
\hline $\begin{array}{l}\text { moving man (Level A suit } \\
\text { on overhead crane) }\end{array}$ & & stopped, did not hit \\
\hline
\end{tabular}

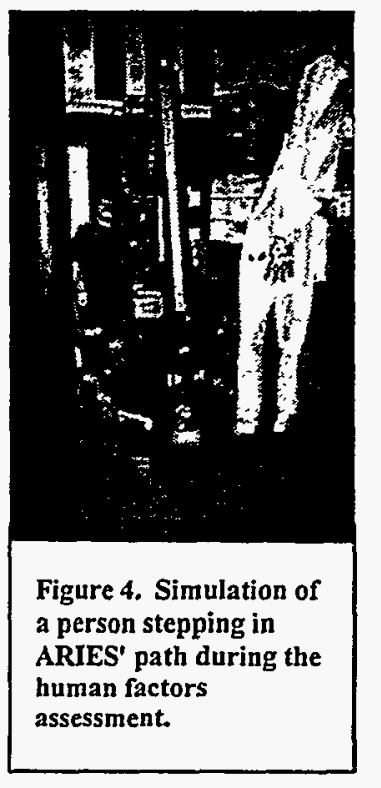

When ARIES came upon an obstacle which it could see (was located by the sonar), it immediately stopped and beeped a warning to indicate that it had stopped. If the obstacle was removed within an appropriate period of time, ARIES would continue along its path, as previously programmed. If the obstacle was not removed within the designated period of time, ARIES would not continue and had to be manually moved back to its starting location (in this case the charging station) before it could continue on its mission. Manual removal requires a worker, utilizing the appropriate PPE, to enter the hazardous area to retrieve the robot using the tether line. The ability to re-start the robot to continue along its path from the operator's station would eliminate the need for a worker to enter the hazardous area.

When ARIES came upon an obstacle it could not see (was not located by the sonar), one of two results occurred: (1) the robot ran into the obstacle and stalled or (2) it ran over the obstacle. If ARIES stalled, it would not continue and had to be manually moved back to its starting location (in this case the charging station) before it could continue on its mission. Manual removal would present the concerns discussed above. If the obstacle was small enough that the robot did not stall, it ran over it. There is concern in that this presents the potential for the robot to run over things such as the foot of a worker.

An additional concern is that when the robot does not see an obstacle and runs into it, the robot may attempt to go over the obstacle which could cause the robot to tip. Although there is a feature to set the drive on the robot to avoid the robot attempting to continue, there is still concern for two reasons: (1) the center of gravity of the robot is not known; and (2) there is no stall out feature based on the robot angle of operation. That is, the robot will continue regardless of the angle at which it is climbing. The robot tipping could result in severe injury if it were to fall on or strike a worker. Additional problems could be caused if the robot tipped and knocked over a drum and caused a spill. This has the potential to expose workers to a variety of contaminants. In addition, workers would have to enter the area to clean up the spill. The robot may also become contaminated which presents additional problems which will be discussed in a later section of this report. 
Another situation which causes concern for creating a tipping hazard, is an obstacle sticking out at a height above the ground whereby it hits the mast of the robot. The sonar would not "see" an obstacle at that height and the robot would continue until it ran into the obstacle. If the robot continues forward and the obstacle did not move the robot may tip until it falls over. Again, since the center of gravity is not known, it is not possible to determine at what angle the robot will tip.

During the human factors assessment, several substances were spilled on the floor directly in ARIES' path. This was done to determine if a spill occurred and ARIES ran through it, if it would hang-up and burn out the motor or if it would stall out due to the current limit and stall servo kickout features. Water, oil (vegetable oil), a water and oil combination, and a water, oil, liquid soap combination were spilled. ARIES did not have any difficulty navigating through any of the spills. ARIES' ability to navigate through thicker and more slippery spills needs to be evaluated at a later date.

Decontamination of the base of the robot may be difficult, particularly for radiation contamination. The main areas of concern on the base of the robot are the cooling fan for the on board computer and the access doors for areas such as the on board computer and the batteries. Filtering the air being pulled into the on board computer area by the cooling fan would prevent contamination from getting inside the robot. It needs to be assured that the access doors are sealed to prevent any contamination from getting inside the robot.

Due to the design of the mast and its camera payload arm, it appears to be virtually impossible to decontaminate this section of the robot. Water cannot be used to decontaminate this part of the robot due to all of the open electrical connections and wiring. Where the wiring, chains, and belts run through conduit, the conduit is an open design. Consideration needs to be given to enclosing the electronics, wiring, camera payload and associated components to enable decontamination to take place. 


\section{SECTION 4 - JOB SAFETY ANALYSIS}

\section{JOB SAFETY ANALYSIS \\ UNIVERSITY OF SOUTH CAROLINA - CYBERMOTION, INC. A ROBOTIC INSPECTION EXPERIMENTAL SYSTEM (ARIES)}

\begin{tabular}{|c|c|}
\hline HAZARD & CORRECT \\
\hline \multicolumn{2}{|c|}{ UNLOADING/LOADING ARIES COMPONENTS } \\
\hline $\begin{array}{l}\text { * Potential for severe back injury from } \\
\text { lifting the mast }\end{array}$ & $\begin{array}{l}{ }^{*} \text { Develop a crate or container or a } \\
\text { transport vehicle that will allow the mast } \\
\text { to be lifted and carried strictly by } \\
\text { mechanical means, such as a forklift } \\
{ }^{*} \text { Ergonomic training to include correct } \\
\text { lifting techniques }\end{array}$ \\
\hline $\begin{array}{l}\text { * Potential for sprain/strain to the back, } \\
\text { shoulders/arms/hands from lifting and } \\
\text { carrying system components }\end{array}$ & $\begin{array}{l}\text { * Place components on a pallet to } \\
\text { facilitate lifting and moving them with a } \\
\text { forklift } \\
{ }^{*} \text { Ergonomic training to include correct } \\
\text { lifting techniques }\end{array}$ \\
\hline $\begin{array}{l}{ }^{*} \text { Ergonomic stressors from bending, } \\
\text { lifting, stooping, and/or kneeling during } \\
\text { crating/uncrating the mast }\end{array}$ & $\begin{array}{l}\text { * Develop a crating system that could be } \\
\text { raised and/or lowered to eliminate the } \\
\text { need for all of the bending, stopping, } \\
\text { kneeling } \\
{ }^{*} \text { Ergonomic training to include correct } \\
\text { lifting techniques }\end{array}$ \\
\hline & \\
\hline
\end{tabular}




\begin{tabular}{|c|c|}
\hline \multicolumn{2}{|c|}{ ATTACHING/DETACHING TURRET TO/FROM SUBTURRET } \\
\hline $\begin{array}{l}\text { * Incorrect or missed contact with } \\
\text { specially designed sleeves for moving } \\
\text { mast to/from the base of the robot which } \\
\text { knocks the mast over resulting in the } \\
\text { mast striking a worker causing severe } \\
\text { injury }\end{array}$ & $\begin{array}{l}\text { *Assure the forks of the forklift are } \\
\text { correctly spaced for the sleeves before } \\
\text { moving toward the mast } \\
\text { *Assure all workers are out of the radius } \\
\text { of where the mast would fall as the forklift } \\
\text { approaches and places forks into sleeves }\end{array}$ \\
\hline $\begin{array}{l}\text { * Use of a forklift to mount mast to the } \\
\text { base of the robot }\end{array}$ & $\begin{array}{l}\text { * Assure the person operating the forklift } \\
\text { is properly trained in its operation } \\
\text { * Assure adequate communication } \\
\text { between the forklift operator and all } \\
\text { others in the area }\end{array}$ \\
\hline $\begin{array}{l}\text { * Mast topples when being moved by } \\
\text { forklift and becomes struck-by or fall- } \\
\text { from-above hazard }\end{array}$ & $\begin{array}{l}\text { * Develop method to stabilize mast to } \\
\text { forklift as it is moved instead of having } \\
\text { workers walk with it and stabilize it by } \\
\text { hand } \\
\text { * Require anyone in the area to wear a } \\
\text { hard hat and steel toed work boots } \\
\text { * Assure the person operating the forklift } \\
\text { is properly trained in its operation }\end{array}$ \\
\hline $\begin{array}{l}\text { *Pinch point between the base of the } \\
\text { robot and the turret, as the turret is } \\
\text { lowered onto the base, severe crushing } \\
\text { hazard for the arms/hands/fingers }\end{array}$ & $\begin{array}{l}\text { * Do not allow workers to use hands to } \\
\text { assist in aligning mast as it is lowered on } \\
\text { to the subturret - instead of using the } \\
\text { hands use some type of pole to guide the } \\
\text { mast for alignment }\end{array}$ \\
\hline CHAR & G ARIES \\
\hline * Shock hazard from the charging probe & $\begin{array}{l}\text { *Standard Operating Procedures } \\
\text { (SOP's) and training to include instruction } \\
\text { on keeping hands away from the probe } \\
\text { and port on the base where the probe } \\
\text { inserts, while the robot is docking } \\
\text { * Do not allow workers in the immediate } \\
\text { area of the charging station while the } \\
\text { robot docks }\end{array}$ \\
\hline
\end{tabular}




\begin{tabular}{|c|c|}
\hline \multicolumn{2}{|c|}{ CHARGING ARIES } \\
\hline $\begin{array}{l}\text { * The probe protrudes out approximately } \\
10-12 \text { inches from the charting station. A } \\
\text { worker may easily run into it and be } \\
\text { injured or break the probe. }\end{array}$ & $\begin{array}{l}\text { * Use a bright color (such as orange) on } \\
\text { the probe so it can be easily seen } \\
\text { * Place the charting station well out of the } \\
\text { traffic flow } \\
{ }^{*} \text { Mark off the charging station area so } \\
\text { workers can not get close enough to } \\
\text { come in contact with the probe }\end{array}$ \\
\hline $\begin{array}{l}\text { * Explosion hazard from the production of } \\
\text { hydrogen gas during the charging of the } \\
\text { lead-acid batteries }\end{array}$ & $\begin{array}{l}\text { "Post "No Smoking" signs within } 50 \text { feet } \\
\text { of the charging station } \\
\text { * Do not place the charging station in the } \\
\text { vicinity of any potential ignition sources }\end{array}$ \\
\hline \multicolumn{2}{|c|}{ OPERATION OF ARIES } \\
\hline $\begin{array}{l}\text { * Tripping hazards - fiduciaries used for } \\
\text { robot navigation }\end{array}$ & $\begin{array}{l}{ }^{*} \text { Mark base of fiduciary in a bright color } \\
\text { (such as orange) so they are more } \\
\text { noticeable } \\
{ }^{*} \text { Mark off the area around the fiduciary } \\
\text { so personnel cannot get close to base } \\
\text { and therefore can not trip on it }\end{array}$ \\
\hline $\begin{array}{l}\text { *Eye hazard, particularly to the retina, } \\
\text { from Class Illb laser }\end{array}$ & $\begin{array}{l}\text { * Use of goggles designed specifically for } \\
\text { laser use } \\
\text { * Laser safety training for anyone working } \\
\text { with the laser }\end{array}$ \\
\hline $\begin{array}{l}\text { Fall-from-above hazards from robot } \\
\text { bumping into things and knocking them } \\
\text { down }\end{array}$ & $\begin{array}{l}{ }^{*} \text { Awareness of where the robot is at all } \\
\text { times } \\
{ }^{*} \text { Install real-time video on robot so } \\
\text { operator can see location and what is in } \\
\text { the area at all times }\end{array}$ \\
\hline
\end{tabular}




\begin{tabular}{|l|l|}
\hline \multicolumn{2}{|c|}{ OPERATION OF ARIES } \\
\hline $\begin{array}{l}\text { * Struck-by-hazards from robot knocking } \\
\text { something into personnel or the robot } \\
\text { running into personnel }\end{array}$ & $\begin{array}{l}\text { "Awareness of where the robot is at all } \\
\text { times } \\
\text { * Install real time video on robot so } \\
\text { operator can see location and what is in } \\
\text { the area at all times } \\
\text { * Set drive motors at lowest level } \\
\text { possible while still allowing the robot to } \\
\text { perform its mission }\end{array}$ \\
\hline $\begin{array}{l}\text { * Due to robot maneuvering with arm } \\
\text { extended (from mast), knocks things over } \\
\text { which may strike a worker }\end{array}$ & $\begin{array}{l}\text { * Program an interlock into the system so } \\
\text { the robot cannot move as long as the } \\
\text { arm is extended } \\
\text { * Develop a mechanism for manual } \\
\text { retraction of the arm }\end{array}$ \\
\hline $\begin{array}{l}\text { * The mast of the robot contacts } \\
\text { overhead hazards and they become fall- } \\
\text { from-above hazards for personnel }\end{array}$ & $\begin{array}{l}\text { "Assure operators are trained to always } \\
\text { be aware of the environment in which the } \\
\text { robot is operating } \\
\text { * Train operators to always be looking for } \\
\text { changes in the environment and new } \\
\text { hazards that may necessitate changes in } \\
\text { the program }\end{array}$ \\
\hline $\begin{array}{l}\text { * Never permit the operator to walk } \\
\text { backwards when manually removing the } \\
\text { robot from an area } \\
\text { * Assure the operator has a clear "line of } \\
\text { sight" when walking behind the robot }\end{array}$ \\
\hline * Struck-by or tripping hazards during \\
manual removal of robot
\end{tabular}




\begin{tabular}{|c|c|}
\hline \multicolumn{2}{|c|}{ OPERATION OF ARIES } \\
\hline $\begin{array}{l}{ }^{*} \text { Crush hazard for feet - robot runs over } \\
\text { foot of worker because sonar cannot see } \\
\text { it }\end{array}$ & $\begin{array}{l}\text { * Set drive motors at lowest level } \\
\text { possible while still allowing the robot to } \\
\text { perform its mission } \\
{ }^{*} \text { Require anyone working in area where } \\
\text { robot is operating to wear steel-toed } \\
\text { boots } \\
{ }^{*} \text { Assure personnel are aware of the } \\
\text { robot's path and where the robot is } \\
\text { operating at all times }\end{array}$ \\
\hline \multicolumn{2}{|c|}{ MAINTENANCE } \\
\hline $\begin{array}{l}\text { "Sparking/shock/burn hazard from the } \\
\text { lead-acid battery wires accidentally } \\
\text { touching the frame of the base when the } \\
\text { batteries are being changed }\end{array}$ & $\begin{array}{l}\text { * Install an electrical disconnect to } \\
\text { prevent this }\end{array}$ \\
\hline $\begin{array}{l}\text { * Shock hazard from the energized } \\
\text { computer components in the base of the } \\
\text { robot }\end{array}$ & $\begin{array}{l}\text { *Place a shock hazard label on the } \\
\text { drawer cover } \\
\text { * SOP's to include lockout/tagout } \\
\text { procedures to be used when it is required } \\
\text { to reach into this area }\end{array}$ \\
\hline $\begin{array}{l}\text { * Abrasions, cuts, or bruises from } \\
\text { bumping into the sharp corners of the } \\
\text { charging station }\end{array}$ & $\begin{array}{l}\text { * Design the charging station with } \\
\text { rounded blunt corners } \\
\text { * Place the charging station well out of } \\
\text { the traffic flow } \\
\text { * Mark off the charging station area so } \\
\text { workers can not get close enough to } \\
\text { come in contact with the probe }\end{array}$ \\
\hline $\begin{array}{l}\text { * Exposure to the lead contaminated } \\
\text { sulfuric acid from the lead-acid batteries, } \\
\text { should a leak occur }\end{array}$ & $\begin{array}{l}\text { * Proper storage and transportation of the } \\
\text { batteries } \\
\text { " Proper disposal of the batteries } \\
\text { * Immediate clean up of any spills, } \\
\text { utilizing the proper personal protective } \\
\text { equipment (PPE) } \\
\text { * All personnel working with batteries } \\
\text { need to be trained in their use and the } \\
\text { hazards associated with them }\end{array}$ \\
\hline
\end{tabular}




\begin{tabular}{|l|l|}
\hline \multicolumn{2}{|c|}{ DECONTAMINATION } \\
\hline * Exposure to contaminants & * Utilization of the proper PPE \\
\hline "ARIES not "clean" after decontamination & $\begin{array}{l}\text { "Enclose electronics, wiring, camera } \\
\text { payload, and associated components }\end{array}$ \\
\hline
\end{tabular}




\section{SECTION 5 - FAILURE MODE AND EFFECTS ANALYSIS}

\section{FAILURE MODE AND EFFECTS ANALYSIS \\ UNIVERSITY OF SOUTH CAROLINA - CYBERMOTION, INC. A ROBOTIC INSPECTION EXPERIMENTAL SYSTEM (ARIES)}

\begin{tabular}{|c|c|}
\hline FAILURE MODE & EFFECT \\
\hline $\begin{array}{l}\text { * Emergency stop buttons fail to work - } \\
\text { do not stop robot when engaged }\end{array}$ & $\begin{array}{l}{ }^{*} \text { Robot may strike worker causing struck- } \\
\text { by injury } \\
{ }^{*} \text { Robot may strike drum and cause spill } \\
\text { of hazardous waste which then has the } \\
\text { potential to cause workers to be exposed } \\
\text { to contaminants }\end{array}$ \\
\hline${ }^{\star}$ Collision avoidance system (sonar) fails & $\begin{array}{l}{ }^{*} \text { Robot may strike worker causing struck- } \\
\text { by injury } \\
{ }^{*} \text { Robot may strike drum and cause spill } \\
\text { of hazardous waste which then has the } \\
\text { potential to cause workers to be exposed } \\
\text { to contaminants }\end{array}$ \\
\hline $\begin{array}{l}\text { * Current limit and stall servo kickout } \\
\text { feature fail - robot continues to move } \\
\text { forward after encountering an obstacle }\end{array}$ & $\begin{array}{l}{ }^{*} \text { Robot may strike worker causing struck- } \\
\text { by injury } \\
{ }^{*} \text { Robot may strike drum and cause spill } \\
\text { of hazardous waste which then has the } \\
\text { potential to cause workers to be exposed } \\
\text { to contaminants }\end{array}$ \\
\hline${ }^{*}$ Collision avoidance system fails & $\begin{array}{l}{ }^{*} \text { Robot may strike worker causing struck- } \\
\text { by injury } \\
{ }^{*} \text { Robot may strike drum and cause spill } \\
\text { of hazardous waste which then has the } \\
\text { potential to cause workers to be exposed } \\
\text { to contaminants }\end{array}$ \\
\hline
\end{tabular}




\section{SECTION 6 - TECHNOLOGY SAFETY DATA SHEET}

\section{TECHNOLOGY SAFETY DATA SHEET UNIVERSITY OF SOUTH CAROLINA - CYBERMOTION, INC. A ROBOTIC INSPECTION EXPERIMENTAL SYSTEM (ARIES)}

\begin{tabular}{|c|c|}
\hline $\begin{array}{l}\text { Manufacturer's Name and Address: } \\
\text { Cybermotion Inc. }\end{array}$ & $\begin{array}{l}\text { Emergency Contact: } \\
\text { Ken Kennedy (540) } 981-0012\end{array}$ \\
\hline \multirow{2}{*}{$\begin{array}{l}\text { Cybermotion Inc. } \\
719 \text { Gainsboro Road, NW } \\
\text { Roanoke, VA } 24016\end{array}$} & $\begin{array}{l}\text { Information Contact: } \\
\text { Ken Kennedy (540) 981-0012 }\end{array}$ \\
\hline & Date Prepared: \\
\hline $\begin{array}{l}\text { Other Names: } \\
\text { A Robotic Inspection Experimental } \\
\text { System }\end{array}$ & $\begin{array}{l}\text { Signature of Preparer: } \\
\text { Operating Engineers National Hazmat } \\
\text { Program } \\
1293 \text { Airport Road } \\
\text { Beaver, WV } 25813 \\
\text { phone (304) 253-8674 } \\
\text { fax (304) 253-7758 } \\
\text { Under cooperative agreement DE-FC21- } \\
95 \text { MC } 32260\end{array}$ \\
\hline
\end{tabular}


SECTION 2: PROCESS DESCRIPTION

The mobile robot inspection system, ARIES, has been developed for the DOE to remove workers from the potentially hazardous environment encountered during the routine inspection of drums used to store radioactive waste. The robot will roam the three-foot wide aisles of 55-gallon drums, stacked three high, making decisions about the surface condition of the drums and maintaining a database of information about each drum. The robot system will locate and identify each drum, characterize relevant surface features (such as paint blisters, dents, rusted areas, etc.), and update a database containing inspection information. A camera positioning system (CPS) positions the vision camera and any other required instrumentation packages (bar-code reader, etc.) to perform the inspection process for each drum. It is anticipated that this mobile robot system, based on a commercial mobile platform, will improve the quality of inspection, generate required reports, and relieve workers from potential low-level radioactive exposure and contamination hazards. Workers will be required for computer operations, maintenance of the system and its components, and decontamination, when necessary.

The robot consists of a 6-wheeled K3A mobile platform, a compact subturret, a sonar (sound navigation and ranging) imaging system, a laser-based lidar (light detection and ranging) navigation beacon system, and a camera positioning system. It has a sonar imaging system used in navigation and collision avoidance and an automatic docking/charging system. Drum-referencing algorithms and camera-positioning algorithms have been included in the primitive instruction set for the robot. The vehicle for the mobile autonomous robot is commercially available, and is capable of unsupervised navigation in a variety of semi-structured environments. The robot's navigation is based on "SynchroDrive," a patented design that utilizes concentric shafts to distribute drive and steering power to the six wheels simultaneously. This gives the vehicle an ability to dead-reckon its navigation with good accuracy to any given locale over rough and dynamic indoor terrain. The K3A platform is equipped with several onboard and offboard computers. The navigation computer is located in the vehicle base and manages the drive and steering functions. The collision avoidance computer resides in the movable turret and oversees the data acquisition from eight ultrasonic transducers (also located in the turret). ARIES uses a virtual path concept in which only a limited amount of information needs to be provided to the control computer in order to get the vehicle moving. Low-level, real-time control algorithms perform dead-reckoning navigation with relatively low-cost sensor and computing hardware. The vehicle updates its estimated position in a Cartesian coordinate plane with every 0.07 inches that it travels regardless of how locomotion is obtained. While navigating a path, the PID drive and steering controllers are initiated every 0.1 seconds to correct any perceived errors accumulated as the vehicle travels. 
SECTION 2: PROCESS DESCRIPTION

Referencing instructions provide dynamic navigational corrections to the vehicle by referencing the system to walls, halls, doorways, etc.

The additional special computer systems for ARIES consist of an onboard management system and an offboard supervisory system. The onboard system, housed in the subturret, provides control of the inspection processes and manages other onboard activities. Low-level primitive instructions used by the drum navigation algorithms have been added to the instruction set of the K3A. The onboard computers are essentially transparent to the operator during autonomous operations. Standard UNIX workstations are used for the offboard supervisory computers. The software is written to be portable across most UNIX systems and currently runs on Silicon Graphics, DEC, HP, and Sun workstations. Silicon Graphics systems are used for development purposes and some 3-D features require this system for acceptable performance. Provisions have been made for alternative representations in other systems. The offboard system provides three primary functions: (i) functional compatibility with the PC-based software provided by Cybermotion for control and programming of the basic robot; (ii) programming tools for creating the mission program; and (iii) the ability to monitor and control the robot during the inspection process. An assembler for the virtual path language of the robot has been provided. The assembler operates in the DOS and UNIX environment. The offboard computers are used by operators for mission setup, monitoring and control when human interaction is necessary.

Offboard computers networked via wireless Ethernet with onboard computers provide the high-level planning, monitoring, reporting, and general supervision of ARIES. Multiple control and monitoring stations may be employed. Planning and inspection task (the mission) begins with the implementation of a world representation of the robot's environment (the Robot World). A path planner automatically generates robot path programs for user-specified paths, based on the site description contained in the robot world. The mission program, used to control the inspection process, is downloaded from the offboard system to the onboard computer where it is executed. The offboard systems may be used to monitor and control the system during the inspection process.

The mission represents the system description of the tasks to be performed by the robot. The mission is created by the Site Manager (mission planning), down-loaded to the robot, (mission assignment), and executed by the onboard Mission Controller. 


\section{SECTION 2: PROCESS DESCRIPTION}

The Site Manager may be used off-line to plan and create a mission or on-line to control and/or monitor the operation of the robot. It is the user's primary access to the system at the task level. The Mission Controller is charged with the task of carrying out the mission. It is a peer of the Site Manager in that it receives the mission from the Site Manager. However, it is primarily a real-time program, since it directly controls the robot during the survey. The mission consists of (I) the mission script, a high-level description of the mission used by the onboard Mission Controller, (ii) the Path library, a set of path programs that may be used to travel between the nodes included in the survey area, and (iii) a local copy of the drum list.

The mobile platform transports an inspection application payload that includes a mechanical fixed-mast deployment system, the CPS. The inspection payload consists of color and black and white cameras, bar-code scanner, and strobe lighting. For the drum inspection process, at each stack of drums (three drums in height), the CPS deploys the inspection module at various heights on the drums required by the vision system. A major component of the inspection module is the vision system. It is used to analyze the drums' external and visible conditions and to determine their structural integrity. The overall function of the vision module is to locate suspect drums and to report their condition. Once drums have been located by the robot's navigation system, visual assessment of drum condition is primarily an autonomous assessment of visible and quantifiable surface characteristics. 


\section{SECTION 3: PROCESS DIAGRAMS}
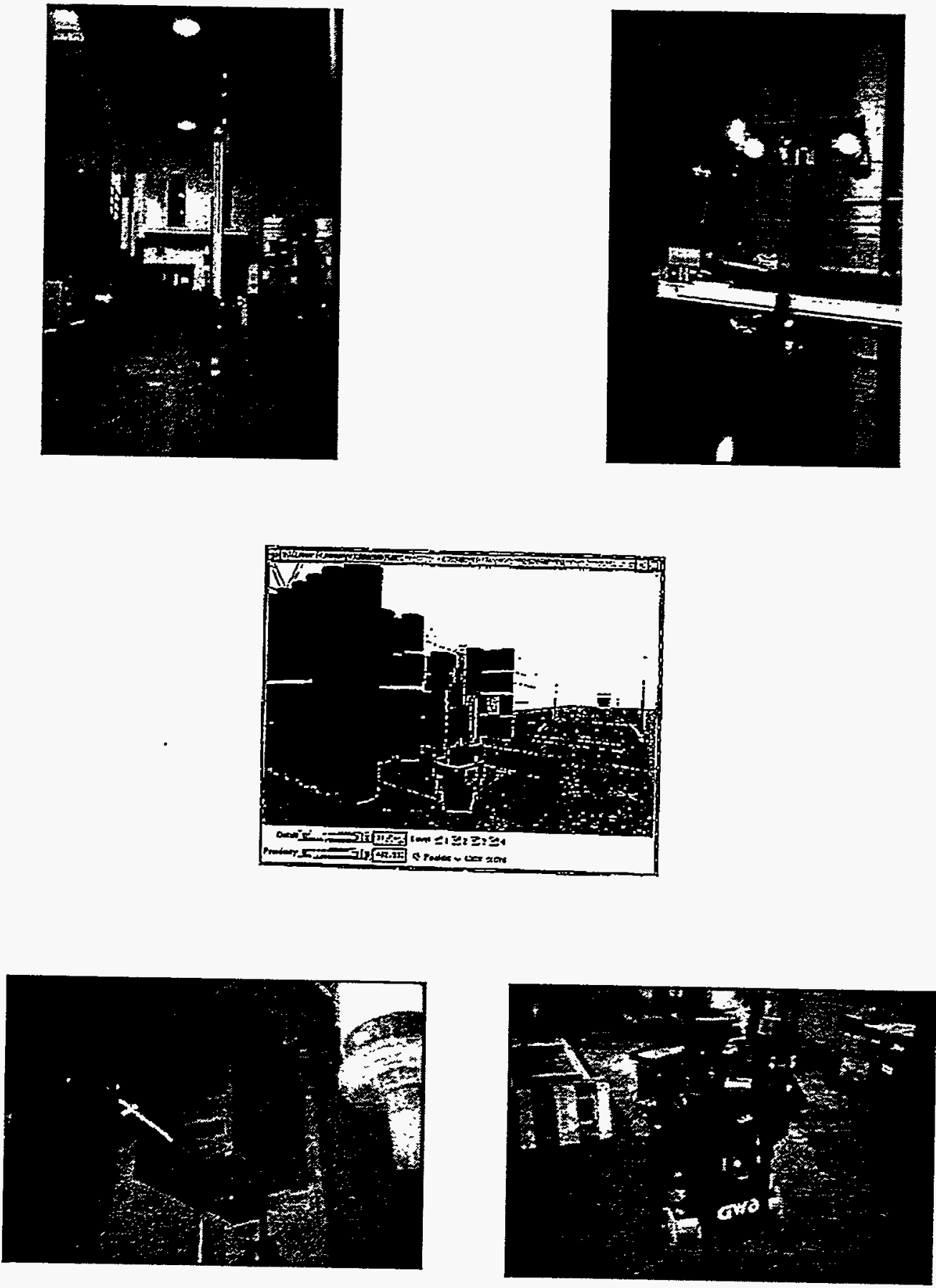


\section{SECTION 4: CONTAMINANTS AND MEDIA}

The contaminant of greatest concern with ARIES is the lead-acid batteries used to power the base of the robot. The batteries used to power the base of the robot are 12 volt 85 amp. sealed lead-acid. Under normal circumstances there should not be any exposure to the hazardous constituents of the battery but the potential for exposure to lead and lead contaminated sulfuric acid must be realized and proper precautions must be used. This may include handling the batteries utilizing personal protective equipment (PPE), when appropriate, training personnel in the hazards associated with lead-acid batteries, and proper storage and waste disposal. In 1985, the Environmental Protection Agency (EPA) declared lead-acid batteries to be hazardous waste.

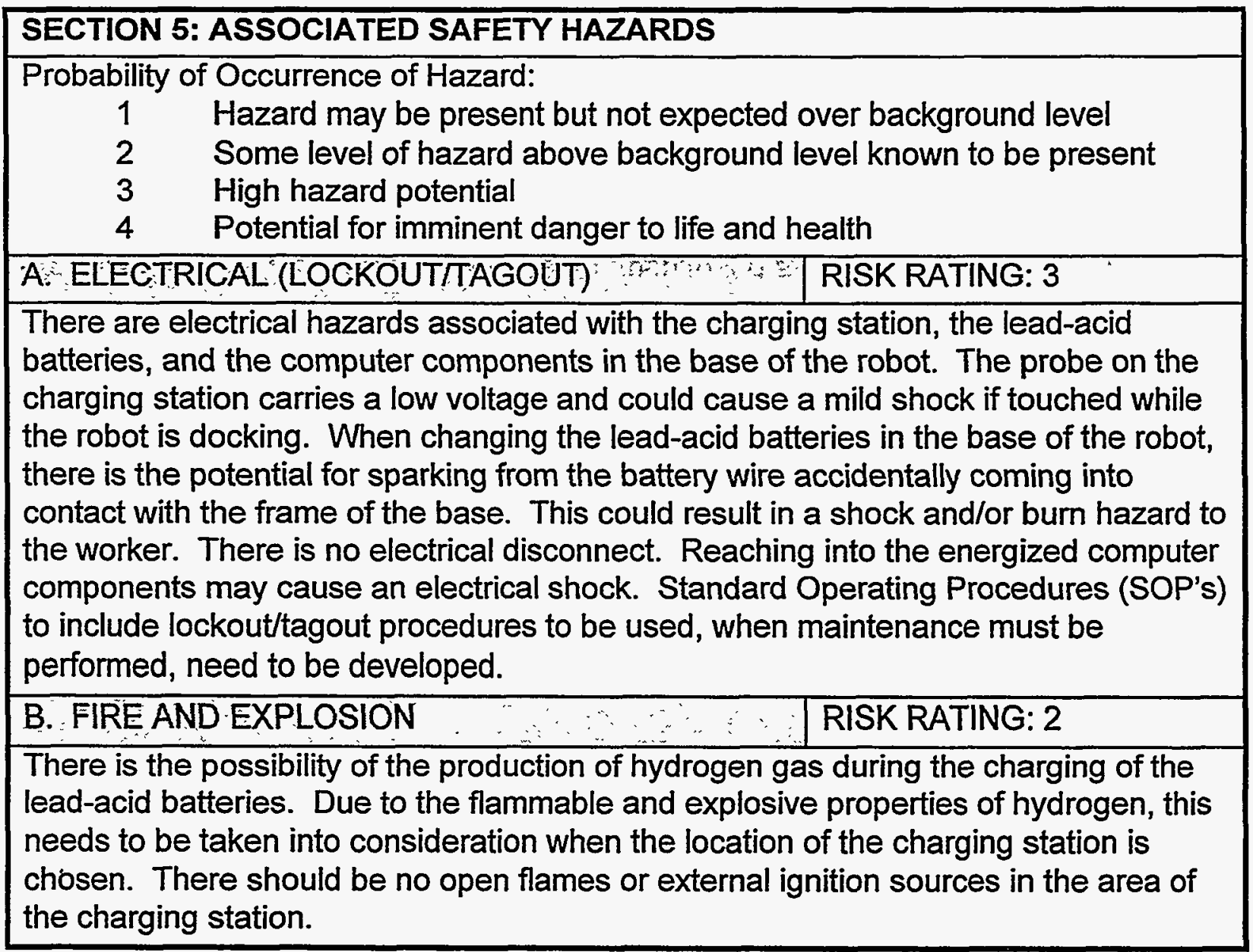




\begin{tabular}{|c|c|}
\hline C. CONFINED SPACE ENTRY & RISK RATING: N/A \\
\hline \multicolumn{2}{|l|}{ Not part of this technology. } \\
\hline D. MECHANICAL HAZARDS & RISK RATING: 2 \\
\hline \multicolumn{2}{|c|}{$\begin{array}{l}\text { There are pinch points associated with several belts located on the lower part of the } \\
\text { mast assembly. These should be guarded and labeled as pinch points. }\end{array}$} \\
\hline E. PRESSURE HAZARDS & RISK RATING: N/A \\
\hline \multicolumn{2}{|l|}{ Not part of this technology. } \\
\hline F. TRIPPING AND FALLING & RISK RATING: 2 \\
\hline \multicolumn{2}{|c|}{$\begin{array}{l}\text { The fiduciaries used for robot navigation are tripping hazards. Workers should be } \\
\text { made aware of their location and the area around them marked off. }\end{array}$} \\
\hline G. LADDERS AND PLATFORMS & RISK RATING: N/A \\
\hline \multicolumn{2}{|l|}{ Not part of this technology. } \\
\hline H. MOVING VEHICLES & RISK RATING: 3 \\
\hline \multicolumn{2}{|c|}{$\begin{array}{l}\text { A forklift is required to lift the mast onto the base of the robot. Proper forklift safety } \\
\text { should be observed. It needs to be assured that all warning devices on the forklift } \\
\text { such as the backup alarm are in operating condition at all times and the forklift } \\
\text { operators are properly trained. }\end{array}$} \\
\hline \multicolumn{2}{|c|}{$\begin{array}{l}\text { The robot itself may be considered a moving vehicle. There is the potential the robot } \\
\text { may not see a worker or part of a worker (such as a foot) and run into him/her or over } \\
\text { a part of him/her. Workers need to be aware of the robots location and programmed } \\
\text { path anytime they are working in the same area as the robot. The current limit drive } \\
\text { servo needs to be set at the lowest possible power which will still allow the robot to } \\
\text { perform its mission but lower the risk of running into/over any workers in the area. }\end{array}$} \\
\hline 1. BURIED UTILITIES, DRUMS, AND TANKS & RISK RATING: N/A \\
\hline \multicolumn{2}{|l|}{ Not part of this technology. } \\
\hline J. PROTRUDING OBJECTS & RISK RATING: 2 \\
\hline \multicolumn{2}{|c|}{$\begin{array}{l}\text { The probe on the charging station sticks out and could easily be run into. This may } \\
\text { injure the person and/or break the probe. It is recommended that the probe be } \\
\text { brightly colored or a brightly colored marker be placed on it so it is more easily seen. } \\
\text { Additionally, the charging station should be placed well out of the flow of traffic areas. } \\
\text { The charging station area could also be marked off so workers could not get close } \\
\text { enough to it to come into contact with the probe. }\end{array}$} \\
\hline
\end{tabular}




\begin{tabular}{|l|l|}
\hline K. GAS CYLINDERS & RISK RATING: N/A \\
\hline Not part of this technology. & RISK RATING: N/A \\
\hline L. TRENCHING AND EXCAVATIONS & RISK RATING: N/A \\
\hline Not part of this technology. & RISK RATING: 2 \\
\hline M. OVERHEAD LIFTS & Not part of this technology. \\
\hline N. OVERHEAD HAZARDS & $\begin{array}{l}\text { There is the potential for an overhead hazard to be created by ARIES knocking into a } \\
\text { drum that is located above floor height. Overhead hazards such as pipe racks that } \\
\text { the mast of ARIES could run into need to be taken into consideration when the } \\
\text { mission is programmed. }\end{array}$ \\
\hline
\end{tabular}

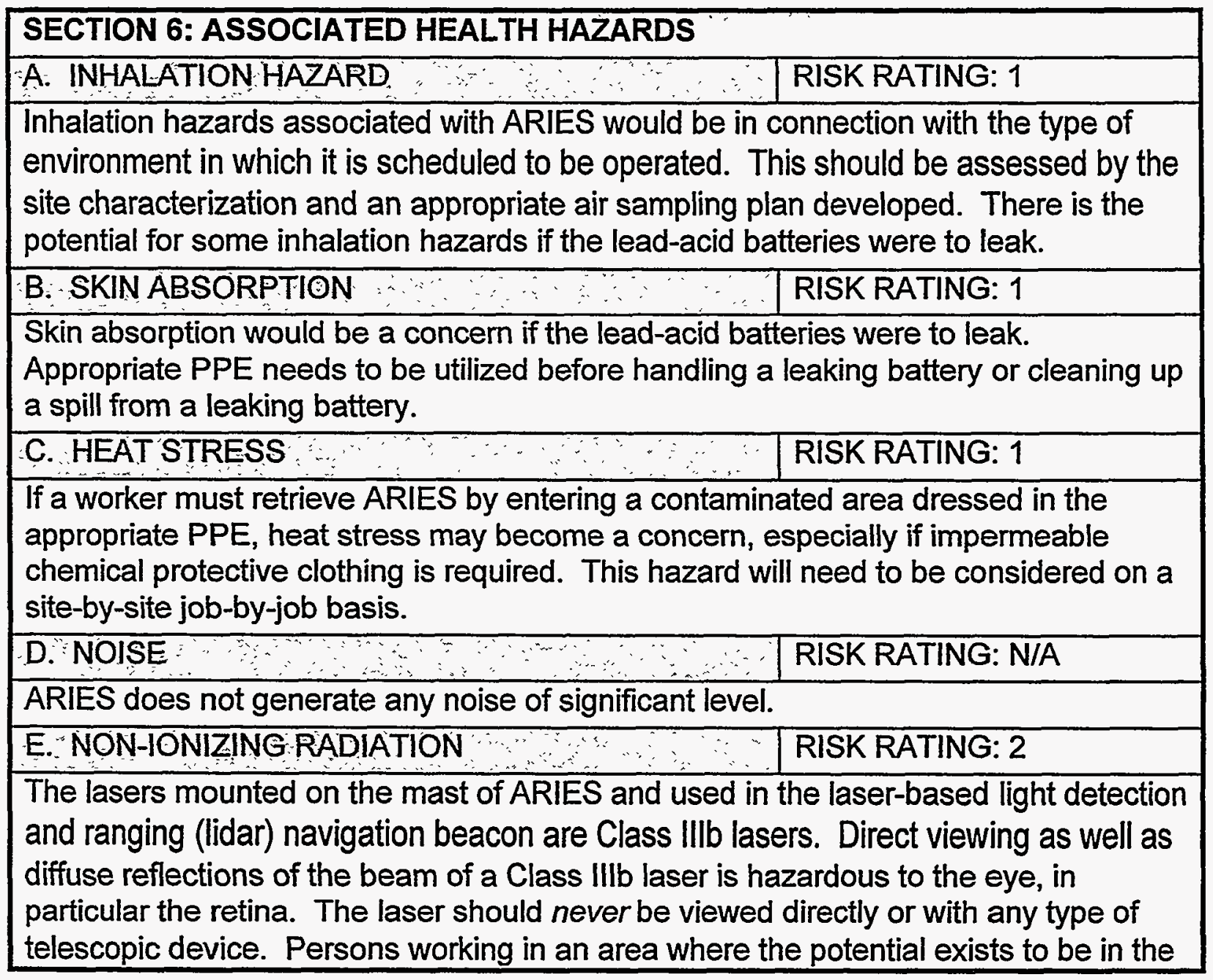


SECTION 6: ASSOCIATED HEALTH HAZARDS

direct or reflected view of the laser beam need to use goggles developed specifically for laser use. All persons working with or performing any type of maintenance activities on the laser must be trained in laser safety.

\begin{tabular}{l|l}
\hline F. IONIZING RADIATION & RISK RATING: N/A
\end{tabular}

Not part of this technology.

G. COLD STRESS

RISK RATING: 1

Cold stress will be determined by the environment in which ARIES is operating. The extent of this hazard needs to be determined on a site-by-site job-by-job basis.

H. ERGONOMIC HAZARDS

RISK RATING: 4

The robot, including the base with subturret and mast, and the associated system components must be loaded and unloaded from the transport vehicle. The base of the robot with the subturret can be manually "walked" off or on to the vehicle but the mast and all other components must be hand-carried. The main concern is the mast. The mast which weighs approximately 300 pounds is contained in a wooden cratelike structure used to carry it. Although there are handles located on the crate for carrying, there is a great potential for severe back injury and/or injury to the shoulders/arms/hands from workers having to lift and carry this amount of weight. There is also potential for ergonomic stressors to the back and shoulders/arms/hands from lifting and carrying other system components.

Uncrating/crating the mast may require bending, lifting, stooping, and/or kneeling. These activities increase the ergonomic stressors placed on the back, legs, knees, shoulders, and arms. Additionally, uncrating/crating requires the crate to be disassembled from around or assembled around the mast. This requires removing/placing of screws and nails, which at times are in difficult to reach locations.

I. OTHER RISK RATING: 2

Laser (see $E$ under this section) 


\section{SECTION 7: PHASE ANALYSIS}

A. CONSTRUCTION/START-UP

The robot, including the base with subturret and mast, and the associated system components must be loaded and unloaded from the transport vehicle. The base of the robot with the subturret can be manually "walked" off of or on to the vehicle but the mast and all other components must be hand-carried. The main concern is the mast. The mast which weights approximately 300 pounds is contained in a wooden crate-like structure used to carry it. Although there are handles located on the crate for carrying, there is a great potential for severe back injury and/or injury to the shoulders/arms/hands from workers having to lift and carry this amount of weight. There is also potential for ergonomic stressors to the back and shoulders/arms/hands from lifting and carrying other system components.

Uncrating/crating the mast may require bending, lifting, stooping, and/or kneeling. These activities increase the ergonomic stressors placed on the back, legs, knees, shoulders, and arms. Additionally, uncrating/crating requires the crate to be disassembled from around or assembled around the mast. This requires removing/placing of screws and nails, which at times are in difficult to reach locations. A forklift must be used to lift the mast onto the base of the robot. Specially designed extensions for the forks are used during this maneuver. The mast is not stable during this move and must be steaded and guided by hand. This presents the potential for a hand or arm to be placed between the mast and the base. Proper precautions and proper forklift safety must be used.

\section{B: OPERATION}

The fiduciaries used for robot navigation are tripping hazards. In addition, they are easily moved, by tripping on them, which could cause navigational problems for the robot. Marking the base of the fiduciary with a brighter color (they are black) or marking off the area around the fiducial would make them more noticeable. In addition, weighting the base of the fiducial so it will not move so easily when it is bumped would help with the navigational problems that could be created.

There are electrical hazards associated with the charging station, the lead-acid batteries, and the computer components in the base of the robot. The probe on the charging station carries a low voltage and could cause a mild shock if touched while the robot is docking.

When changing the lead-acid batteries in the base of the robot, there is the potential for sparking from the battery wire accidentally coming into contact with the frame of the base. This could result in a shock and/or burn hazard to the worker. An electrical 


\section{SECTION 7: PHASE ANALYSIS}

disconnect is not provided. Reaching into the energized computer components may cause an electrical shock. The computer drawer cover needs to be labeled as an electrical hazard.

The laser used on ARIES in the laser-based lidar navigation beacon system is a Class IIlb. Direct viewing as well as diffuse reflections of the beam of a Class IIlb laser is hazardous to the eye, in particular the retina. Anyone working in the area where there is the potential to in direct view or reflected view of the laser beam needs to use goggles developed specifically for laser use. In addition, all persons working with or performing any type of maintenance activities on the laser must be trained in laser safety.

During robot operation, tipping is a concern. There are two areas of concern associated with tipping, the first being that when the robot does not see an obstacle and runs into it, the robot may attempt to go over the obstacle which could cause the robot to tip. The robot tipping could result in severe injury if it were to fall on or strike a worker. Additional problems could be caused if the robot tipped and knocked over a drum and caused a spill. This has the potential to expose workers to a variety of contaminants. In addition, workers would have to enter the area to clean up the spill. The robot may also become contaminated which presents additional problems which will be discussed in a later section of this report. The second situation which causes concern for creating a tipping hazard, is an obstacle sticking out at a height above the ground whereby it hits the mast of the robot. The sonar would not "see" the obstacle at that height and the robot would continue until it ran into the obstacle. If the robot continues forward and the obstacle did not move the robot may tip until it falls over.

C. MAINTENANCE

When changing the lead-acid batteries in the base of the robot, there is the potential for sparking from the battery wire accidentally coming into contact with the frame of the base. This could result in a shock and/or burn hazard to the worker.

Reaching into the energized computer components may cause an electrical shock. Standard Operating Procedures (SOP's) to include lockout/tagout procedures to be used when maintenance must be performed need to be developed.

The Class IIlb laser presents a potentially severe eye hazard and burn hazard. Anyone working with or performing maintenance on the laser must be trained in laser safety. 
D. DECOMMISSIONING

Due to the design of the mast and its camera payload arm, it appears to be virtually impossible to decontaminate this section of the robot. Water cannot be used to decontaminate this part of the robot due to all of the open electrical connections and wiring. Where the wiring, chains, and belts run through conduit, the conduit is an open design which also makes decontamination difficult. Special care needs to be taken when assessing ARIES to determine if it is "clean".

\section{SECTION 8: HEALTH AND SAFETY PLAN REQUIRED ELEMENTS}

A. AIR MONITORING :

Air monitoring needs to be conducted for the environment in which ARIES is operating. The specific contaminants that monitoring needs to be conducted for will be determined by the site characterization. There is not any specific air monitoring that needs to be done in association with ARIES operation.

B. WORKER TRAINING

Workers must be trained in the specific operation of the system. This will include the operation of the computer system. Additional training required may include but not be limited to Hazardous Waster Operations and Emergency Response (HAZWOPER), Hazard Communication (HAZCOM), PPE, lockout/tagout, radiation worker II, ergonomics, electrical safety, laser safety, forklift training, hand signal communication, and construction safety and/or general industry safety.

\section{EMERGENCY RESPONSE}

Emergency response and preparedness must be part of every hazardous waste site health and safety plan (HASP). During normal operation of ARIES there is not any indication for any out of the ordinary emergencies. However, emergency situations could arise if there were problems such as ARIES tipping or running into something that could potentially knock over and spill a waste drum. This would then require emergency response activities to be put into motion.

All workers must be trained to operate the emergency shut off controls located on ARIES and the manual pendant control. Additionally, they need to trained to handle any emergencies that may occur in the area where ARIES is operating.

The operator located at the operation station may be out of "line of sight" with ARIES and not be able to see where the robot is or what it is doing in real-time. An emergency situation may occur and not be realized until someone enters the area. This could be remedied by installing a real-time video camera on ARIES that would 


\begin{tabular}{l}
\hline SECTION 8: HEALTH AND SAFETY PLAN REQUIRED ELEMENTS \\
\hline provide visual feedback to the operator as to ARIES' location and the present \\
operational conditions at any point in time. \\
Electrical hazards and the potential for leaking lead-acid batteries are the two main \\
concerns for responders to an emergency involving ARIES. A complete shutdown of \\
the system and the use of the proper PPE may be necessary before responding to \\
such an emergency. \\
\hline D. MEDICAL SURVEILLANCE \\
\hline $\begin{array}{l}\text { An eye examination with particular attention to the retina should be conducted for } \\
\text { anyone working in the area with the Class llib laser. }\end{array}$ \\
\hline E. INFORMATIONAL PROGRAM \\
\hline $\begin{array}{l}\text { Under Occupational Safety and Health Administration's (OSHA's) Hazardous Waste } \\
\text { standard, } 29 \text { CFR } 1910.120, \text { the employer is responsible for providing information on } \\
\text { new technologies to the workers who will be using the equipment. }\end{array}$ \\
\hline
\end{tabular}

\section{SECTION 9: COMMENTS AND SPECIAL CONSIDERATIONS}

From the perspective of software usage, consideration should given to three types of users for the system: (1) the expert, who is the person that knows the details of the operation of the robot, its programming and the internal hardware. This may be a representative of the developer; (2) the programmer, who is the person that programs the aisle paths, location of the fiduciaries, etc. This person must have the knowledge (training) required to use the "Site Manager" and other software provided by the developer to program the path and normal operational features of the robot. This person may have limited knowledge of the internal workings of the robot and internal programming details such as UNIX codes; and (3) the operator, who will start the robot operation for each mission, after which the robot will perform its tasks. If the robot stalls, the operator would take it out to a safe location and report the incident to the supervisor. The operator would not be required to have any knowledge of the software/hardware aspects of the robot. 


\section{SECTION 7 - EMERGENCY RESPONSE/PREPAREDNESS}

Emergency response and preparedness must be part of every hazardous waste site health and safety plan (HASP). During normal operation of ARIES there is no indication for any out of the ordinary emergencies. However, emergency situations could arise if there were problems such as ARIES tipping or running into something that could potentially be knocked over and spill. This would then require emergency response activities to be put into motion.

All workers must be trained to operate the emergency shut off controls located on ARIES and the manual pendant control. Additionally, they need to be trained to handle any emergencies that may occur in the area where they are operating ARIES.

One concern is that the operator located at the operation station may be out of "line of sight" with ARIES and not be able to see where the robot is or what it is doing in realtime. An emergency situation may occur and not be realized until someone enters the area. This could be remedied by installing a real-time video camera on ARIES that would provide visual feedback to the operator as to ARIES' location and the present operational conditions at any point in time.

Electrical hazards and the potential for leaking lead-acid batteries are the two main concerns for responders to an emergency involving ARIES. A complete shutdown of the system and the use of the proper PPE may be necessary before responding to such an emergency.

\section{SECTION 8 - REGULATORYIPOLICY ISSUES}

Regulations that apply to this technology may be divided into four categories. First, core requirements are those regulations that would apply to any hazardous waste work site, regardless of the type of job. Second, technology-specific requirements are those regulations that apply due to the specific technology being used. Third, special requirements are standards and policies that are specific to the technology itself, and are required by reference in a regulation. Fourth, best management practices are not required but are recommended by organizations such as the American National Standards Institute (ANSI), the National Institute of Occupational Safety and Health (NIOSH), DOE, National Fire Protection Association (NFPA), etc. These regulations/standards may include, but not be limited to, the following:

\section{CORE REQUIREMENTS:}

- OSHA 29 CFR 1926.25 Housekeeping 
$\checkmark \quad$ OSHA 29 CFR 1910.141 (a)(3) covers housekeeping

- OSHA 29 CFR 1926 Subpart Z Toxic and Hazardous Substances

OSHA 29 CFR 1910 Subpart Z Toxic and Hazardous Substances

OSHA 29 CFR 1926.59 Hazard Communication

OSHA 29 CFR 1910.1200 Hażard Communication

OSHA 29 CFR 1926.64 Process Safety Management of Highly Hazardous Chemicals

- OSHA 29 CFR 1910.119 Process Safety Management of Highly Hazardous Chemicals

- OSHA 29 CFR 1926.65 Hazardous Waste Operations and Emergency Response

$-\quad$ OSHA 29 CFR 1910.120 Hazardous Waste Operations and Emergency Response

- Occupational Safety and Health Act 1970(5)(a)(1) General Duty Clause

\section{TECHNOLOGY SPECIFIC REQUIREMENTS:}

$-\quad$ OSHA 29 CFR 1910.147 The Control of Hazardous Energy (Lockout/Tagout)

$\checkmark \quad$ OSHA 29 CFR 1926.102 Eye and Face Protection

$\checkmark \quad$ OSHA 29 CFR 1910.133 Eye and Face Protection

- OSHA 29 CFR 1910.1000 Toxic and Hazardous Substances

- OSHA 29 CFR 1926 Subpart K Electrical

$\checkmark \quad$ OSHA 29 CFR 1910 Subpart S Electrical

- OSHA 29 CFR 1926.54 Non-ionizing Radiation

- OSHA 29 CFR 1910.97 Non-ionizing Radiation 
- OSHA 29 CFR 1926.602 Material Handling Equipment

- OSHA 29 CFR 1910.178 Powered Industrial Trucks

SPECIAL REQUIREMENTS:

ANSI B56.1-1969, Safety Standards for Powered Industrial Trucks

BEST MANAGEMENT PRACTICES:

ACGIH Threshold Limit Value for Chemical Substances and Physical Agents and Biological Exposure Indices

ANSI 136.1-1993 Safe Use of Lasers

Association for Robotics in Hazardous Environments "Guidelines for Procurement Specifications for Remote and Robotic Systems and Equipment to Operate in Hazardous Environments" RHE01.01-1996

Robotics Industries Association, R15.06 Safety Requirements Draft 10

NIOSH "Safe Maintenance Guidelines for Robotic Workstations", DHHS (NIOSH) Publication No. 88-108, March 1988

NIOSH "Elements of Ergonomics Programs, A Primer Based on Workplace Evaluations of musculo-skeletal Disorders" March 1997

\section{TRAINING REQUIREMENTS:}

In addition to the above regulations and policies, it is imperative that all workers have appropriate and adequate training for the task and associated safety and health conditions. Training that would be required may be divided into four categories. Core training is that which is required for anyone entering a hazardous waste site to perform work, regardless of the type of job. Technology specific training is that training that is specific to the technology and required by safety and health standards. Special training is that which is specific to the technology to assure the worker is adequately trained for the task but is not necessarily required by safety and health standards. Best management practices are training that while not mandated by health and safety standards, provide information and knowledge to the worker that will allow the worker to perform the job safely. Training to be applied for ARIES may include but not be limited to: 
Core training requirements:

HAZWOPER (Hazardous Waste Operations and Emergency Response)

- HAZCOM (Hazard Communication)

Technology Specific training:

- Personal Protective Equipment

- Lockout/Tagout

- Radiation Worker II (due to the environment where ARIES is scheduled to be operated)

\section{Special training:}

- Job specific training for equipment operation

\section{Best Management Practice training:}

- Ergonomics (proper lifting, bending, stooping, kneeling, arm-hand vibration)

- CPR/First Aid/Emergency Response/Bloodborne Pathogens

- Electrical Safety

$\checkmark \quad$ Laser Safety

- Fork Lift Training

- Hand Signal Communication

- Construction Safety (OSHA 500) and or General Industry Safety (OSHA 501)

\section{SECTION 9 -}

\section{OPERATIONAL CONSIDERATIONS AND RECOMMENDATIONS}

- The fiduciaries used for robot navigation are tripping hazards. In addition, they are easily moved, by tripping on them, which could cause navigational problems 
for the robot. Marking the base of the fiduciary with a brighter color (they are black) would make it more noticeable to anyone walking by. In addition, weighting the base of the fiducial so it will not move so easily when it is bumped would help with the navigational problems that could be created.

There are electrical hazards associated with the charging station, the lead-acid batteries, and the computer components in the base of the robot. The probe on the charging station carries a low voltage and could cause a mild shock if touched while the robot is docking. During maintenance the energized circuit could result in severe injury or death. The probe needs to be labeled as an electric shock hazard and proper lockout/tagout techniques must be used during maintenance activities.

When changing the lead-acid batteries in the base of the robot, there is the potential for sparking from the battery wire accidentally coming into contact with the frame of the base. This could result in a shock and/or burn hazard to the worker. An electrical disconnect would alleviate this problem.

Reaching into the energized computer components may cause an electrical shock. The computer drawer cover needs to be labeled as an electrical hazard. SOP's to include lockout/tagout procedures to be used when maintenance must be performed needs to be developed.

The laser used on ARIES in the laser-based lidar navigation beacon system is a Class Illb. Direct viewing as well as diffuse reflections of the beam of a Class $\mathrm{Illb}$ laser is hazardous to the eye, in particular the retina. Anyone working in the area where there is the potential to direct or reflected view of the laser beam needs to use goggles developed specifically for laser use. In addition, all persons working with or performing any type of maintenance activities on the laser must be trained in laser safety.

Tipping is a concern with the robot. There are two major concerns associated with tipping, the first being that when the robot does not see an obstacle and runs into it, the robot may attempt to go over the obstacle which could cause the robot to tip. Although there is a feature to set the drive on the robot to avoid attempting to continue, there is still concern for two reasons: (1) the center of gravity of the robot is not known and (2) there is no stall out feature based on the robot angle of operation. That is, the robot will continue regardless of the angle at which it is climbing. The robot tipping could result in severe injury if it were to fall on or strike a worker. Additional problems could be caused if the robot tipped and knocked over a drum and caused a spill. This has the potential to expose workers to a variety of contaminants. In addition, workers would have to enter 
the area to clean up the spill. The robot may also become contaminated which presents additional problems which will be discussed in a later section of this report.

The second situation which causes concern for creating a tipping hazard, is an obstacle sticking out at a height above the ground, therefore, it hits the mast of the robot. The sonar would not "see" an obstacle at that height and the robot would continue until it ran into the obstacle. If the robot continues forward and the obstacle did not move the robot may tip until it falls over. Again, since the center of gravity is not known, it is not possible to determine at what angle the robot will tip.

It is recommended that the center of gravity for the robot be calculated so the angle of tipping required for the robot to fall over will be known. This would then allow the robot to be programmed that when it reaches a certain angle (less than the tipping angle), it will stall and not continue forward until it tips.

Two types of hazardous situations that may be caused by the robot are fall-fromabove hazards and struck-by hazards. There is the potential for fall-from-above hazards if the robot strikes an object and knocks it onto personnel. There is also the potential for struck-by hazards if the robot runs into personnel in the area as well as running into other objects which may then become a struck-by hazard for personnel.

Ergonomics during unloading and loading of the ARIES system is of major concern. The robot, including the base with subturret and mast, and the associated system components must be unloaded from and loaded onto the transport vehicle. The base of the robot with the subturret can be manually "walked" off of or on to the vehicle but the mast and all other components must be hand-carried off of or on to the vehicle. The main concern is the mast. The mast which weighs approximately 300 pounds is contained in a wooden cratelike structure that is used to carry it. Although there are handles located on the crate for carrying, there is a great potential for severe back injury and/or injury to the shoulders/arms/hands from workers having to lift and carry this amount of weight. A crate or container or a transport vehicle needs to be developed that will allow the mast to be lifted and carried strictly by mechanical means, such as a forklift.

There is also potential for ergonomic stressors to the back and shoulders/arms/hands from lifting and carrying other system components. Placing these components on pallets to facilitate lifting and moving them with a forklift would alleviate many of these stressors. 
Uncrating/crating the mast may require bending, lifting, stooping, and/or kneeling. These activities increase the ergonomic stressors placed on the back, legs, knees, shoulders, and arms. Additionally, uncrating/crating requires the crate to be disassembled from around or assembled around the mast. This requires removing/placing of screws and nails, which at times are in difficult to reach locations. Bolts with wing nuts would be easier to reach and maneuver. $A$ system that would raise and/or lower the crate would eliminate the need for all of the bending, stooping, kneeling.

ARIES is capable of being manually controlled should the need arise. A manual control pendant can be attached to the base of the robot which is then controlled by a "joy-stick" type of control lever. During manual operation, sonar (obstacle avoidance capabilities) are inoperable and the operator must have a clear "line of sight". This is of concern because since the aisles for which the ARIES mission is slated are only 36 inches wide. This requires the operator to manually remove ARIES by walking behind or in front of it. When walking behind ARIES vision may be totally or partially obscured. When walking in front of ARIES the operator must walk backwards and cannot see where he/she is going. Both of these situations have the potential to result in injury to the operator and/or to others in the area. It is recommended that SOP's for the manual removal of ARIES be developed to include the operator checking the path for obstacles before ARIES is moved and notifying others in the area that ARIES is being manually moved so they will stay clear of the path. An alarm (different from the stalled/stopped alarm) would also be useful for notifying other personnel in the area. The operator should never walk backwards while manually moving ARIES.

- The front bumper of the base of the robot is large enough that someone could stand on it, although it is not designed for this purpose. Stepping on the bumper could cause the robot to tip which could result in personal injury or drums being knocked over and spilled or damaged. It is recommended that a "no step" label be placed on the bumper.

- The probe on the charging station sticks out and could easily be run into. This

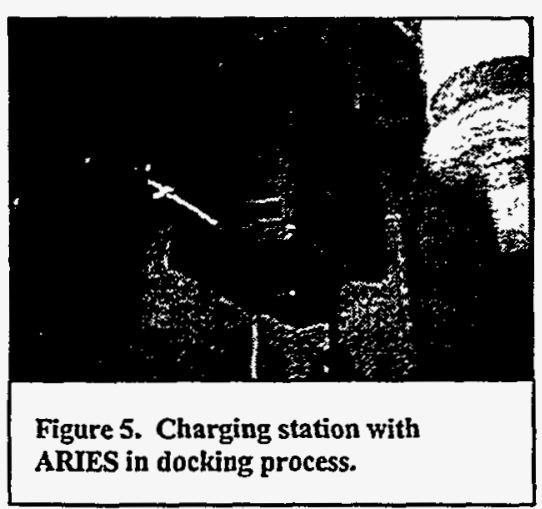
may injure the person and/or break the probe. It is recommended that the probe be brightly colored or a brightly colored marker be placed on it so it is more easily seen. Additionally, the charging station should be place well out of the flow of traffic areas. The charging station area could also be marked off so workers could not get close enough to it to come into contact with the probe. 
- The lead-acid batteries have the potential to create a toxicity/corrosion hazard should they leak. The batteries need to be properly stored and disposed of in accordance with all applicable regulations. If a spill should occur, it needs to be cleaned up immediately. All personnel working with the batteries need to be trained to use them and informed of their potential hazards.

- The recharging of lead-acid batteries produces hydrogen gas which has the potential to result in an explosion. It is recommended that "no smoking" signs be posted within 50 feet of the charging station and that the charging station not be placed in the vicinity of any potential ignition sources.

-When changing the lead acid batteries in the base of the robot, there is the potential for accidental sparking from the battery wires contacting the frame. There needs to be an electrical disconnect to prevent this from happening.

- The robot is able to move and navigate with the arm, which carries the camera payload, of the mast extended. Fully extended the arm can reach 3'8" from center. This will change the center of gravity and may make the robot

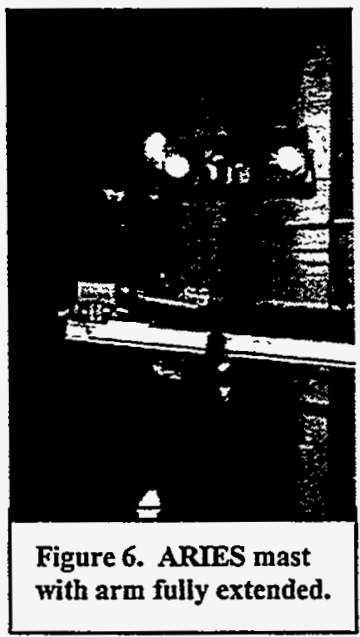
more unstable. Consideration needs to be given to programming an interlock into the system so the robot cannot move as long as the arm is extended. Additionally, the robot would have to be manually moved with the arm extended if it were to fail in that position. This is due to the fact that failure of autonomous control does not provide a mechanism to retract the arm. If the robot were to be manually moved in this position there is the potential for the arm to hit a drum and knock it over. A mechanism for manual retraction of the arm needs to be developed.

- The robot, in particular the mast section of the robot, contains a lot of wiring and small delicate connections. These small connections and the tight areas where they are contained will make it very difficult to perform any maintenance/repair if gloves are required due to the contaminated environment. This area would also be very difficult to decontaminate to move the robot to a clean area for maintenance/repair. Consideration needs to be given to enclosing these areas so they could be easily decontaminated which would make it possible to do maintenance/repair without gloves or other PPE. 
- Due to its height (which is approximately 11 feet), there is the potential for the mast to contact overhead hazards. All overhead hazards need to be taken into consideration when programming the robot. Operators should be trained to be aware of the environment in which the robot is operating and to always be looking for changes and new hazards that may necessitate changes in the program. A real-time video camera attached to ARIES would aid the operator's ability to monitor the environment. 


\section{APPENDIX A REFERENCES}

American National Standards Institute, American National Standard for the Safe Use of Lasers: ANSI Z 136.1 (1993), Laser Institute of America, New York, NY (1993)

Occupational Safety and Health Standards for General Industry, 29 CFR Part 1910, Occupational Safety and Health Administration United States Department of Labor, 1995

Occupational Safety and Health Standards for the Construction Industry, 29 CFR Part 1926, Occupational Safety and Health Administration United States Department of Labor, 1995

U.S. Department of Health and Human Services, Public Health Services, Applications Manual for the Revised NIOSH Lifting Equation, DHHS (NIOSH) Publication No. 94110, January 1994 


\section{APPENDIX C ACRONYMS}

$\begin{array}{lll}\text { ACGIH } & - & \text { American Conference of Governmental Industrial Hygienists } \\ \text { ANSI } & - & \text { American National Standards Institute } \\ \text { ARIES } & - & \text { A Robotic Inspection Experimental System } \\ \text { CFR } & - & \text { Code of Federal Regulations } \\ \text { CPS } & - & \text { camera positioning system } \\ \text { DOE } & - & \text { Department of Energy } \\ \text { EPA } & - & \text { Environmental Protection Agency } \\ \text { HASP } & - & \text { Health and Safety Plan } \\ \text { HAZCOM } & - & \text { Hazard Communication } \\ \text { HAZWOPER } & - & \text { Hazardous Waste Operations and Emergency Response } \\ \text { LIDAR } & - & \text { light detection and ranging } \\ \text { MM } & - & \text { millimeter } \\ \text { MW } & - & \text { milliwatt } \\ \text { MWFA } & - & \text { Mixed Waste Focus Area } \\ \text { NFPA } & - & \text { National Fire Protection Association } \\ \text { NIOSH } & - & \text { National Institute of Occupational Safety and Health } \\ \text { OENHP } & - & \text { Operating Engineers National Hazmat Program } \\ \text { OSHA } & - & \text { Occupational Safety and Health Administration } \\ \text { PPE } & - & \text { personal protective equipment } \\ \text { RCRA } & - & \text { Resource Conservation and Recovery Act } \\ \text { RIA } & - & \text { Robotics Industries Association } \\ \text { SOP's } & - & \text { standard operating procedures } \\ \text { TRU } & - & \text { transuranic }\end{array}$




\section{CARNEGIE MELLON UNIVERSITY BOA TABLE OF CONTENTS}

ACKNOWLEDGEMENTS iii

EXECUTIVE SUMMARY iv

SECTION 1 - SUMMARY 1

Technology Description 1

Key Results

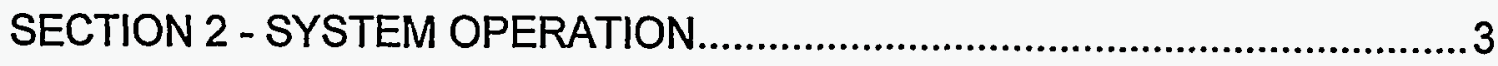

SECTION 3 - HEALTH AND SAFETY EVALUATION ......................................5

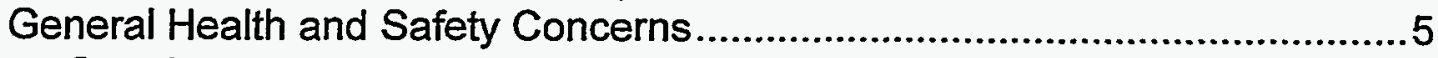

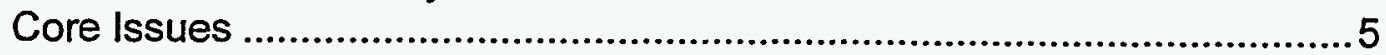

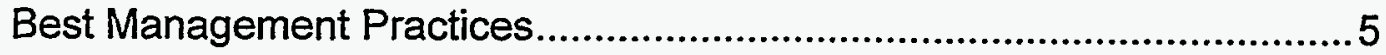

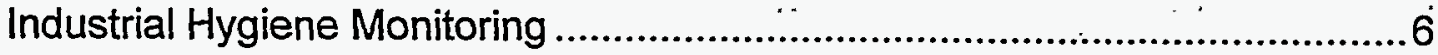

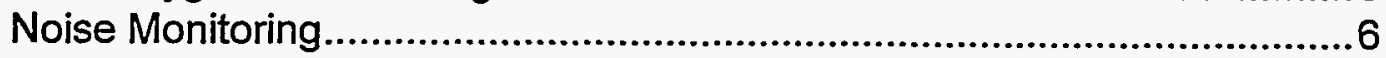

Evaluation of Airborne Particles .......................................................... 7

Real Time MIE Data RAM Particulate Monitoring................................

Total and Respirable Dust Air Sampling ............................................. 8

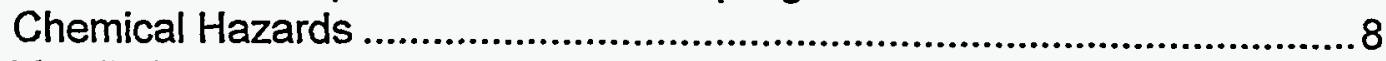

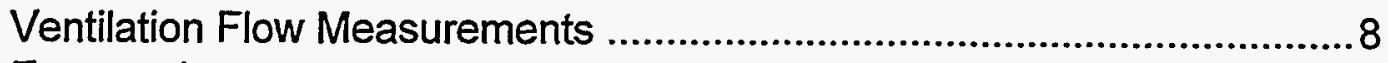

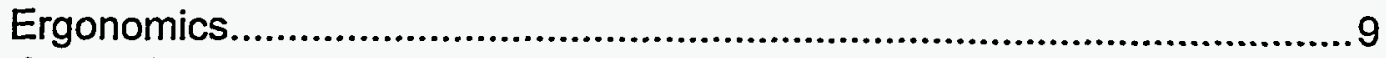

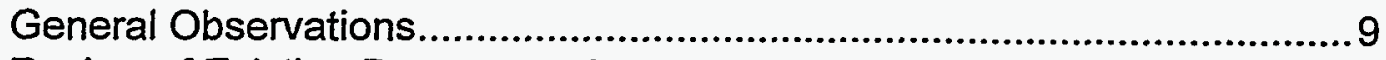

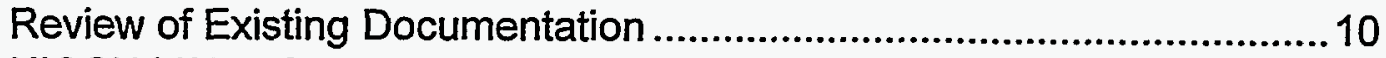

NIOSH Lifting Calculation ..................................................................11

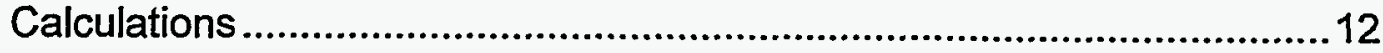

Software and Hardware Considerations .................................................... 12

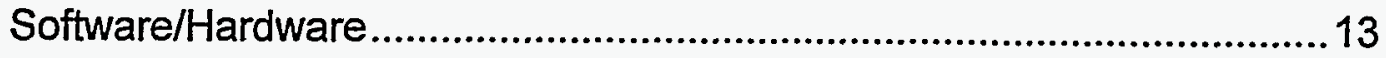

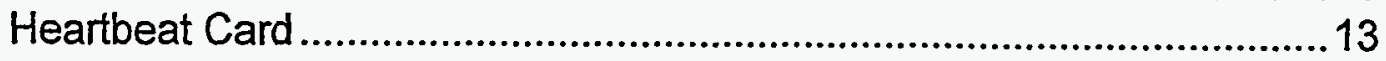

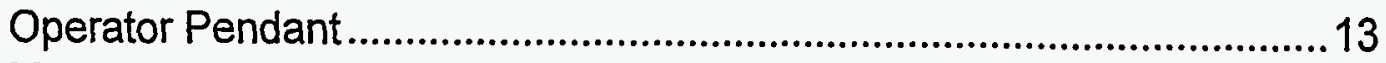

Manual Button Box ......................................................................... 13

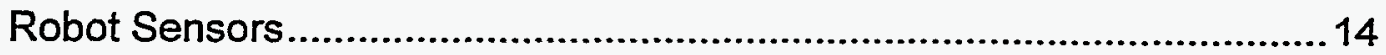

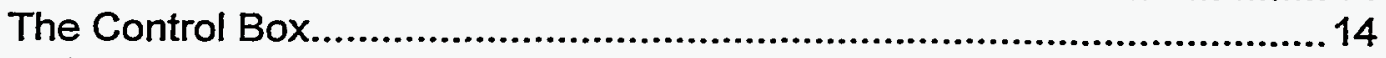

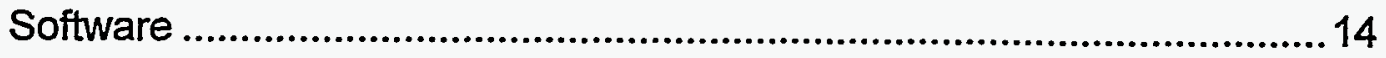

Exception Handling........................................................................... 14 
(CONTINUED)

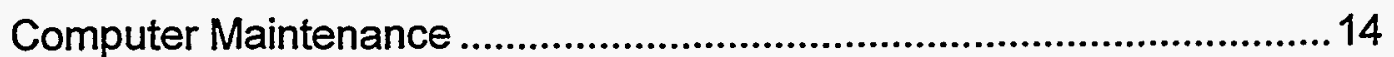

Modular Commercial Hardware ............................................................... 14

Recommendations for Computer Operation ............................................ 14

Human Factors Interface ..............................................................................15

Technology Applicability ....................................................................... 16

SECTION 4 - JOB SAFETY ANALYSIS (JSA) .........................................17

SECTION 5 - FAILURE MODES AND EFFECTS ANALYSIS (FMEA).............27

SECTION 6 - TECHNOLOGY SAFETY DATA SHEET (TSDS) ........................30

SECTION 7 - EMERGENCY RESPONSE/PREPAREDNESS ........................45

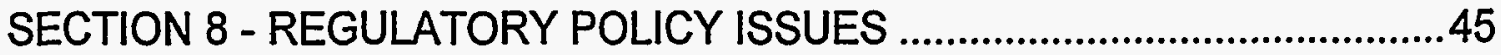

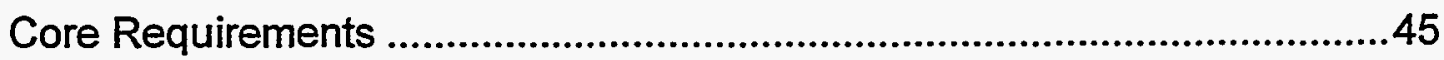

Technology Specific Requirements ..........................................................46

Best Management Practices.......................................................................47

Core Training Requirements ..................................................................48

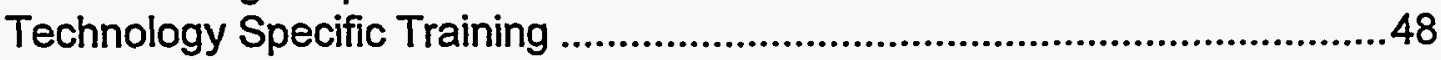

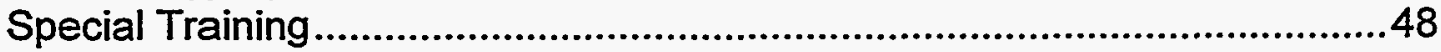

Best Management Practice Training .........................................................49

SECTION 9 - OPERATIONAL CONSIDERATIONS AND

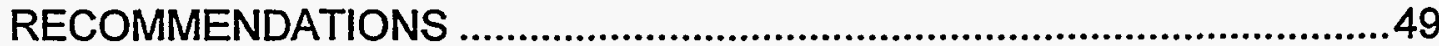

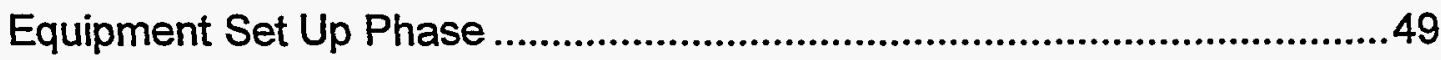

Equipment Operation Phase .................................................................51

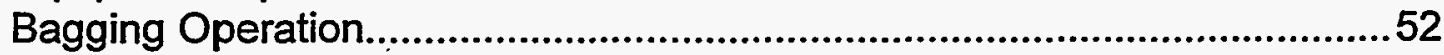

Maintenance and Decontamination Phase ..............................................52

Emergency Situations..................................................................................52

ADDENDUM

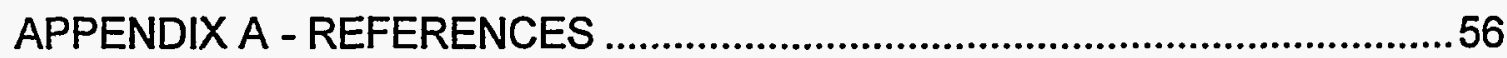

APPENDIX B - INDUSTRIAL HYGIENE DATA ........................................57

APPENDIX C - PENDANT CONTROL BUTTONS LAYOUT ............................61

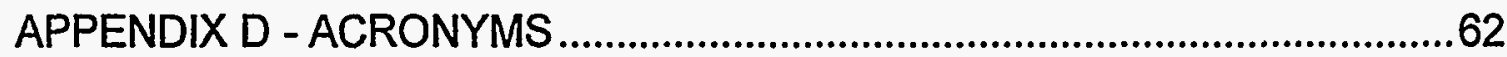




\section{ACKNOWLEDGEMENTS}

The human factors assessment of Carnegie Mellon University's BOA robotic system was conducted under support of the U.S. Department of Energy's Federal Energy Technology Center, under cooperative agreement DE-FC21-95MC32260 with the Operating Engineers National Hazmat Program. The Operating Engineers National Hazmat Program would like to thank the following people for their participation on the "research action team" and the professional expertise they provided for this assessment:

\section{Team Member}

Barbara McCabe

Patrick Bell

Robert Harrold

Randy Norris

Joe Byrd

Bruce Lippy

Tony Szwiliski

\section{Affiliation}

Operating Engineers National Hazmat Program Operating Engineers National Hazmat Program Operating Engineers National Hazmat Program Operating Engineers Local Union Consultant to OENHP Consultant to OENHP (University of Maryland) Consultant to OENHP (Marshall University) 


\section{EXECUTIVE SUMMARY}

The BOA asbestos removal system designed by Carnegie Mellon University's (CMU) Robotics Institute was assessed for human factors by a team from the Operating Engineers National Hazmat Program. The team found that the system was generally well designed and incorporated many features that considered the protection of workers. The basic concept underlying the system represents the most important worker protection feature: remotely removing asbestos pipe insulation eliminates the use of glovebags, the standard abatement technique that requires working on ladders with arms constrained by a plastic bag while wearing respiratory protection and protective suits. Asbestos exposure and fall hazards are significant risks for workers using this standard technique. The BOA system is a major improvement in asbestos removal design. Not only does it remove asbestos insulation automatically, but the debris is cut into chunks and moved to a bagging machine under a strong vacuum. Prior to reaching the bagging operation, the material passes through a water separator which greatly reduces the weight of the debris and allows recirculation of water, after sufficient filtration. Additionally, the unit is capable of moving around pipe hangers and applying encapsulant to both cut edges of asbestos insulation. The unit also encapsulates the surface of the pipe after removal has taken place.

The use of encapsulant in the system means that operators need to wear gloves and eye protection whenever exposed to the liquid encapsulant, which is indicated as a skin and eye irritant in the Material Safety Data Sheet (MSDS).

Air sampling during the human factors assessment indicated that worker exposures may be kept low enough during normal operation of BOA to eliminate the need for respiratory protection. Currently, this is based on BOA removing calcium silicate insulation from pipe. Ventilation measurements documented strong air flow into the cutting head, between 500 and 1000 cubic feet per minute when the main vacuum was operating and between 200 to 300 cubic feet per minute when only the auxiliary vacuum was working. Given the high air flow into the cutter head, the low level of particle release is believable. Actual asbestos measurements from a field test will be critical, however.

Noise levels during operation of the unit were generally below the Occupational Safety and Health Administration (OSHA) 85 dBA "action level" that would require a hearing conservation program. The large vacuum unit, however, was well over the OSHA level and had correctly been placed outdoors to limit exposure to personnel. It required almost no attention by workers, after being started.

The CMU Robotics Institute has not completed the minimal amount of documentation on the BOA system that is recommended by the Robotic Industries Association (RIA). 
Critical documents, such as standard operating procedures and maintenance procedures, will enlarge the understanding of worker risks and protection.

The computer hardware and software designed for the BOA system are robust and contain several key interlocks to protect operators. The software architecture is simple, straight-forward, yet provides the required functionality and exception handling necessary for a real-time system such as the BOA robot. "Fail Safe Status" occurs for system power failure and heartbeat loss. Operator Interaction is required for Emergency Stops (manual buttons) or operator actions from the Pendant keypad. System malfunctions occur from loss of vacuum, bumper activation on the robot, etc. The Feedback System Monitoring includes the status monitoring of limit switches on all system subsystems, motor current limits, activator positions, and water pressure and flow.

The primary missing item is diagnostic software to help a maintenance person locate faults within the system. An error log is provided that can be accessed from the system hard disk; however, this information is not organized is a manner which would be easy for maintenance to use. This is recommended before putting the system into full production.

Improvements in the ergonomic design of the operation are clearly possible. The work stations for several of the pieces of equipment involve awkward body positioning. During the set up phase, the connection of hoses and lines requires much bending over, while connecting the hoses and lines on the bagging unit requires reaching up over six feet. Similarly, connecting hoses to the large vacuum unit requires reaching approximately seven feet. Attaching the cutter head to elevated piping involves more awkward positions, including reaching out from an elevated manlift and working under the cutter head, both of which are serious safety hazards, in addition to ergonomic concerns. A calculation of the NIOSH Recommended Weight Limit for the bagging operation showed that the weight of the bags should be reduced from the present average of 48 pounds to approximately 30 pounds to avoid back stress that could lead to injuries. 


\section{CARNEGIE MELLON UNIVERSITY BOA \\ HUMAN FACTORS ASSESSMENT}

\section{SECTION 1 - SUMMARY}

\section{TECHNOLOGY DESCRIPTION}

A team from the Operating Engineers National Hazmat Program (OENHP) conducted a human factors assessment of BOA, a robotic technology developed by CMU's Robotic Institute. The main focus of the assessment was the human factors issues associated with the installation, operation, maintenance, and decontamination of this robotic equipment developed to remove asbestos insulation from pipe.

Many facilities throughout the Department of Energy (DOE) complex are slated for decontamination and decommissioning over the next several decades. Most of these facilities have asbestos-containing insulation on steam and process piping. Environmental Protection Agency (EPA) and Occupational Safety and Health Administration (OSHA) regulations require that this thermal system insulation (TSI) must be abated before the pipes can be dismantled. This will require abatement workers to handle a known carcinogen, removing the insulation primarily with glovebags that is an expensive and slow technique that presents potentially serious exposures to fall hazards, as well as ergonomic stressors. The projected abatement and disposal costs for TSI across the DOE complex is in the tens of millions of dollars with current practices.

The development of the CMU technology, called BOA, an automated pipe-insulation abatement system, represents a valuable effort to provide a robotic process that could remove workers from direct asbestos exposure and reduce abatement costs while meeting all federal and local regulations.

CMU, through the Robotic Institute's Field Robotics Center, has developed an automated asbestos pipe-insulation removal system called BOA. This system is a selfpropelled automated mini-enclosure, able to remove insulation from installed pipes, primarily of 4" nominal outside diameter (OD). The system is designed for two operators, one at the abatement head and another at the cyclonic bagging station. Since the abatement head is its own enclosure there is no obvious need for further enclosures to be built, as long as there is no asbestos fiber released during operation. Additionally, operators may not need the respirators and protective garments required 
for glovebag removal, although there is not sufficient air monitoring data upon which to allow any reduction of protection at this point in time. This will need to be assessed further during actual asbestos insulation removal.

\section{KEY RESULTS}

The safety and health evaluation, during the human factors assessment, focused on: noise, dust concentrations, ergonomics, and computer software. Industrial hygiene sampling indicated that worker exposures may be kept low enough during normal operation of BOA to eliminate the need for respiratory protection or hearing protection around the cutting head and bagging operation. Ventilation measurements documented strong air flow into the cutting head when the main vacuum unit was operating and acceptable levels when only the auxiliary vacuum was working. Airborne particulate measurements using particle counting instruments showed a slight rise in dust particles over background levels during the operation of BOA, but the average of all the readings during operation was only 1.6 percent of the OSHA respirable dust standard. More reliable samples were collected by the approved NIOSH method and yielded results that were all below the laboratory's level of detection. Given the high air flow into the cutter head, the low level of particle release is believable. Actual asbestos measurements during field testing will be critical, however.

Noise levels from operation of the unit were generally below the OSHA $85 \mathrm{dBA}$ "action level" which would require a hearing conservation program. The large vacuum unit, however, was well over the OSHA "action level", as well as the permissible exposure limit (PEL) and had correctly been placed outdoors to limit exposure to personnel. It required almost no attention by workers after being started. Personal dosimetry measurements will be needed during actual BOA operation to ensure that worker noise levels are not above $85 \mathrm{dBA}$.

The computer hardware and software designed for the BOA system are robust and contain several key interlocks to protect operators. The software architecture is simple and straight-forward, yet provides the required functionality and exception handling necessary for a real-time system such as the BOA robot. Fail Safe Status occurs for system power failure and heartbeat loss. Operator Interaction is required for Emergency Stops (manual buttons) or operator actions from the Pendant keypad. The primary missing item is diagnostic software to help a maintenance person locate faults within the system.

Improvements in the ergonomic design of the operation are clearly possible. The work stations for several of the pieces of equipment involve awkward body positioning. During the set up phase, the connection of hoses and lines requires much bending over, while connecting the hoses and lines on the bagging unit requires reaching up over six feet. Similarly, connecting hoses to the large vacuum unit requires reaching 
approximately seven feet. Attaching the cutter head to elevated piping involves more awkward positions including reaching out from an elevated manlift and working under the cutter head, both of which are serious safety hazards. A calculation of the NIOSH RWL for the bagging operation showed that the weight of the bags should be reduced from the present average of 48 pounds to approximately 30 pounds to avoid back stress that could lead to injuries.

\section{SECTION 2 - SYSTEM OPERATION}

The BOA system is a major improvement in design for the removal of asbestos insulation from pipes. The system is a self-propelled automated mini-enclosure, able to remove insulation from installed pipes, primarily of 4 " outside diameter. The system is

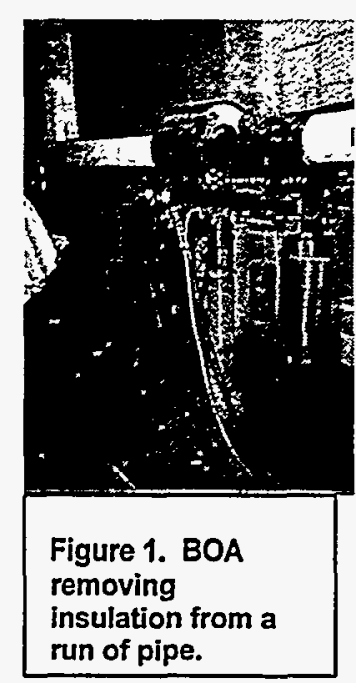
designed for two operators: one oversees the abatement head from a distance of 10 or 15 feet using a pendant control and the other bags the debris at a cyclonic bagging station that is attached by a vacuum hose to the cutting head. Since the abatement head is its own enclosure, there may be no need for further enclosures to be built. The system wets and removes asbestos insulation automatically, cutting the debris into consistent "chunks" and moving the waste under a strong vacuum to a bagging machine. Prior to reaching the bagging operation, the material passes through a water separator that greatly reduces the weight of the debris and allows recirculation of water, after sufficient filtration.

The basic concept underlying the system represents the most important worker protection feature: remotely removing asbestos pipe insulation eliminates the use of glovebags, the standard abatement technique that requires working on ladders with arms constrained by a plastic bag while wearing respiratory protection and protective suits. Asbestos exposure and fall hazards are significant risks for workers with this standard technique.

BOA's abatement head, which weighs approximately 160 pounds, is clamped onto the pipe after positioning the unit with jib-crane. A tether containing power, pressurized water, and

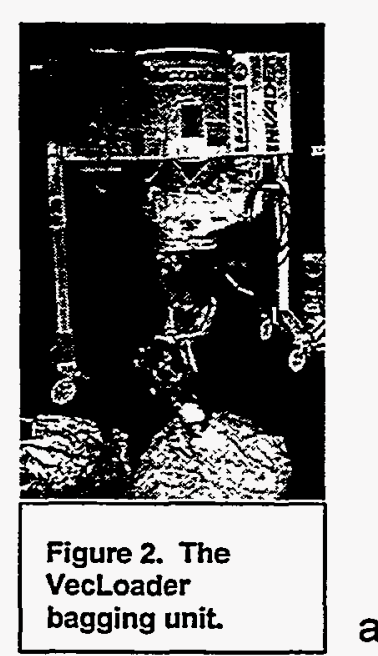
encapsulant lines, as well as a 4-inch diameter vacuum hose is connected between the abatement head and the other pieces of equipment. The tether is currently configured to allow up to 150 feet between the control-box and the abatement head. The abatement head removes asbestos with three omni-directional specially designed endmill/water jet cutters that cut through metal jackets, cloth lagging, and insulation using a combination of mechanical cutters and high pressure water jets. The jets 
perform the final cuts so that the mechanical cutters never come in contact with the pipe surface.

An infrared light sensor and a bump sensor on the front of BOA will detect a hanger or other hindrance, stop, and prompt the operator. If it is a hanger, the operator can use the pendant control to initiate a sequence during which BOA will leave a small, encapsulated section of asbestos on both sides of the hanger, move past the hanger, and continue removing insulation. These small sections will have to be removed with glove bags. BOA cannot move around bends in the pipe and must be physically disengaged from the pipe and transported to the next straight run.

The other equipment that makes up the system includes a diesel-powered generator, a $1,000 \mathrm{cfm}$ industrial HEPA-filtered vacuum unit, a cyclonic waste-bagging system, and a water-separator system. A central controller box controls, coordinates, and monitors all system parameters. The only site-supplied requirements are tap-water (about 50 gallons per day) and a 110 VAC shore power to run the backup HEPA vacuum. The computer system constantly monitors a number of system parameters and shuts down the operation if it detects something outside acceptable bounds, such as a drop in pressure in the abatement head.

Several of these components were purchased commercially. The vacuum unit, called a VEC-Loader, is built by VEC, Inc. and was designed for vacuuming asbestos waste directly from an enclosed work area and into containers. The unit runs continually when $\mathrm{BOA}$ is in operation. The cyclonic bagger is also commercially available and is commonly used in the asbestos abatement industry. During the removal cycle, when sufficient insulation has been cut, the robot stops and the large vacuum is bypassed and an auxiliary vacuum is used to maintain negative pressure in the system while the materials are bagged. The operator must manually throw a lever to get the waste to drop out of the cyclonic bagger into a properly labeled asbestos bag. Once "bag-out" is completed, the system switches back to the large vacuum and the robot head begins a new removal cycle.

The high pressure water pump is a modified off-the-shelf unit that is standard in any industrial operation. The encapsulant system is a commercially available airless pump system that has been slightly modified for this operation. A commercially available penetrating encapsulant is used. The water separator is a unit that was custom built for the BOA operation. It removes all of the loose water that was not absorbed into the insulation, which keeps the weight (and cost) of disposal of the asbestos insulation much lower. The water is drawn through two filters before it is recycled for use by the system. 


\section{SECTION 3 - HEALTH AND SAFETY EVALUATION}

\section{GENERAL HEALTH AND SAFETY CONCERNS}

Personnel working with the BOA asbestos removal system need to be concerned with safety and health issues that may be divided into two categories. First, core issues are those that are based on current safety and health regulatory requirements. Second, best management practices are not regulatory requirements, but are key elements in preventing worker injury and illness on the job. Safety and health issues of concern with the BOA system included:

\section{Core Issues:}

- Tripping hazards - Although necessary, vacuum hoses, water lines, electrical cables, and encapsulant lines are tripping hazards. Therefore, the need for stringent housekeeping must be evaluated.

- Lockout/tagout - The user of the technology will need to develop a lockout/tagout program to assure there is not an accidental release of energy during maintenance/repair activities.

- Noise - BOA.is acceptably quiet but the VEC-Loader vacuum unit exceeded the OSHA Noise standard. Hearing protection should be worn while working around this unit.

- Dust - The equipment did not generate visible dust during operation nor were significant amounts measured during operation. This is reasonable given the thorough wetting of insulation and the strong vacuum maintained during operation.

Working at heights - The operation of BOA was much more hazardous during the removal of insulation located on elevated pipe sections.

\section{Best Management Practices:}

- Heat stress - The operator will potentially be subjected to an increase in heat stress if personal protective equipment (PPE), particularly disposable suits, is necessary. The individual removing filled bags from the bagging operation will be at more of a risk due to the increased activity level. The user will need to develop a heat stress program for the environment in which the technology is being used, taking into consideration any PPE that may need to be utilized. 
- Ergonomics - There are several ergonomic concerns with the operation of BOA. During the equipment set up, particular care must be given to lifting large containers off of the truck. During setup there are hoses and cables that must be attached to the various pieces of the equipment which requires bending, twisting, kneeling, stooping, and wrist, hand, arm, shoulder, and back stress and abnormal positioning. In addition, the weight of the bags of asbestos should not exceed 30 pounds in order to avoid back injuries for the bagging operator.

Struck by hazards - The high pressure water lines have the potential to cause severe injury if their fittings were to fail. A safety line between the male and female end of the fittings would prohibit the line from becoming airborne. The accidental release of the cutting head during attachment to an overhead pipe could be fatal to workers underneath of the unit.

\section{INDUSTRIAL HYGIENE MONITORING}

\section{Noise Monitoring}

Noise monitoring was conducted with a Quest Technologies Model 2700 Sound Level Meter that was calibrated pre-and-post monitoring with a Quest Calibrator Model QC10.

Area noise monitoring was conducted during the operation of BOA and all associated equipment (vacuum unit, VecLoader, high pressure water pump, etc.). Readings ranged from 80-89 dBA inside the building and 96-103 dBA outside the building where the vacuum unit was located. These readings indicate noise to be a potential exposure problem during the operation of BOA. See Appendix B for specific locations and noise levels for noise monitoring.

The noise levels generated and therefore, the noise levels the workers are exposed to will be dependent on several factors. This includes the placement of all the associated equipment (especially the vacuum unit) in relation to the cutting head, the position(s) where the operators need to be located (which is related to the placement of equipment), and the construction materials of the area where BOA is being used. The closer together the equipment must be and therefore, the closer the operators must be to it, the higher the noise levels/levels of exposure would be expected to be. The smaller the area in which BOA must operate and the more reverberation from construction materials in the area, the higher the noise levels/levels of exposure would be expected to be. 


\section{Evaluation of Airborne Particles}

Calcium silicate pipe insulation was used, in lieu of asbestos during the human factors assessment. Calcium silicate is similar in texture but not nearly as fibrous as asbestos, consequently the fiber counting analytical procedure for asbestos (NIOSH Method 7400 ) was deemed to be inappropriate. Air samples were collected following NIOSH Methods 0500 and 0600 for gravimetric analysis of total dust and respirable dust, respectively. Samples were collected onto pre-weighed filters and sent for analysis to Galson Laboratories, an American Industrial Hygiene Association (AlHA) accredited lab. All samples were collected using MSA Escort Elf personal air sampling pumps. MSA cyclones were used for respirable dust sampling. The pumps were calibrated preand-post sampling with a BIOS DryCal-1 primary calibration source. Field blanks were collected on each day of sampling.

Additionally, real-time MIE personal/Data RAM model pDr-100 samplers were used to measure the concentration of airborne particulates. These photometric instruments provide an estimate of airborne mass based on particle counting and sizing.

Air sampling with both the personal air sampling pumps and the MIE Data RAM was conducted prior to the operation of BOA and during the operation of BOA. Since total and respirable dust were the analytes being monitored, this was done to account for any ambient airborne particulate that may have been present in the area where the BOA operation took place. The results were compared to the OSHA PEL and the American Conference of Governmental Industrial Hygienists (ACGIH) threshold limit value (TLV) of $15 \mathrm{mg} / \mathrm{m}^{3}$ for total dust and $5 \mathrm{mg} / \mathrm{m}^{3}$ for respirable dust and $10 \mathrm{mg} / \mathrm{m}^{3}$ for total dust and $3 \mathrm{mg} / \mathrm{m}^{3}$ for respirable dust, respectively.

\section{Real-Time MIE Data RAM Particulate Monitoring}

Background dust measurements were made one day prior to the operation of BOA. Up to 10 readings were taken at each station from which the mean, standard deviation, and coefficient of variation (CV) were determined. The CV was derived by dividing the mean into the standard deviation and then multiplying by 100 , to express the result as a percentage. The larger the $C V$, the greater the variation in the data. See Appendix $B$ for air sampling data.

Dust measurements were also taken during the operation of BOA. During operation, exposures would be expected to be higher when the cutting head is actually engaged. Consequently, a maximum reading was taken at each work station. Similarly, the Short Term Exposure Limit (STEL) was recorded at each work station. See Appendix B for air sampling data.

The dust readings using the MIE personal/Data RAM samples prior to operation of BOA 
were all between 0.032 and $0.048 \mathrm{mg} / \mathrm{m}^{3}$. During operation, the results were higher: ranging from 0.043 to $0.102 \mathrm{mg} / \mathrm{m}^{3}$, with the highest readings obtained by hanging the samplers on the operator and bag-out worker. The average of all the exposures was $0.08 \mathrm{mg} / \mathrm{m}^{3}$. The standard deviation and coefficient of variation for these readings were calculated and are included in Appendix B. These statistical calculations indicate that the readings were very consistent which allows more confidence in the data. The OSHA PEL for total dust is $15 \mathrm{mg} / \mathrm{m}^{3}$ for respirable dust.

\section{Total and Respirable Dust Air Sampling}

All of the mass measurements - both before and during operation of the BOA system were reported as below the level of quantification by the analytical laboratory. The differences reported below are due to the variations in air volumes collected. For example, the highest result, $<0.90 \mathrm{mg} / \mathrm{m}^{3}$, corresponded to the smallest air volume collected, 44.4 liters, after a pump failure. This result is well below the OSHA PEL. A complete air sampling plan for a site would need to be developed by all users of BOA. See Appendix $B$ for sampling data.

\section{Chemical Hazards}

The only chemical that is used in the system, besides standard lubricants, is the encapsulant that is sprayed to seal asbestos insulation exposed during movement around hangers. The encapsulant is also sprayed onto the pipes to seal any fibers potentially left behind on the pipe. There are several different commercially-available encapsulants that can be used in this system, however; during the assessment CP-210 Chil-Abate ${ }^{\mathrm{TM}}$ by Childers Products $\mathrm{Co}$. was used. The MSDS for this product lists only one hazardous component: 1,2 Ethanediol, CAS Number 107-21-1. This chemical makes up only 1-5 percent of the product and has an OSHA PEL of 50 parts per million. The MSDS indicates that 1,2 Ethanediol may be an eye and skin irritant. Consequently, the manufacturer recommends that safety glasses or goggles and impermeable rubber gloves should be worn. Additionally, they recommend having an eye wash nearby. The product is not flammable or reactive. The MSDS for the encapsulant being used needs to be evaluated and PPE and monitoring needs must be established on a job-by-job basis.

\section{Ventilation Flow Measurements}

Ventilation flow measurements, into the cutting head of the BOA system, were made during the human factors assessment. Measurements were made with an Alanor Thermo Anemometer Model 8525. Additionally, ventilation smoke tubes were used to assess the air movement pattern(s) in the area of the cutting head.

Air flow immediately outside the opening between the cutter head cover and the pipe 
insulation while the main vacuum was operating averaged 500-1000 feet per minute. When only the auxiliary vacuum was operating, the air flow was 200-300 feet per minute. See Appendix B for flow measurements.

Smoke tube testing visually reinforced the data reported for air flow measurements. While operational, the cutter head is under strong negative pressure. Smoke released anywhere near the cutter head was quickly drawn into the unit, including when only the auxiliary vacuum was operating.

\section{Ergonomics}

Through general observational techniques, the potential for ergonomic problems was evaluated during the human factors assessment. There is potential for muscle/back stress and/or injuries due to bending, twisting, and lifting associated with setup, operation, maintenance, and decontamination.

\section{General Observations}

- The work stations for several of the pieces of equipment involve awkward body positioning. During the set up phase, the connection of hoses and lines requires much bending over, while connecting the hoses and lines on the bagging unit requires reaching up over six feet. Similarly, connecting hoses to the large vacuum unit requires. reaching approximately seven feet. Attaching the cutter head to elevated piping involves more awkward positions including reaching out from an elevated manlift and working under the cutter head, both of which are serious safety hazards, in addition to ergonomic stressors.

- In emergency situations, the emergency stop button on the electrical box will require reaching over considerably to shut down the operation.

- Some of the portable equipment is not ergonomically designed. The water pump has four wheels on it, for instance, but their positions are rigidly fixed so there is no way to steer the unit. The water filters are permanently affixed to a dolly that makes it easier to move the equipment. However, the load sets too far forward which puts significant stress on the back of the person pulling this unit back on the dolly to move it.

- The color coding that is used on the unit is helpful but does not conform to national standards nor does it seem particularly intuitive. The developer has marked in gold everything with moving parts that poses safety risks. All other parts are blue. The color coding for the hazardous parts is not easily recognized as indicating danger, which is a real concern considering the possibility of finger amputation by the BOA's 
pipe clamping mechanism. Red would be much more effective than gold, and more warning stickers would be helpful.

- The icons used for the remote pendant are not intuitive and require serious training before an operator can effectively use the controls.

\section{Review of Existing Documentation}

The RIA has identified the following as important documents from the manufacturer of robotics systems. The following is information that was provided by Dr. Hagen Schempf concerning the availability of these documents. The software documentation was reviewed during this assessment and is discussed in greater detail under the software and hardware considerations section of this report.

\section{Document}

1. Function and location of all controls

2. Robot specifications, including range and load capacity

3. Limiting device information

4. Number, location, and degree of adjustment of hard stops

5. Number and location of control reliable limiting means

6. Lifting procedures and precautions

7. Precautionary information

8. Operating instructions

9. Maintenance and repair information, including preventive maintenance schedules

10. Information required for installation

11. Special environmental requirements

12. Electrical requirements

13. Lockout procedures

14. Failure mode analysis information

15. Hazard analysis and description of all hazard controls

\section{Available}

Yes No N/A Under development

口

凶

口 $\square$ 冈

$\square$ 凶

$\square \quad \square \quad$ 口

$\square$ 田

口

凶

ㅁ

$\square \quad \square \quad \square \quad \square$

$\square \quad \square \quad \square \quad$ 品

凶 $\quad \square \quad \square \quad \square$

$\square$

$\square \quad \square \quad \square \quad$ 口

$\square \quad \square \quad \square \quad$ 口 
The OENHP assessment of Type III, robotic technologies requires the following be reviewed in addition to the previous list:

\section{Document}

1. Training manuals and training requirements

2. Health and safety plan

3. Job Safety Analyses

4. Operations Manual

5. Maintenance Manual

6. Software listing

\section{Available}

Yes No N/A Under development

\section{NIOSH Lifting Calculation}

NIOSH has developed an equation for determining the RWL which is defined for a specific set of task conditions as the weight of the load that nearly all healthy workers could perform over a substantial period of time without an increased risk of developing lifting-related lower back pain. The RWL is based on a multiplicative model that provides a weighting for each of six task variables. The weightings are expressed as coefficients that serve to decrease the load constant, which represent the maximum recommended load to be lifted under ideal conditions. The RWL is defined by the following equation:

\section{$R W L=L C \times H M \times V M \times D M \times A M \times F M \times C M$}

\section{Where:}

\begin{tabular}{|l|l|l|l|l|}
\hline Name & Abbrev. & Formula & $\begin{array}{l}\text { Raw data } \\
\text { from BOA }\end{array}$ & $\begin{array}{l}\text { Multiplier } \\
\text { Determination }\end{array}$ \\
\hline Load Constant & LC & n/a & n/a & 51 lbs. (given) \\
\hline Horizontal Multiplier & HM & $(10 / \mathrm{H})$ & 9 inches & 1.0 \\
\hline Vertical Multiplier & VM & $1-(.0075 \mid \mathrm{V}-30 /)$ & 32 inches & 1.0 \\
\hline Distance Multiplier & DM & $.82+(1.8 / D)$ & 22 inches & .90 \\
\hline Asymmetric Multiplier & AM & $1-(.0032 \mathrm{~A})$ & 45 degrees & .86 \\
\hline
\end{tabular}




\begin{tabular}{|l|l|l|l|l|}
\hline Name & Abbrev. & Formula & $\begin{array}{l}\text { Raw data } \\
\text { from BOA }\end{array}$ & $\begin{array}{l}\text { Multiplier } \\
\text { Determination }\end{array}$ \\
\hline Frequency Multiplier & FM & $\begin{array}{l}\text { Designation of Long duration } \\
\text { task from Table 5 in NIOSH } \\
\text { text }\end{array}$ & $\begin{array}{l}1 \text { lift every 10 } \\
\text { minutes } \\
(0.1 \text { lift/min. })\end{array}$ & .85 \\
\hline Coupling Multiplier & $\mathrm{CM}$ & $\begin{array}{l}\text { Designation of Poor from } \\
\text { Table 6 }\end{array}$ & V>30 & .90 \\
\hline
\end{tabular}

\section{CALCULATIONS:}

$$
\begin{aligned}
& \mathrm{RWL}=\mathrm{LC} \times \mathrm{HM} \times \mathrm{VM} \times \mathrm{DM} \times \mathrm{AM} \times \mathrm{FM} \times \mathrm{CM} \\
& \mathrm{RWL}=52 \times 1.0 \times 1.0 \times .90 \times .86 \times .85 \times .90 \\
& \mathrm{RWL}=30.2 \mathrm{lbs} .
\end{aligned}
$$

$\mathrm{NIOSH}$, in its guidance documents points out that, "it is likely that lifting tasks with a lifting index $(\mathrm{LI})>1.0$ poses an increased risk for lifting-related low back pain for some fraction of the workforce. Hence, the goal should be to design all lifting jobs to achieve a LI of 1.0 or less...experts agree that nearly all workers will be at an increased risk of a work-related injury when performing highly stressful lifting tasks (i.e., lifting tasks that would exceed $\mathrm{a} \mathrm{Ll}$ of 3.0)." Calculations for the bagging operation show a $\mathrm{LI}$ of 1.6. Calculations further indicate that the waste bags should be kept to approximately 30 pounds.

$$
\begin{aligned}
\text { Lifting Index } & =\text { load weight/Recommended Weight Limit } \\
& =48.7 / 30.2 \\
& =1.6
\end{aligned}
$$

\section{SOFTWARE AND HARDWARE CONSIDERATIONS}

The BOA system has considerable fail-safe systems built into its operation but few are mechanical interlocks. The majority is software interlocks that exist in the computer programs designed for the system, not in mechanical interlocks that are routinely found in industry. The software/hardware was assessed to determine the robustness of the fail-safe computer interlocks.

The following resources were part of the computer software evaluation:

- listing of software program code;

1 U.S. Department of Health and Human Services, Public Health Service, Applications Manual for the Revised NIOSH Lifting Equation, DHHS (NIOSH) Publication No. 94-110,, January 1994, pg. 35. 
- discussions with Brian Chemel (programmer); and

- observations during assessment operations of the robot.

The computer system (in the final version) will be an embedded system contained in the system Control Box. Boot up operations will be initiated in firmware by the operator using the Pendant, so that an external computer terminal is not necessary for operation. The boot up firmware was not employed with the system used for the assessment; an external computer terminal was used for boot-up operation and to log operational status during system activity. This "log" information will be put on the embedded hard disk drive in the final version. An operator (or maintenance person) will be able to access this information by externally connecting a terminal.

\section{Hardware/Software}

The computer hardware implementation uses a modular, plug-in 486/33 PC with 4M RAM, 2M EPROM, ADC board, DAC board, a special Heartbeat board, and servo amplifier circuitry. All components are commercially available with the exception of the Heartbeat board and amplifiers.

Heartbeat Card: This performs a "dead-man" switch function. Control inputs to this card monitor various system operations which provide a "heartbeat" clock $(20 \mathrm{~Hz}$ update clock) to keep the system active and enabled. Any malfunction in the software or hardware results in an irregular "heartbeat" which disables all system components in a fail-safe mode. When a single-axis failure occurs (jammed pipe clamp, etc.), the system can be re-started by operator action. When two failures occur sequentially the system shuts down, and a re-boot is necessary to restart the system. The E-Stop buttons located on several system components (pendant, control box, etc.) activate a heartbeat failure.

Operator Pendant: This commercial unit is environmentally sealed from dust, etc. Programming an EPROM customizes the unit to a unique application. BOA pendant control consists of simple, single actions, i.e. open clamp, close clamp. See Appendix $\mathrm{C}$ for Layout of Pendant Control Buttons. Full control by the operator is via this pendant. The pendant has a message display panel which displays operational and fault information to the operator. It does not provide a complete diagnostic message but simply states the actions required or the current status of the system.

Manual Button Box: This unit provides simple controls and power to the robot, if the $B O A$ unit has to be removed from the pipe due to computer system failure. The normal input connections are disconnected and the Button Box provides the basic functions to unclamp the robot so that it can be moved to another location for maintenance purposes. 
Robot Sensors: The BOA robot has a bumper tactile sensor and a pipe hanger detection infrared (IR) sensor.

The Control Box: This is a centrally located, portable unit that interconnects input power and all electrical and control signals/cables for the BOA system components. The computer system is housed in this Control Box. Input power requirements for the system are $208 \mathrm{v}$ ac, 3 -ph, 50 -amp. A separate $115 \mathrm{v}$ ac, 10 -amp power input is required for the HEPA pony vacuum unit used in emergency situations. This power input is intentionally separated from the main system power for safety reasons (if main power fails, the HEPA unit will remain active.)

Software: The software architecture is simple, straight-forward, yet provides the required functionality and exception handling necessary for a real-time system such as the BOA robot. It is written in Borland $\mathrm{C}++$. At the highest level, a Planning Module plans and controls operations for two basic operational modes: Manual and Automatic. Once the system is in the Automatic mode, it must be terminated by operator action or by a system fault. The lowest level uses system interrupts.

Exception Handling: The system "exceptions" are organized as follows: Fail Safe Status, Operation Interaction Required, System Malfunction, and Feedback System Monitoring. Fail Safe Status occurs for system power failure and heartbeat loss. Operator Interaction is required for Emergency Stops (manual buttons) or operator actions from the Pendant keypad. System Malfunctions occur from loss of vacuum, bumper activation on robot, etc. The Feedback System Monitoring includes the status monitoring of limit switches on all system subsystems, motor current limits, activator positions, and water pressure and flow.

Computer Maintenance: Access to the computer is at the Control Box. The only other computer component is the Operator Pendant. Except for the lack of diagnostic software, this system should be relatively easy to maintain by anyone trained in computer maintenance: The system is an embedded system. An external terminal may be connected for maintenance purposes (read out the system log, run diagnostic programs if/when available, etc.) The software is presented in good format and is well documented with appropriate comments. It is easy to follow by someone knowledgeable in programming.

Modular Commercial Hardware: Modular commercial hardware simplifies system maintenance. Several special cards would have to be built for spare parts.

\section{Recommendations for Computer Operation:}

- The primary missing item is diagnostic software to help a computer maintenance person locate faults within the system. An error log is provided that can be 
accessed from the system hard disk; however, this information is not organized in a manner that would be easy for maintenance to use. All the "hooks" are there for providing these diagnostic tools. This would be recommended before the system went into full production use.

- Diagnostic messages at the Operator Pendant could be improved to provide more explicit information.

- The exception handling design and implementation appears to be adequate to provide fail safe systems under any unusual failure within the software and/or hardware.

- System valves and motors fail in a "safe" deactivated condition. For example, if power or computer failure occurs, the robot will remain securely clamped to the pipe and requires manual power to be applied to move it.

- The heartbeat card is an effective monitoring tool for hardware and software and shuts down the system should failures occur.

\section{HUMAN FACTORS INTERFACE}

The computer system responsible for operating BOA provides an important human factors interface. A Heartbeat Card in the system basically performs a dead-man switch function. Control inputs to this card monitor various system operations which provide a "heartbeat" clock ( $20 \mathrm{~Hz}$ update clock) to keep the system active and enabled. Any malfunction in the software or hardware results in an irregular "heartbeat" which disables all system components in a fail-safe mode. When a single-axis failure occurs (jammed pipe clamp, etc.), the system can be re-started by operator action. When two failures occur sequentially the system shuts down, and a re-boot is necessary to restart the system. The E-Stop buttons located on several system components (pendant, control box, etc.) activates a heartbeat failure.

System operation from the pendant is simple and straight forward. The Operator Pendant is a commercial unit that is environmentally sealed from dust, etc. Programming an EPROM customizes the unit to a unique application. The BOA pendant control consists of simple, single actions, i.e. open clamp, close clamp. Full control by the operator is via this operator pendant. The pendant has a message display panel which displays operational and fault information to the operator. It does not provide a complete diagnostic message but simply states the actions required or the current status of the system.

The Manual Button Box provides simple controls and power to the robot, if the unit has to be removed from the pipe due to computer system failure. The normal input 
connections are disconnected and the Button Box provides the basic functions to unclamp the robot so that it can be moved to another location for maintenance purposes. BOA has a bumper tactile sensor and a pipe hanger detection IR sensor. The Control Box is a centrally located, portable unit that interconnects input power and all electrical and control signals/cables for the BOA system components. The computer system is housed in this Control Box. Input power requirements for the system are $208 \mathrm{v}$ ac, 3-ph, 50-amp. A separate $115 \mathrm{v}$ ac, 10 -amp power input is required for the HEPA unit used in emergency situations. This power input is intentionally separated from the main system power for safety reasons (if the main power fails, the HEPA unit will remain active.)

The software architecture is simple, straight-forward, yet provides the required functionality and exception handling necessary for a real-time system such as the BOA robot. It is written in Borland $\mathrm{C}++$. At the highest level, a Planning Module plans and controls operations for two basic operational modes: Manual and Automatic. Once the system is in the automatic mode, it must be terminated by operator action or by a system fault. The lowest level uses system interrupts.

For computer maintenance, access to the computer is at the Control Box. The only other computer component is the Operator Pendant. Except for the lack of diagnostic software, this system should be relatively easy to maintain by anyone trained in computer maintenance. The system is an embedded system. An external terminal may be connected for maintenance purposes (read out the system log, run diagnostic programs if/when available, etc.) The software is presented in good format and is well documented with appropriate comments. It is easy to follow by someone knowledgeable in programming.

\section{TECHNOLOGY APPLICABILITY}

On observation the technology did not generate visible dust and air monitoring did not show a significant dust level. Noise measurements were also acceptable for the new technology. The need to work only on 4" O.D. pipe runs that do not have many bends limits the applicability of the technology. The time needed to physically move the head around a pipe bend may negate the savings associated with the unit automatically operating on a straight run. 


\section{SECTION 4 - JOB SAFETY ANALYSIS}

\section{JOB SAFETY ANALYSIS CARNEGIE MELLON UNIVERSITY}

BOA

HAZARD

CORRECTIVE ACTION

EQUIPMENT UNLOADINGISET UP

Crushed toes from large containers dropped onto feet

* Contact ("struck-by" hazard) from fork lift

* Lifting injuries

* Struck-by hazard (for workers) due to equipment size and the need to back into an acceptable location for the VecLoader

* Falling on/struck-by hazard (for workers) from Vec-Loader tipping/rolling over if location is not level

* Wear hard hat and safety shoes while unloading the truck

* Ensure that all fork lift operators have been properly trained as required by OSHA 29 CFR 1910.178(I)

* Ergonomics training to include proper lifting techniques

* Tow with truck equipped with backup alarm

* Ensure the location is level and the soil/surface is acceptably packed before placing the unit

* Wear safety shoes and hard hat during set up

* Do not allow workers too close to moving vehicles/equipment 


\section{HAZARD}

CORRECTIVE ACTION

* Tripping hazards from the vacuum, air, and water hoses (ranging in diameter from less than one inch to five inches) as they are unspooled

* Ergonomic hazards such as strain/sprain to the back and shoulder muscles when unrolling hoses

* Place hoses to avoid clutter and tripping hazards - good housekeeping essential

* Bundle cables and lines (with the large vacuum hose) to limit the space covered on the floor

* Mark hoses to indicate the hazard

* Avoid awkward postures and positions during unrolling of hoses and cables

* Use reels with special handles, where possible

* Ergonomic training to include proper lifting techniques

* Exposure to contaminant (asbestos) seals on hoses may break from movement when attaching vacuum hoses to Vec-Loader

* Pinch points with potential for serious injury to fingers/hand from connectors for attaching vacuum hoses to Vec-Loader

* Sprain/strain to neck, upper back, shoulders, and/or arms from reaching above shoulder/head height to attach vacuum hoses to Vec-Loader

* Fall onto/struck by hazard from vacuum hose/vacuum hose end cover being dripped while attaching vacuum hoses to Vec-Loader

* Wear proper PPE, when necessary including respiratory protection with HEPA filters - during vacuum hose connection

* Training/awareness of pinch hazards associated with attaching vacuum hoses to Vec-Loader

* Label connectors as "pinch points"

* Ergonomics training to include proper techniques for working above shoulder/head height

* Use platform to reach vacuum hose attachment location on Vec-Loader

* Redesign the hose end coverings with a safety line so cannot fall 
* Pinch points associated with attaching high pressure water hoses, encapsulate line, and electrical cable

* Electrical hazards - when energize system

* Ergonomic hazards due to awkward positions that must be assumed to connect some of the lines and hoses (high pressure water hoses, encapsulant line, and electrical cable)

* Fall from above/struck by hazard from BOA abatement head being accidentally released from jib crane used to remove it from the transport box

* Redesign the clamps used to hold the abatement head on the jib crane to provide for a more secure attachment * Technology specific training on the proper methods for removal of the abatement head from the transport box including properly securing the clamps used to hold the head on the jib crane

${ }^{*}$ Require workers to wear hard hats and steel-toed safety shoes

* Use SOP's to assure effective communication between workers * Use proper lockout/tagout procedures when connecting lines (prior to electrical system checkout) 


\begin{tabular}{|c|c|}
\hline HAZARD & CORRECTIVE ACTION \\
\hline $\begin{array}{l}{ }^{*} \text { Fall from above/struck by hazard from } \\
\text { abatement head falling }\end{array}$ & $\begin{array}{l}\text { * Using established SOP's workers have } \\
\text { been trained in to assure coordination } \\
\text { between workers } \\
\text { " Require hard hats to be worn during } \\
\text { lifting operations } \\
{ }^{*} \text { Do not allow workers under the } \\
\text { abatement head during lifting procedures }\end{array}$ \\
\hline $\begin{array}{l}\text { * Fall from above/struck by hazard from } \\
\text { pipe rack falling - potential to be caused } \\
\text { by the weight of the abatement head }\end{array}$ & $\begin{array}{l}\text { * Inspection/assessment of the pipe rack } \\
\text { before the abatement head is attached to } \\
\text { assure the rack will hold the weight of the } \\
\text { head } \\
\text { " Require hard hats to be worn during } \\
\text { lifting operations } \\
{ }^{*} \text { Do not allow workers under the } \\
\text { abatement head during lifting procedures }\end{array}$ \\
\hline $\begin{array}{l}\text { * Exposure to contaminants/substances } \\
\text { contained in pipe (if pipe rack were to } \\
\text { fall) }\end{array}$ & $\begin{array}{l}\text { * Pre-job planning to determine what is } \\
\text { presently in or what was in the pipes. } \\
\text { Use appropriate precautions including } \\
\text { lockout/tagout as required }\end{array}$ \\
\hline $\begin{array}{l}\text { * Pinch points from the clamper arms } \\
\text { used to hold the abatement head on the } \\
\text { pipe - this may cause severe injury or } \\
\text { may sever fingers/hand/arm }\end{array}$ & $\begin{array}{l}\text { * Technology specific training to include } \\
\text { information on the pinch point hazard of } \\
\text { the clamper arms including the color } \\
\text { coding used on BOA - gold colored parts } \\
\text { are moving parts and are considered } \\
\text { potential pinch points (in addition the } \\
\text { clamper arms are labeled as pinch } \\
\text { points) } \\
\text { * Do not allow workers near the clamping } \\
\text { arms during the clamping sequence, and } \\
\text { require pendant operator to keep both } \\
\text { hands on pendant at all times as part of } \\
\text { the SOP's }\end{array}$ \\
\hline
\end{tabular}




\section{HAZARD}

CORRECTIVE ACTION

* Struck by hazard from high pressure water lines becoming disconnected during the initial full system check. The system will sense the pressure difference and shut down but injury could occur before this happens

* Pinch points/nip points on the belt drive (if the water pump is run with the cover off)

\section{OPERATION}

* Exposure to noise from vacuum unit

* Exposure to diesel exhaust (if the vacuum unit is diesel powered)

* Operate the vacuum unit outside or at a distance (sufficient to decrease noise levels below the OSHA "action level") from the asbestos removal operation * Require hearing protection be used anytime a worker is in the area of the vacuum unit

* Ensure exhaust does not get drawn into the building (if the vacuum unit is outside) or assure proper ventilation (if the vacuum unit is inside) 


\section{HAZARD}

* Exposure to contaminant (asbestos) when abatement head opens to move around hangers or other obstructions

${ }^{*}$ Exposure to encapsulant when it is sprayed on the pipe or when dripping from the pipe

* Pinch points from the clamper arms used to hold the abatement head on the pipe - this may cause severe injury or may sever fingers/hand/arm

\section{CORRECTIVE ACTION}

* Assure through exposure monitoring that asbestos fibers are not being released when the abatement head opens. Until such time use proper PPE including respiratory protection with HEPA filters

* Assure proper maintenance on the abatement head to maintain a proper water spray and vacuum pressure at all times

* Adjust encapsulant spray nozzles to avoid overspray conditions

* Use proper PPE (in accordance with manufacturer's MSDS) when in area where encapsulant is being sprayed * Hazard Communication (HAZCOM) training for all workers using the , encapsulant

* Technology specific training to include information on the pinch point hazard of the clamper arms including the color coding used on BOA - gold colored parts are moving parts and are considered potential pinch points (in addition the clamper arms are labeled as pinch points)

* Keep personnel away from the cutter head and the pendant control operator sufficiently back from the operation during movement around hangers - as part of SOP's 


\section{HAZARD}

* Back sprain/strain from lifting bags of waste that have been overfilled during the bagging operation
CORRECTIVE ACTION

* Program BOA to stop removing insulation and send the waste to the bagging operation at intervals where the bags of waste will not weigh more than 30 pounds. NOTE: The 30 pound weight limit is based on NIOSH Lifting formula calculations for the job

* Use a "lazy Susan" type of system with wheels - place the waste bag on the lazy Susan and turn for twisting bag shut and for moving bag to the waste accumulation area

* Ergonomics training to include proper lifting techniques

\section{MAINTENANCE}

* Laceration hazard to finger(s) from cutter heads themselves being sharp or from an accidental activation during replacement/maintenance

*Exposure to asbestos if the head is opened for maintenance after the residue inside is allowed to dry
* Use gloves to protect against laceration when handling the cutter heads

* Use appropriate lockout/tagout procedures when cutter head (or any) maintenance is being performed. NOTE: $B O A$ is designed with a computer interlock that shuts down all operations when a pressure drop occurs (as when the head is opened). This should not be relied on and appropriate lockout/tagout procedures need to be applied

* Assure residue is not dry before maintenance activities are initiated. Perform a wash down on the inside of the head before maintenance activities are initiated

* Use proper PPE - including a respirator with HEPA cartridges - while performing maintenance activities 
* Slipping hazards from water spilled on the floor while changing the filters in water filtration unit

* Electrical hazards from water spraying or spilling onto electrical wires while changing the filters in the water filtration unit

* Back sprain/strain from lifting the covers and filters in the water filter unit
* Technology specific training for techniques for properly removing and changing the filters in the water filtration unit

* Wipe up all spilled water immediately in accordance with good housekeeping practices

* Use ground fault circuit interrupter (GFCl) circuits

* De-energize the system and use proper lockout/tagout procedures during water filter changing activities

* Position water filtration unit away from the electrical box and major cables so when the filters are changed, spilling/spraying water is not a concern for electrical components

* Ergonomics training to include proper lifting techniques

\section{DECONTAMINATION AND EQUIPMENT BREAKDOWNS}

* Exposure to asbestos during cleaning of the abatement head and vacuum hose
* Assure a thorough flush of the abatement head and the vacuum hose at the end of the job - as part of the SOP's

* Assure the residue is still wet before sealing the end of the hose

* Seal the abatement head in plastic after flushing - to move to next job location 


\begin{tabular}{|c|c|}
\hline HAZARD & CORRECTIVE ACTION \\
\hline $\begin{array}{l}\text { * Fall from above/struck by hazard from } \\
\text { abatement head falling }\end{array}$ & $\begin{array}{l}\text { * Using established SOP's (that workers } \\
\text { have been trained in) to assure } \\
\text { coordination between workers } \\
\text { " Require hard hats to be worn during } \\
\text { removal operations } \\
\text { * Do not allow workers under the } \\
\text { abatement head during lifting } \\
\text { procedures, do not allow workers near } \\
\text { the clamping arms during the clamping } \\
\text { sequence, and require pendant operator } \\
\text { to keep both hands on pendant at all } \\
\text { times as part of the SOP's }\end{array}$ \\
\hline $\begin{array}{l}\text { *Pinch points from the clamper arms } \\
\text { opening to release the abatement head } \\
\text { from the pipe - this may cause severe } \\
\text { injury or may sever fingers/hand/arm }\end{array}$ & $\begin{array}{l}\text { * Technology specific training to include } \\
\text { information on the pinch point hazard of } \\
\text { the clamper arms including the color } \\
\text { coding used on BOA - gold colored parts } \\
\text { are moving parts and are considered } \\
\text { potential pinch points (in addition the } \\
\text { clamper arms are labeled as pinch } \\
\text { points) } \\
\text { * Require hard hats to be worn during } \\
\text { removal operations } \\
\text { * Do not allow workers under the } \\
\text { abatement head during lifting } \\
\text { procedures, do not allow workers near } \\
\text { the clamping arms during the clamping } \\
\text { sequence, and require pendant operator } \\
\text { to keep both hands on pendant at all } \\
\text { times as part of the SOP's }\end{array}$ \\
\hline
\end{tabular}




\begin{tabular}{|c|c|}
\hline HAZARD & CORRECTIVE ACTION \\
\hline $\begin{array}{l}\text { *Electrical shock hazards present during } \\
\text { disconnect activities }\end{array}$ & $\begin{array}{l}\text { *Assure } \mathrm{GFCl} \text { protection is used on the } \\
\text { system } \\
\text { *Assure any water (from spills or } \\
\text { spraying) around the electrical } \\
\text { connections is cleaned up before } \\
\text { disconnecting } \\
\text { " Ensure that the main electrical box is } \\
\text { shut down and proper lockout/ragout } \\
\text { procedures are used before } \\
\text { disconnecting }\end{array}$ \\
\hline $\begin{array}{l}\text { *Slipping hazards from water spilled while } \\
\text { draining water through the filters }\end{array}$ & $\begin{array}{l}\text { *Assure that spilled water is cleaned up } \\
\text { immediately in accordance with good } \\
\text { housekeeping practices }\end{array}$ \\
\hline $\begin{array}{l}\text { * Slipping hazards from spilling water } \\
\text { when pumping out the water separator } \\
\text { (to be removed as waste) into plastic } \\
\text { lined drums } \\
\text { * Back sprain/strain from moving drums } \\
\text { filled with waste from pumping out the } \\
\text { water separator }\end{array}$ & $\begin{array}{l}\text { *Assure that spilled water is cleaned up } \\
\text { immediately in accordance with good } \\
\text { housekeeping practices } \\
\text { * Assure that the drum is not overfilled } \\
\text { and that it is moved slowly so the } \\
\text { movement of the liquid in the drum does } \\
\text { not cause the worker be stressed } \\
\text { ergonomically } \\
\text { * Use mechanical method for moving the } \\
\text { drum } \\
\text { * Ergonomics training to include proper } \\
\text { lifting techniques and proper techniques } \\
\text { for moving heavy objects }\end{array}$ \\
\hline $\begin{array}{l}\text { * Falling on/struck-by hazard (for } \\
\text { workers) from Vec-Loader tipping/rolling } \\
\text { over if the unit is moved too aggressively } \\
\text { during the spray down process. (Unit } \\
\text { has a small wheel base) }\end{array}$ & $\begin{array}{l}\text { *Assure the Vec-Loader is stable before } \\
\text { beginning the spray down }\end{array}$ \\
\hline
\end{tabular}




\section{FAILURE MODE AND EFFECTS ANALYSIS CARNEGIE MELLON UNIVERSITY BOA}

\begin{tabular}{|l|l|}
\hline \multicolumn{1}{|c|}{ FAlLURE MODE } & \multicolumn{1}{|c|}{ EFFECT } \\
\hline $\begin{array}{l}\text { * The weight of the cutting head causes } \\
\text { the pipe to break or a pipe hanger to fail }\end{array}$ & $\begin{array}{l}\text { * Serious injury or death may result from } \\
\text { the unit falling on (fall from above hazard) } \\
\text { someone } \\
\text { *Hot water, steam, or a hazardous } \\
\text { substance the pipe is/was carrying may } \\
\text { be released into the atmosphere and/or } \\
\text { onto workers }\end{array}$ \\
\hline $\begin{array}{l}\text { *'The VecLoadertips over while hoses } \\
\text { are being attached }\end{array}$ & $\begin{array}{l}\text { * The unit may become a "struck by" } \\
\text { hazard, falling on a worker and causing } \\
\text { serious injury }\end{array}$ \\
\hline $\begin{array}{l}\text { * High pressure jets spray during } \\
\text { unplanned maintenance activity }\end{array}$ & $\begin{array}{l}\text { * Severe injuries to operator (of particular } \\
\text { concern is the faceleyes) }\end{array}$ \\
\hline * High pressure on water or air line \\
releases
\end{tabular}




\begin{tabular}{|l|l|}
\hline \multicolumn{1}{|c|}{ FAILURE MODE } & \multicolumn{1}{|c|}{ EFFECT } \\
\hline * Pump fails on the encapsulant sprayer & $\begin{array}{l}\text { * Potential for release of asbestos fibers } \\
\text { into the atmosphere, if they are not } \\
\text { captured by the vacuum. Therefore, a } \\
\text { potential for worker exposure to asbestos } \\
\text { fibers }\end{array}$ \\
\hline $\begin{array}{l}\text { * Hopper on bagging unit becomes too } \\
\text { full causing impeller to jam }\end{array}$ & $\begin{array}{l}\text { * Potential (although remote) of catching } \\
\text { hand inside because of need to manually } \\
\text { reach up inside unit to free jammed } \\
\text { impeller } \\
\text { * Potential for exposure to asbestos }\end{array}$ \\
\hline * Water pressure drops & $\begin{array}{l}\text { * Potential for exposure to asbestos } \\
\text { fibers because there is not enough water } \\
\text { available for wetting }\end{array}$ \\
\hline * Loss of vacuum during bagging \\
operation
\end{tabular}




\begin{tabular}{|l|l|}
\hline \multicolumn{1}{|c|}{ FAILURE MODE } & \\
\hline * Motor fails for the chain belt & $\begin{array}{l}\text { * Potential for exposure to asbestos } \\
\text { fibers because the insulation "cubes" will } \\
\text { collect in the unit which will cause a drop } \\
\text { in vacuum and the machine will shut } \\
\text { down }\end{array}$ \\
\hline $\begin{array}{l}\text { * Cover is removed from the unit for } \\
\text { maintenance (and lockout/tagout } \\
\text { procedures are not followed) }\end{array}$ & $\begin{array}{l}\text { "Fingers could be severely injured or } \\
\text { severed by belt }\end{array}$ \\
\hline * Lid is not tight on the filter cylinders & $\begin{array}{l}\text { * Potential for exposure to water } \\
\text { containing asbestos fibers due to water } \\
\text { spraying on the floor until the high } \\
\text { pressure alarm sounds - potential for } \\
\text { exposure to asbestos fibers after water } \\
\text { dries (if not cleaned up properly). } \\
\text { *Water on walking surface causes a } \\
\text { slipping hazard }\end{array}$ \\
\hline $\begin{array}{l}\text { * C-clamps used to hold the crane on the } \\
\text { man lift fail or become loose due to } \\
\text { movement of the crane }\end{array}$ & $\begin{array}{l}\text { * The crane could topple off of the man } \\
\text { lift and become a "fall from above" } \\
\text { hazard that could strike someone } \\
\text { causing serious injury or death }\end{array}$ \\
\hline * open with material inside & $\begin{array}{l}\text { * Potential for exposure to water } \\
\text { containing asbestos fibers due to first jet } \\
\text { of water containing asbestos - potential } \\
\text { for exposure to asbestos fibers after } \\
\text { water dries (if not cleaned up properly). } \\
\text { *Water on walking surface causes a } \\
\text { slipping hazard }\end{array}$ \\
\hline
\end{tabular}




\section{SECTION 6 - TECHNOLOGY SAFETY DATA SHEET}

\section{TECHNOLOGY SAFETY DATA SHEET CARNEGIE MELLON UNIVERSITY \\ BOA}

\begin{tabular}{|c|c|}
\hline \multicolumn{2}{|l|}{ SECTION 1: TECHNOLOGY IDENTITY } \\
\hline $\begin{array}{l}\text { Manufacturer's Name \& Address: } \\
\text { Carnegie Mellon University }\end{array}$ & $\begin{array}{l}\text { Emergency Contact: } \\
\text { Carnegie Mellon (412) 268-6884 }\end{array}$ \\
\hline $\begin{array}{l}\text { Field Robotic Center } \\
5000 \text { Forbes Avenue } \\
\text { Pittsburgh, PA }\end{array}$ & $\begin{array}{l}\text { Information Contact: } \\
\text { Carnegie Mellon (412) 268-6884 } \\
\text { (412) 268-5895 (fax) } \\
\text { Attn: Hagen Schempí, Ph.D. ' }\end{array}$ \\
\hline & Date Prepared: \\
\hline $\begin{array}{l}\text { Other Names: } \\
\text { BOA, Big on Asbestos, Robotic Asbestos } \\
\text { Remover }\end{array}$ & $\begin{array}{l}\text { Name of Preparer: } \\
\text { Operating Engineers National Hazmat } \\
\text { Program } \\
1293 \text { Airport Road, Beaver, WW } 25813 \\
\text { phone 304-253-8674, fax 304-253-1384. } \\
\text { Under cooperative agreement DE-FC21- } \\
95 \text { MC } 32260\end{array}$ \\
\hline
\end{tabular}




\section{SECTION 2: PROCESS DESCRIPTION}

This system is a self-propelled automated mini-enclosure that removes asbestos insulation from nominal 4" outside diameter piping. The system is designed for two operators, one at the abatement head, and another at the bagging station. Since the abatement head is its own enclosure there is no obvious need for further enclosures to be built.

The abatement head for BOA consists of a system for moving "inch worm-like" down the pipe with three clamps to hold the head in place. Removal takes place by high pressure water jets and endmill cutting heads that cut through all lagging and wire materials. BOA automatically uses water at 1.8 gallons per minute through the three cutting heads to perform the cutting and at 1.2 gallons per minute through separate nozzles to flush the pieces of asbestos into the waste stream.

A high volume vacuum conveys the cut insulation to the bagging operation. A high pressure spray of water cleans the pipe and a spray of encapsulant seals any remaining fibers to the pipe as the unit moves along the pipe. The waste material is directed through a water separator, where the water is separated from the waste material and is filtered and recycled for continued cutting. The waste is vacuumed into the bagging operation where chunks of insulation are dumped into asbestos bags and taped shut. A centrally located control box coordinates all actions to a remote pendant for the operator to supervise and control the abatement process. 


\section{SECTION 3: PROCESS DIAGRAM}

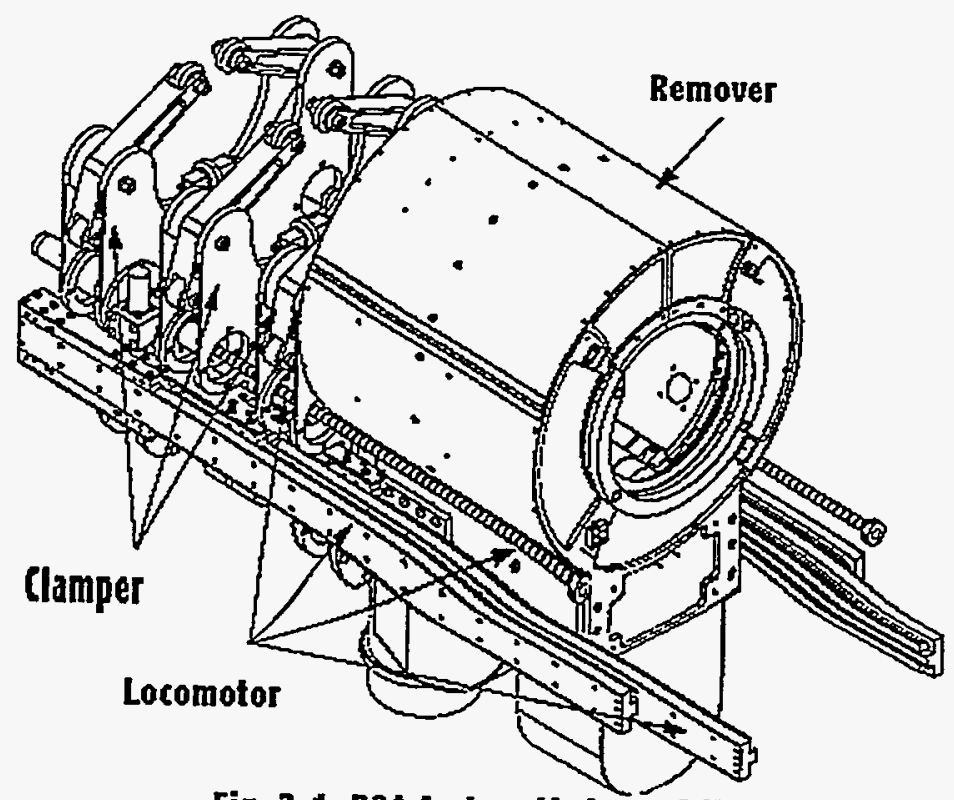

Fig. 3-1 BOA System Abatement Head 


\section{SECTION 3: PROCESS DIAGRAM}

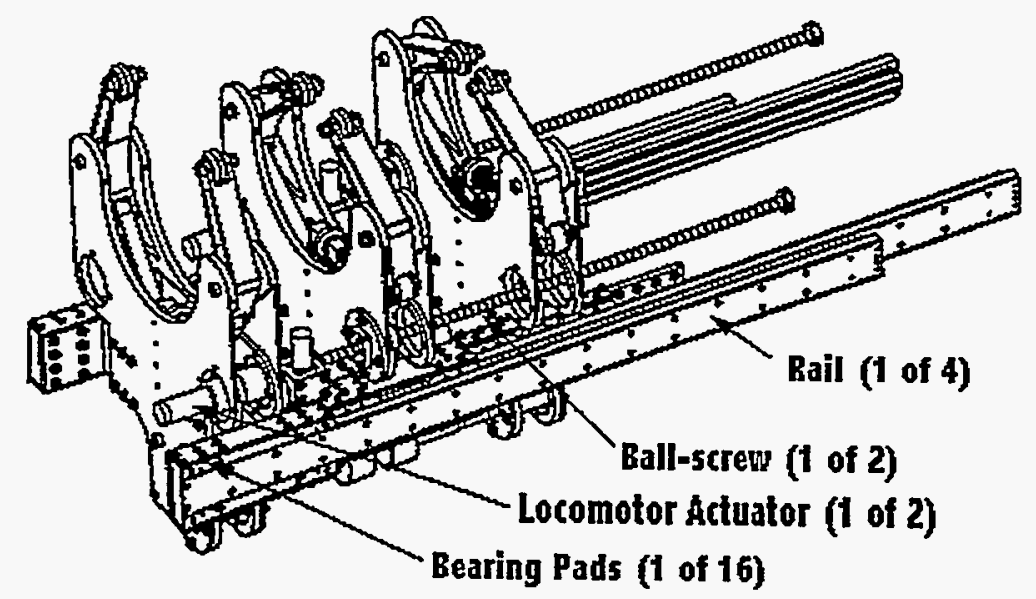

Fig. 3-2 Overview of Locomotor System

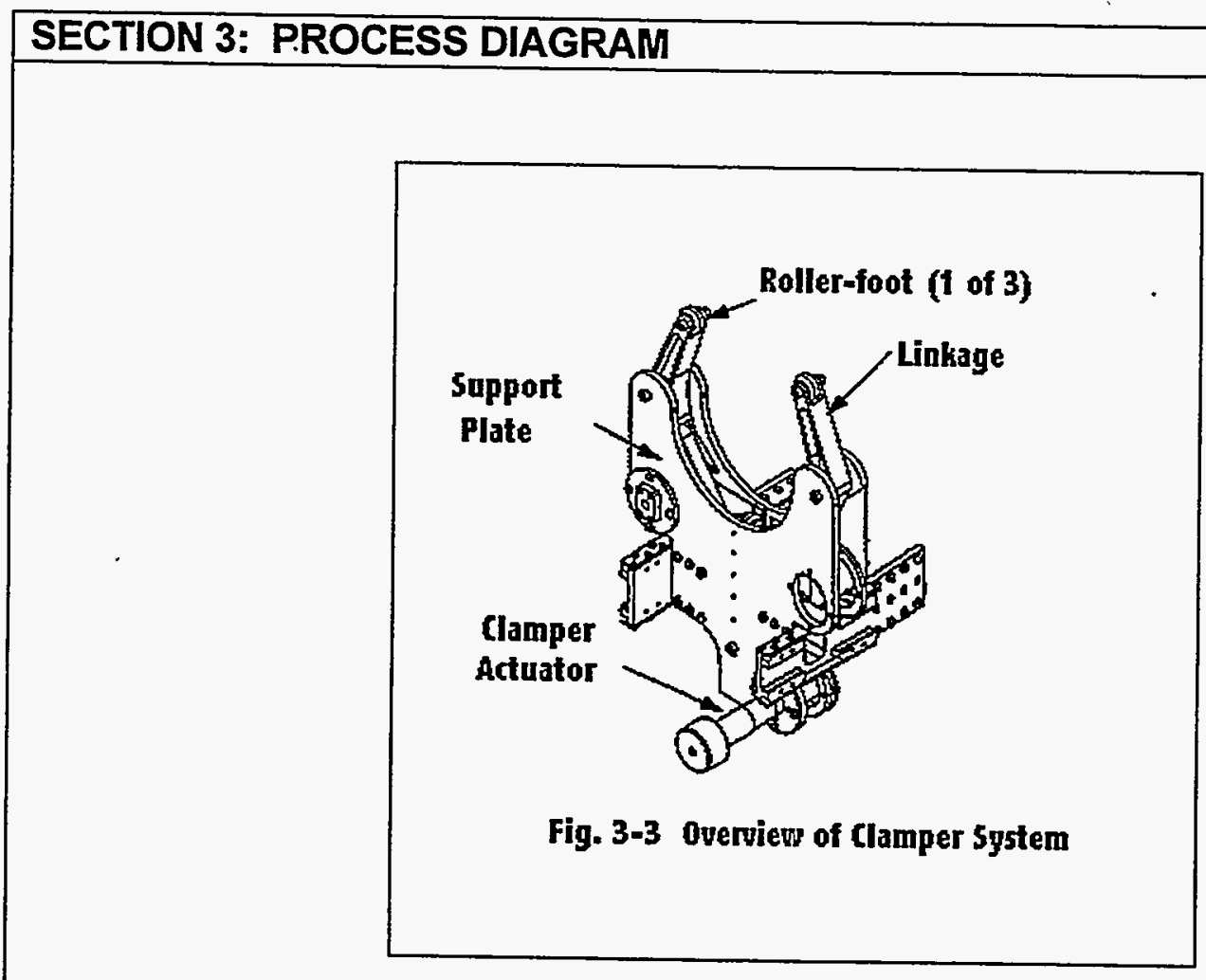




\section{SECTION 3: PROCESS DIAGRAM}
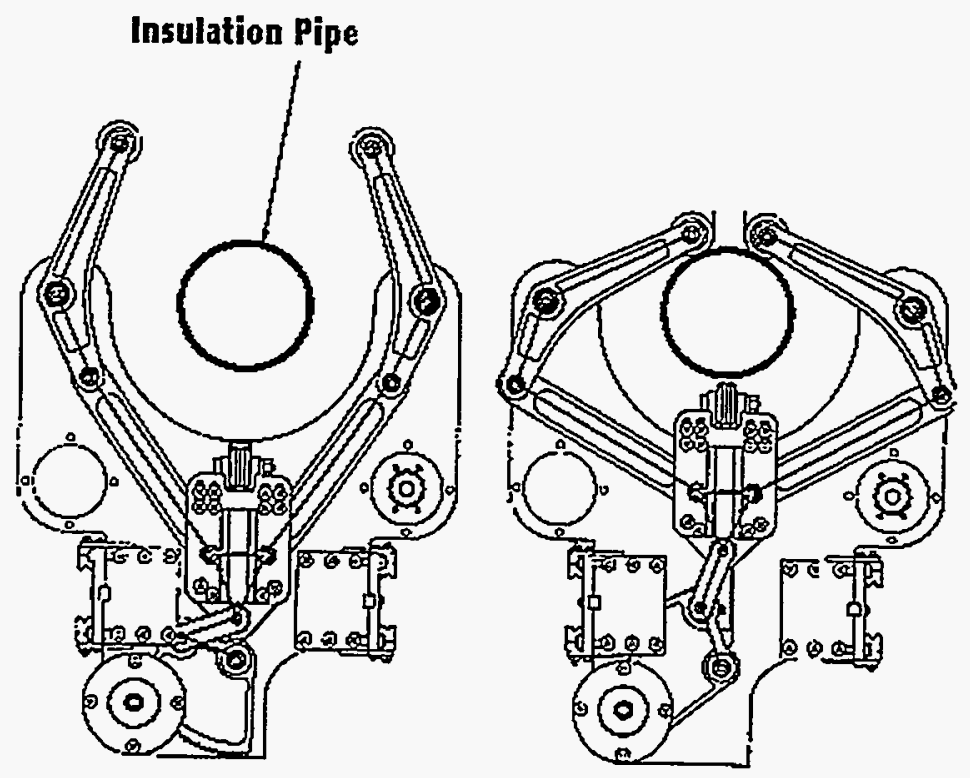

Fig. 3-4 Clamper Overview and Extreme Positions 


\section{SECTION 4: CONTAMINANTS AND MEDIA}

The contaminant of greatest concern is the asbestos found in the insulation that the system is removing. There are several distinct types of asbestos found in insulation. The majority of asbestos used in the U.S. is chrysolite that has wavy fibers and absorbs water well. Of particular concern is Amosite asbestos that is typically found in insulation on high pressure steam lines. This material does not absorb water nearly as well. Removal of Amosite often results in higher airborne asbestos levels during removal. Irrespective of the type of asbestos, respiratory protection should be worn, at a minimum, whenever maintenance or repair work must be done inside the enclosure doors of the abatement head. If the abatement head is allowed to remain on the pipe over a period of time, asbestos residues can dry out and produce an exposure to asbestos fibers when the head is opened. In addition to asbestos, other contaminants may be present and this must be identified, prior to insulation removal. In most cases this will be determined through the site characterization.

\section{SECTION 5: ASSOCIATED SAFETY HAZARDS}

Probability of Occurrence of Hazard:

$1 \quad$ Hazard may be present but not expected over background level

2 Some level of hazard above background level is known to be present

$3 \quad$ High hazard potential

4 Potential for imminent danger to life and health

A. ELECTRICAL (LOCKOUTTAGOUT) RISK RATING: 3

BOA operates off of a 208 volt, 3-phase current that runs into a main control box. The connector is waterproof and $\mathrm{GFCl}$ protection is part of the system. There are eight power cables that run along the floor from the control box to the various pieces of equipment. Given the presence of water in the operation, the risk of electrical shock is elevated.

\section{B. FIRE AND EXPLOSION} RISK RATING: 1

The asbestos insulation is fire resistant and is wetted for removal. The encapsulant used will not burn in the wet state. The large vacuum unit and an auxiliary generator are diesel powered but require no special practices beyond normal safe fueling. There is no flame used in the operation. Consequently, there is no significant fire and explosion hazard. 


\section{CONFINED SPACE ENTRY}

RISK RATING: N/A

None of this equipment is large enough to allow entry of a worker nor is there any reason for entry. Therefore, confined space entry is not part of this technology.

D. MECHANICAL HAZARDS

RISK RATING: 4

There is the real risk of amputation of fingers posed by the clamping system. Once activated, the clamping operation cannot be reversed and is not guarded. The operator, if holding the pendant with two hands, should be out of danger, but other workers performing maintenance or repair may be at risk. Additionally, the drive belt on the water pump is unguarded when the main cover is removed, which may be necessary during operation.

E. PRESSURE HAZARDS RISK RATING: 3

The high pressure water lines presently do not have safety straps so that an accidental release may cause the lines to whip around for several seconds until the pressure difference is sensed and the system shuts down.

F. TRIPPING AND FALLING

RISK RATING: 4

There are many hoses and cables of very different sizes that are an integral part of the system and pose a significant tripping hazard. Careful grouping of the hoses and vivid markings would reduce the hazard. Good housekeeping is essential.

G. LADDERS AND PLATFORMS

RISK RATING: 4

Due to its weight, the system must be mechanically hoisted to high pipe runs where insulation is to be removed. Given the weight of the abatement head and the inability to maintain 3-points of contact, it is too dangerous to attempt to work from a ladder to attach the abatement head. Therefore, some type of platform or manlift must be used. The crane designed to move the abatement head into position might be attached to the platform. Operating this crane from a manlift is difficult and places the workers at risk for falls. The appropriateness of the platform/manlift for this type of application must be evaluated before the job is started. In addition, the need for fall protection must be taken into consideration and fall protection used as appropriate. 
This operation can take place indoors or outdoors so vehicles pose a problem. The work areas must be carefully isolated to prevent trucks and cars from running into the operation outdoors and to prevent tow motors and other vehicles from running into workers or man lifts inside buildings. It is possible that a flagperson would be required for exterior work in busy areas. In addition, all vehicles used must have adequate alarms and signals.

1. BURIED UTILITIES, DRUMS, AND TANKS RISK RATING: N/A

Not part of this technology.

J. PROTRUDING OBJECTS RISK RATING: 2

Each area should be carefully evaluated before work begins to identify objects that can entangle hoses and pose risks to workers.

K. GAS CYLINDERS

RISK RATING: N/A

Not part of this technology.

L. TRENCHING AND EXCAVATIONS RISK RATING: N/A

Not part of this technology.

M. OVERHEAD LIFTS

RISK RATING: 4

BOA must be lifted onto overhead pipe runs. All hazards associated with the use of a crane for lifting are present. Personnel must not be allowed under the cutting head as it is lifted.

N. OVERHEAD HAZARDS

RISK RATING: 4

Working under the system during attachment of the abatement head to elevated pipes poses a significant hazard. If the 150 pound unit fell upon a worker it could be fatal, even if the worker was wearing a hard hat. Hard hats are needed but more importantly, attachment of the abatement head and all associated lines should not be performed with workers directly under the unit. In addition, workers should not be directly under the unit during operation. 


\section{SECTION 6: ASSOCIATED HEALTH HAZARDS}

A. INHALATION HAZARD

RISK RATING: 3

The BOA system is designed to remove asbestos under a strong vacuum without direct worker exposure. A sampling plan will need to be developed for asbestos sampling in compliance with 29 CFR 1910.1001 and/or 29 CFR 1926.1101. In addition, the asbestos removal project will need to be in compliance with the regulations/laws of the state where the project is taking place. Other contaminants, in addition to asbestos, may also be present and must be identified and sampled for in addition to the asbestos sampling.

\section{B. SKIN ABSORPTION}

RISK RATING: 2

The encapsulant used by the system can cause irritation to the skin. Appropriate PPE should be worn. MSDS must be provided from the supplier.

C. HEAT STRESS

RISK RATING: 3

During operation, the heat stress on operators will be less than that for workers physically removing asbestos, but stripping insulation from hot lines may increase the ambient temperature in the work area. Working at elevated levels may increase the risk of heat stress illness. The individual bagging the waste will have a much greater metabolic heat load than the operator and this needs to be considered, particularly if protective clothing is worn. Where conditions warrant, the employer needs to develop and apply a heat stress management program to include, as appropriate, work-rest cycles. These need to be developed for the job in accordance with the recommendations of the ACGIH or other acceptable authority.

D. NOISE RISK RATING: 2

Noise measurements indicated that neither the operator nor the bagging worker should be exposed above the OSHA action level of $85 \mathrm{dBA}$. A good practice is for the operator to stand as far away from the abatement head as the pendant control allows to reduce noise levels well below the OSHA action level. Similarly, the bagging operator should stand back from the unit until it is necessary to fill a bag. The noise readings for the large vacuum unit exceeded the OSHA allowable level of $90 \mathrm{dBA}$, making it necessary for workers to wear hearing protection whenever they work near the unit. Noise monitoring needs to be conducted where the system is being used, since the environment may change the noise levels. 


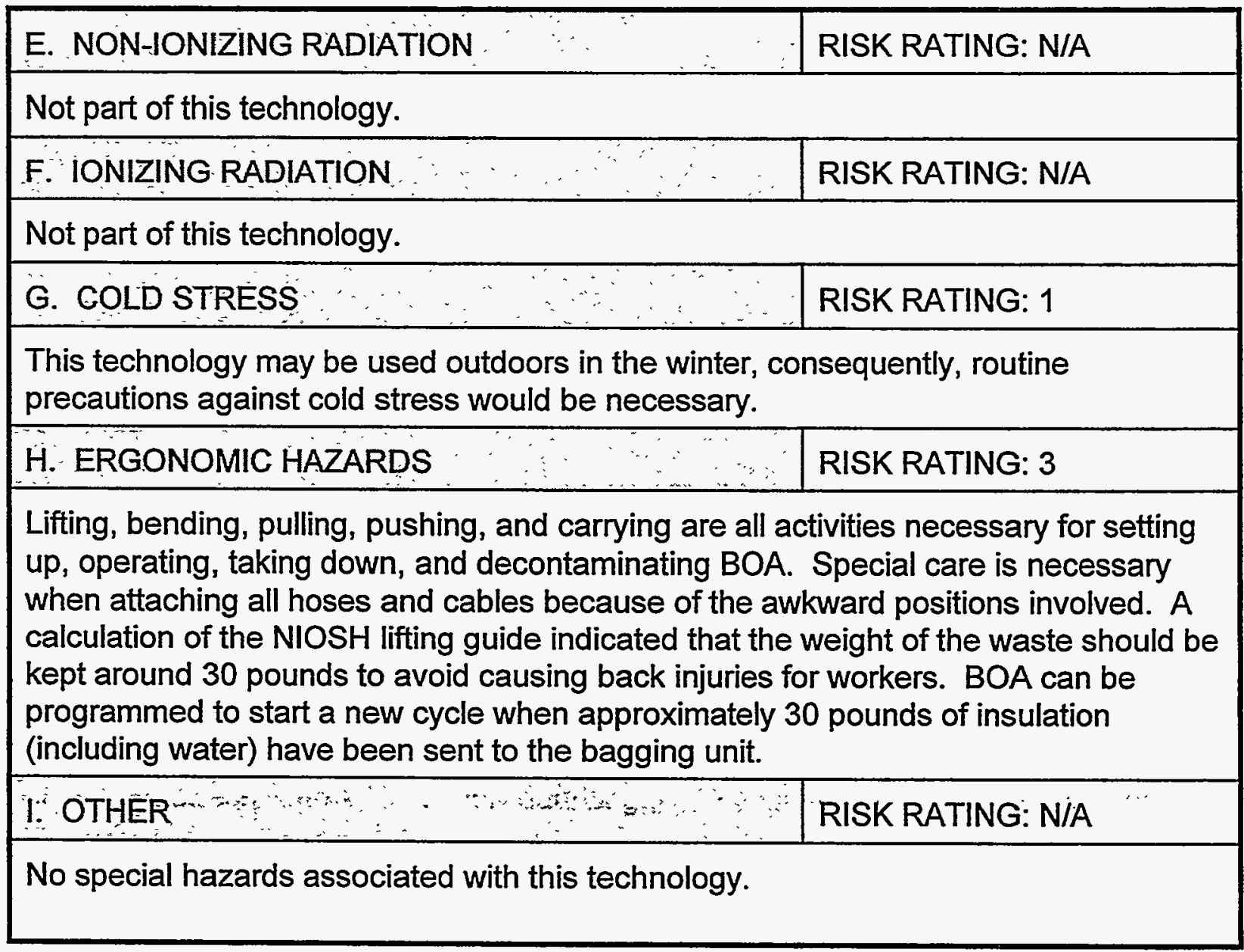




\section{SECTION 7: PHASE ANALYSIS}

\section{A. CONSTRUCTION/START-UP}

The vacuum, air, and water hoses needed to operate BOA pose a significant tripping hazard. Given their integral role in the system, they can not be eliminated or easily re-engineered. Less cluttered deployment and marking would be helpful. The hooking of lines requires poor postures - stooping and also overhead reaching - this has the potential to cause back strain/sprain. Ergonomic training needs to be considered.

The VecLoader (vacuum system), with a narrow wheel base is easy to rock and could potentially tip over. The water pump's wheels are fixed which makes it virtually impossible to steer the unit without lifting it at some point. To avoid back injury, move the pump a little bit at a time.

Using a man lift with an $8^{\prime} \times 10^{\prime}$ platform and a small crane bolted in the center would allow operators to connect BOA without hanging out of the lift, or working under the cutter head, which could disconnect and fall.

The safety caps for the bagging unit are hanging on a chain at a height of nearly 6 feet. This means that hooking up the hoses requires working at a difficult height. The arrangement with hooking the clamps poses a "pinch hazard" for the fingers. 


\section{B. OPERATION}

The clamps (arms) that hold the abatement head to the pipe cannot be stopped in mid-cycle and the force of these clamps has the potential to cut off a finger. The operator, if using the pendant control with both hands, would be guarded according to OSHA machine guarding requirements but there is a real danger to others performing maintenance or repair. Training is critical and additional guarding or at least additional warnings may be appropriate.

If the high pressure water hoses release, they could whip and injure someone before the system shuts down. Adding safety straps to the connectors would significantly reduce this possibility.

The high pressure water pump has a cover that eliminates the possibility of hands being caught in the in-running nip points caused by the moving belt. The pump must always be operated with this cover in place.

The large vacuum unit should be operated outdoors and, if operated indoors, needs to have its diesel fumes exhausted outside and should be positioned to reduce noise exposure as much as possible. All noise readings for the vacuum unit exceeded the OSHA level that would require participation in a hearing conservation program and.. hearing protection if workers needed to be in the area. Additionally, the exhaust of air from this unit could contain asbestos fibers if the filters are not properly placed another reason to continue to operate this unit outdoors.

\section{MAINTENANCE}

The abatement head is designed to provide a water wash and then vacuum the residue away automatically. Materials may remain in the cutter head after the water wash and could become dry after residing in the head between removal jobs, releasing asbestos fibers when the abatement head is opened. This means that operators may need to wear a respirator during maintenance on a unit that has been setting and dried.

If cutting heads need to be changed after removal has begun, the residue around the head could become airborne. Additionally, the heads are sharp and should be handled with gloves to prevent cuts. Maintenance work on the abatement head will require a special workbench. The abatement head will be hard to balance on a flat table. 


\section{DECOMMISSIONING}

The BOA can be left attached to a pipe at the end of the day and started up to continue removal the next day. At the end of the job, the system should be flushed thoroughly with water. Similarly, every piece of associated equipment should be flushed out. The large vacuum hoses can be sealed at each end with a cap and duct tape for shipment to the next job. The abatement head should be kept closed and packed carefully in the custom shipping container.

\section{SECTION 8: HEALTH AND SAFETY PLAN REQUIRED ELEMENTS}

\section{A. AIR MONITORING}

Depending on the job, the 1910 (general industry) or 1926 (construction) OSHA standards will apply to the air sampling required. Under the OSHA Asbestos Standard, 1926.1101(f)(2), each employer removing asbestos insulation must ensure that a "competent person" conduct an exposure assessment immediately before or at the initiation of the operation to ascertain expected exposures during that operation or workplace. The employer must assure that the worker is not exposed to the PEL, 0.1 fibers per cubic centimeter of air as an 8-hour time weighted average or the excursion limit of 1.0 fibers per cubic centimeter of air as averaged over a sampling period of 30 minutes.

Under the OSHA Asbestos Standard, 1910.1001 (d)(1), determinations of employee exposure shall be made from breathing zone air samples that are representative of the 8-hour TWA and 30-minute short-term exposures of each employee. The employer must assure that the worker is not exposed to PEL, 0.1 fibers per cubic centimeter of air as an 8-hour time weighted average or the excursion limits of 1.0 fibers per cubic centimeter of air as averaged over a sampling period of 30 minutes.

In addition, monitoring may be required for other contaminants in the area where the asbestos removal is taking place. These contaminants should be identified by the site characterization. 


\section{B. WORKER TRAINING}

Workers must be trained in the specific operation of the system. Additionally, until asbestos sampling data indicates differently, workers should receive training following the EPA Model Accreditation Plan for asbestos workers ( 40 CFR Part 763 , subpart E, Appendix $\mathrm{C}$ ). Additional training required may include but not be limited to Hazardous Waste Operations and Emergency Response (HAZWOPER), HAZCOM, asbestos worker, respirator, PPE and hearing conservation.

\section{EMERGENCY RESPONSE}

BOA can alert operators to emergency situations. There is a box near the cutting head that flashes with a bright strobe light whenever the head reaches an obstruction. The system automatically stops abatement and proceeds to encapsulate exposed surfaces. There is an emergency stop button on the electrical box that shuts down the entire system. There is also an emergency button on the pendant control unit. This provides the operator with the ability to immediately shut down the system. A vacuum is maintained in the system throughout any emergency shutdown. Even if the main vacuum unit fails to operate, the auxiliary HEPA vacuum will operate, unless a complete loss of electrical power occurs. In this case, all vacuum power could be lost and the potential exists for exposure to asbestos fibers.

D. MEDICAL SURVEILLANCE

A medical surveillance program is necessary for all employees who for a combined total of 30 or more days per year are engaged in Class I, II and III asbestos work or are exposed at or above the permissible exposure limit. Medical tests should be provided according to $1926.1101(\mathrm{~m})$.

E. INFORMATIONAL PROGRAM

Under OSHA's Hazardous Waste standard, 1910.120, the employer is responsible for providing information on new technologies to the workers who will be using the equipment. 


\section{SECTION 9: COMMENTS AND SPECIAL CONSIDERATIONS}

OSHA will allow contractors to vary their work practices from the agency's stringent requirements for Class I asbestos removal work. Under $1926.1101(\mathrm{~g})(6)$, Alternative control methods for Class I work, OSHA recognizes alternative new techniques such as $\mathrm{BOA}$, as long as two requirements are met:

(1) The control method shall enclose, contain or isolate the processes or source of airborne asbestos dust, or otherwise capture or redirect such dust before it enters the breathing zone of employees.

(2) A certified industrial hygienist or licensed professional engineer who is also qualified as a project designer...shall certify in writing that the planned control method is adequate to reduce direct and indirect employee exposure to below the PELS under worst-case conditions of use, and that the planned control method will prevent asbestos contamination outside the regulated area, as measured by clearance sampling which meets the requirements of EPA's Asbestos in Schools rule issued under AHERA, or perimeter monitoring which meets the criteria in paragraph $(\mathrm{g})(4)(\mathrm{ii})(\mathrm{B})$ of this section.

This last OSHA reference permits an employer to use some other isolation method rather than sealing all critical barriers to the work area (a time consuming and labor intensive process) as long as sampling of perimeters of the regulated areas show no elevations of airborne asbestos above background levels. The BOA system may be able to meet all of these criteria and thus be recognized as an alternate control method. This recognition has not formally been received at this time, however. 


\section{SECTION 7 - EMERGENCY RESPONSE/PREPAREDNESS}

Emergency response and emergency preparedness must be part of every hazardous waste site safety and health plan. The possibility of a medical emergency due to an accident resulting from the operation of BOA is credible enough to require contingency planning. Operators should have sufficient first aid materials on site to deal with injuries resulting from falls from heights, lacerations or amputations from the clamping mechanism, and cuts or contusions from high pressure water lines.

All workers on site must be trained to operate the emergency shut off controls at the pendant and the control box. Additionally, they should be trained to handle the medical emergencies above.

The BOA system, however, does not pose the risk of fire, explosion, or chemical release that would threaten outside responders like Emergency Medical Services that may arrive at the site.

\section{SECTION 8 - REGULATORYIPOLICY ISSUES}

Regulations that apply to this technology may be divided into four categories. First, core requirements are those regulations that would apply to any hazardous waste work site, regardless of the type of job. Second, technology-specific requirements are those regulations that apply due to the specific technology being used. Third, special requirements are standards and policies that are specific to the technology itself, and are required by reference in a regulation. Fourth, best management practices are not required but are recommended by organizations such as the American National Standards Institute (ANSI), NIOSH, DOE, National Fire Protection Association (NFPA), etc. These regulations/standards may include, but not be limited to, the following:

\section{Core Requirements:}

OSHA 29 CFR 1926.25 Housekeeping

OSHA 29 CFR 1910.141 Sanitation (1910.141(a)(3) covers housekeeping)

OSHA 29 CFR 1926 Subpart Z Toxic and Hazardous Substances

OSHA 29 CFR 1910 Subpart Z Toxic and Hazardous Substances

OSHA 29 CFR 1926.59 Hazard Communication

OSHA 29 CFR 1910.1200 Hazard Communication 
- OSHA 29 CFR 1926.64 Process Safety Management of Highly Hazardous Chemicals

OSHA 29 CFR 1910.119 Process Safety Management of Highly Hazardous Chemicals

- OSHA 29 CFR 1926.65 Hazardous Waste Operations and Emergency Response

OSHA 29 CFR 1910.120 Hazardous Waste Operations and Emergency Response

- Occupational Safety and Health Act 1970(5)(a)(1) General Duty Clause

EPA 40 CFR 61.145 National Emissions Standards for Hazardous Air Pollutants, Asbestos

- EPA 40 CFR 763.92 Toxic Substance Control Act, Asbestos Hazard Emergency Response Act

Technology Specific Requirements:

- OSHA 29 CFR 1926.1101 Asbestos

- OSHA 29 CFR 1910.1001 Asbestos

OSHA 29 CFR 1926 Subpart L Scaffolding

- OSHA 29 CFR 1910.28 Safety Requirements for Scaffolding

OSHA 29 CFR Subpart N Cranes, Derricks, Hoists, Elevators, and Conveyors

- OSHA 29 CFR 1910 Subpart O Machinery and Machine Guarding

$\checkmark \quad$ OSHA 29 CFR 1910.147 The Control of Hazardous Energy (Lockout/Tagout)

OSHA 29 CFR 1926.52 Occupational Noise Exposure

- OSHA 29 CFR 1910.95 Occupational Noise Exposure

$\checkmark \quad$ OSHA 29 CFR 1926.103 Respiratory Protection 
- OSHA 29 CFR 1910.134 Respiratory Protection

- OSHA 29 CFR 1926.102 Eye and Face Protection

$\checkmark \quad$ OSHA 29 CFR 1910.133 Eye and Face Protection

OSHA 29 CFR 1926.28 Personal Protective Equipment

OSHA 29 CFR 1910.132 Personal Protective Equipment

OSHA 29 CFR 1910.132 General Requirements (Personal Protective Equipment)

OSHA 29 CFR 1926.23 First Aid and Medical Attention

OSHA 29 CFR 1910.151 Medical Services and First Aid

OSHA 29 CFR 1910.1000 Toxic and Hazardous Substances

\section{Best Management Practices:}

- ACGIH Threshold Limit Values for Chemical Substances and Physical Agents and Biological Exposure Indices

NIOSH Revised Lifting Equation, 1994

Association for Robotics in Hazardous Environments "Guidelines for Procurement Specifications for Remote and Robotic Systems and Equipment to Operate in Hazardous Environments" RHE H01.01-1996

- Robotic Industries Association, R15.06 Safety Requirements Draft 10

NIOSH "Safe Maintenance Guidelines for Robotic Workstations," DHHS (NIOSH) Publication No. 88-108, March 1988.

NIOSH "Elements of Ergonomics Programs, A Primer Based on Workplace Evaluations of Musculoskeletal Disorders" March 1997 


\section{Training Requirements}

In addition to the above regulations and policies, it is imperative that all workers have appropriate and adequate training for the task and associated safety and health conditions. Training that would be required may be divided into four categories. Core training is that which is required for anyone entering a hazardous waste site to perform work, regardless of the type of job. Technology specific training is that training that is specific to the technology and required by safety and health standards. Special training is that which is specific to the technology to assure the worker is adequately trained for the task but is not necessarily required by safety and health standards. Best management practices are trainings that while not mandated by health and safety standards, provide information and knowledge to the worker that will allow the worker to perform the job safely. Training to be applied for BOA may include but not be limited to:

\section{Core Training Requirements:}

$\checkmark \quad$ HAZWOPER

$\checkmark \quad$ HAZCOM

Technology Specific Training:

- Scaffolding "

$\checkmark \quad$ Asbestos worker

- Respiratory Protection

- Hearing Conservation

- Personal Protective Equipment

Lockout/Tagout

Special Training:

- Job specific training for equipment operation 


\section{Best Management Practice Training:}

- Ergonomics (proper lifting, bending, stooping, kneeling)

Heat stress (learning to recognize signs and symptoms)

- CPR/First Aid/Emergency Response/Bloodborne Pathogens

$-\quad$ Electrical Safety

- Crane/Hoisting Safety

- Hand Signal Communication

- Construction Safety (OSHA 500) and or General Industry Safety (OSHA 501)

\section{SECTION 9 - \\ OPERATIONAL CONSIDERATIONS AND RECOMMENDATIONS}

Recommendations made here for improved worker safety and health take into consideration that during the human factors assessment, the insulation BOA removed was calcium silicate. Assumptions made regarding asbestos will need to be confirmed at a later date when BOA is used to remove asbestos insulation.

\section{Equipment Set Up Phase}

- The vacuum, air, and water hoses needed to operate the BOA range in diameter from less than an inch to up to 5 inches and pose a significant tripping hazard. Given their integral role in the system, they can not be eliminated or easily reengineered. Less cluttered deployment and better marking would be helpful. Good housekeeping practices are essential.

- The hooking of lines requires poor posture - stooping and also overhead reaching that can cause back problems, as well as stress/injury to knees, shoulders, arms, and neck. Ergonomic training to include proper lifting techniques is indicated.

- The cyclonic bagger (VecLoader) was purchased commercially. It has wheels that are only 32 inches apart while the top of the unit is also 32 inches wide. It is easy to rock the unit and, if placed on uneven ground, could pose a serious flipping hazard. The wheels should be at least 6 more inches apart. Operating procedures should not allow the unit to be placed on uneven ground. 
- The water pump's wheels are fixed which makes it impossible to steer the unit without lifting it at some point - a serious stressor for the back. Re-engineering the wheels to allow movement necessary for steering would alleviate this concern.

- The adapter that was designed for the end of the crane to lift the BOA cutting head out of its container uses clamps to secure the head during lifting. The design of these clamps does not prevent an accidental release. A heavier clamping mechanism with a locking device would help to prevent this.

- During the assessment, the crane for lifting the cutter head was mounted on a scissors man lift and held in place by C-clamps, a temporary solution. Additionally, the crane was positioned such that the operators had to hang over the man lift in order to make the connections. Using a manlift with an $8^{\prime} \times 10^{\prime}$ platform and the crane bolted in the center would allow operators to make the connections without hanging out of the lift, or working under the cutter head, which could disconnect and fall. Even with an ideal setup for a scissor lift, it means that placing the abatement head at a height requires the operation of three sets of controls: the lift, the crane on the lift, and the pendant for the abatement head. Considering a system that allows hoisting the unit in place with a pulley or some sort of ratcheting apparatus might be more appropriate.

- In moving the abatement head from the crane up to the pipe, or changing from the -. jack to crane, there needs to be some way to secure the head to the jack. During the demonstration it was setting on a block of wood. Any serious movement could cause this to fall.

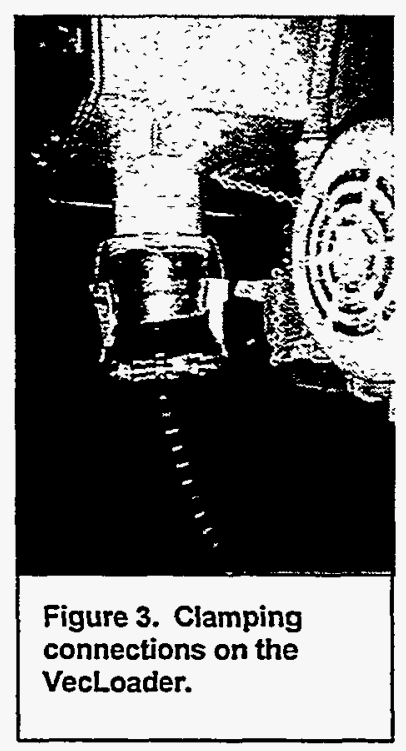

- The safety caps for the bagging unit are hanging on a chain at a height of nearly 6 feet. This means that hooking up the hoses requires working at a difficult height. The arrangement with hooking the clamps mean that fingers could be pinched. SOP's, which require the use of a platform to reach the connection, would help alleviate the height problem. The clamps need to be labeled as pinch points. 


\section{Equipment Operation Phase}

- The clamps that hold the abatement head to the pipe cannot be stopped in midcycle and the force of these clamps can sever a finger.

- The operator, if using the pendant control with both hands, would be guarded according to OSHA machine guarding requirements but there is a real danger to others performing maintenance or repair and additional guarding or at least additional warnings would be appropriate.

-When the high pressure water pump changes from spraying to cutting, or from cutting to spraying, the two 3 -inch hoses jerk as the pressure changes. If the hoses released they could whip and hurt someone before the system was shut down. Adding safety straps to the connectors would significantly reduce this possibility.

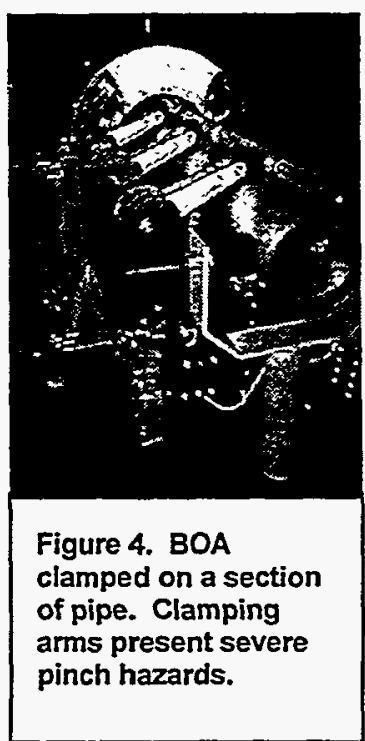

- The high pressure water pump has a cover that eliminates the possibility of hands being caught in the in-running nip points caused by the moving belt. There were several occasions when the pump was operated without the cover in place. An interlock that does not allow the pump to operate without the cover or a permanent guard inside the cover for the belt, would eliminate the possibility of serious injury to fingers.

- The cutter operates with high pressure water jets that can cut through metal and, therefore, flesh. However, the possibility of the jets coming on accidentally is quite low because with the unit open, the vacuum sensor would measure insufficient vacuum and not allow water to flow. This sensor operates quickly: within a half a second. A redundant interlock system that does not allow the water jets to spray when the abatement head is open would provide additional safety measures.

- The large vacuum unit should be operated outdoors and, if operated indoors, needs to have its diesel fumes exhausted outside and should be positioned to reduce noise exposure as much as possible. All noise readings for the vacuum unit exceeded the OSHA PEL level and would require hearing protection if workers needed to be in the area. Additionally, the exhaust of air from this unit could contain asbestos fibers if the filters are not properly placed - another reason to continue to operate outdoors. 


\section{Bagging Operation}

- The BOA system abatement head automatically stops cutting after a certain number of oscillations of the locomotor. The cuttings are then sent to the bagging operation. The weight of materials being bagged can be standardized by the number of oscillations. During the human factors assessment, the setting was too high, according to the results of the NIOSH lifting calculation performed. The adjustments should be made for future work and incorporated into the SOP's.

- After the debris is deposited into the plastic bag, the operator had to manually twist the bag before sealing it with duct tape. This put additional stress on the operator. Some sort of "lazy Susan" apparatus for the bag to rest on could relieve this stress. In addition, a "lazy Susan" with wheels would provide a method for moving the bag to the waste collection area.

\section{Maintenance and Decontamination Phase}

- The abatement head is designed to provide a water wash of the inside of the head and then vacuum the residue away automatically. Any form of manual decontamination is not currently recommended. A visual inspection showed that materials did remain in the cutter head after the water wash. These materials could become dry after residing in the head in between removal jobs, releasing asbestos fibers when the abatement head is opened. Many asbestos abatement contracts require that the contractor not bring any equipment onto the job site that is contaminated. The current method for decontamination of the BOA head may not meet these requirements. A more complete flushing method may be needed.

- If cutting heads need to be changed after removal of the insulation has begun, the residue around the heads could become airborne. Additionally, the heads are sharp and should be handled with gloves to prevent cuts.

- Maintenance work on the abatement head will require a special work bench. The abatement head would be precariously balanced on a flat table. The bench should also be adjustable to prevent maintenance workers from having to bend over or assume abnormal or awkward positions.

\section{Emergency Situations}

- BOA has capabilities for alerting operators to emergency situations. There is a box near the cutting head that flashes with a bright strobe light whenever the head reaches an obstruction. The system automatically stops abatement and proceeds to encapsulate exposed surfaces. 
- There is an emergency stop button on the electrical box that shuts down everything. There is also an emergency button on the pendant control unit. This provides the operator with the ability to immediately shut down the system. A vacuum is maintained in the system throughout any emergency shutdown. Even if the main vacuum unit goes down, the auxiliary HEPA vacuum will operate. 


\section{ADDENDUM}

On August 28, 1997, BOA was demonstrated on an outdoor pipe run located at the K25 facility at the Oak Ridge site. During the demonstration, calcium silicate insulation was removed from an out-of-doors pipe rack that was approximately 6 feet off of the ground. BOA was operated for approximately 30-45 minutes. Changes that had been made since the human factors assessment covered by this report were evaluated during the demonstration.

During the current demonstration, the industrial hygiene department at Oak Ridge conducted air sampling for total dust. Information received from them indicates that the dust levels were below the level of detection.

When the human factors assessment of BOA was conducted at the Carnegie Mellon facility in June 1997, there were safety and health concerns associated with the use of a manlift with a jib-crane to lift the cutter head to an elevated pipe rack and with the clamps used to hold the cutter head onto the jib-crane. During the Oak Ridge demonstration, the jib-crane was attached to the forks of a forklift that was used to lift the cutter head to the pipe rack. The jib-crane was attached to the forks with large cclamps. There is concern that these c-clamps may not be tightened enough by hand, they may come loose during the lift, or they may be bumped and loosened before the lift is even started. This could present the opportunity for the entire structure (jib-crane and cutter head) to fall from the forks of the forklift as the move and lift are being made. If either or both fell and struck a worker, severe injury or a fatality are credible results. A better method would be to design equipment specifically for attaching the jib-crane to the forks of the forklift.

The clamps used to hold the head of the jib-crane (which then holds the cutter head) to the arm are not very substantial, nor did they have a locking mechanism to assure they would stay closed. There was concern during the human factors assessment that these could break and or easily be bumped and open. These same clamps with one modification were used during the Oak Ridge demonstration. The clamping mechanism itself had a wire secured around it. This wire would not allow the clamp to open or if it did open, the wire would hold the head to the arm until it could be placed in a safe position and repaired. There is still concern that the wire would not hold and something more substantial with a higher load rating would need to be used. It is also recommended that the clamps themselves be changed and a clamp with a higher load rating and a safety latching system built in be used.

One of the ergonomic concerns associated with the bagging operation had been addressed and on observation appeared to have greatly lessened the ergonomic 
stressors discussed in this report. The original concern was the bending and lifting the operator had to do to manually lift and twist the bag of waste before duct taping it shut. During the demonstration a "lazy-Susan" type of device with wheels was used, as recommended in this report. The bag was located on this device so that once the waste was dumped into the bag, the operator could turn the "lazy-Susan" without lifting the bag, tape the bag closed, remove the device with the bag on it to the waste accumulation area, and remove the bag from the device. This was a far superior method from an ergonomic standpoint for bagging and waste removal. Two further recommendations are made to further improve this operation: (1) attach an adjustable handle to the "lazy-Susan" to avoid having to bend over to push it out from under the bagging unit and to the waste accumulation site; and (2) use a mechanical materials handling device to remove the bag of waste from the "lazy-Susan". Both of these would continue to reduce ergonomic stressors (and therefore, injury) placed on the back.

Additionally, it is recommended that when BOA is used to remove asbestos insulation, air monitoring for asbestos should be conducted before the system is approved for use without worker respiratory protection and other associated PPE. 


\section{APPENDIX A REFERENCES}

Occupational Safety and Health Standards for General Industry, 29 CFR Part 1910, Occupational Safety and Health Administration United States Department of Labor, 1995

Occupational Safety and Health Standards for the Construction Industry, 29 CFR Part 1926, Occupational Safety and Health Administration United States Department of Labor, 1995

Threshold Limit Values (TLVs) for Chemical Substances and Physical Agents and Biological Exposure Indices (BEls), American Conference of Governmental Industrial Hygienists, 1995-1996

U.S. Department of Health and Human Services, Public Health Services, Applications Manual for the Revised NIOSH Lifting Equation, DHHS (NIOSH) Publication No. 94110, January 1994

U.S. Department of Health and Human Services, Public Health Service, Center for Disease Control and Prevention, The NIOSH compendium of hearing protection devices, October 1994

Guidelines for Hazard Evaluation Procedures, Battelle Columbus Division, The Center for Chemical Process Safety, American Institute of Chemical Engineers, New York, 1985 


\section{APPENDIX B \\ REAL-TIME MIE DATA RAM PARTICULATE MONITORING (PRE-BOA OPERATION)}

\begin{tabular}{|c|c|c|c|c|c|}
\hline TIME & STATION & LOCATION & $\begin{array}{l}\text { Average } \\
\text { Reading } \\
\left(\mathrm{mg} / \mathrm{m}^{3}\right)\end{array}$ & $\begin{array}{l}\text { Standard } \\
\text { Deviation }\end{array}$ & $\begin{array}{l}\text { CV } \\
(\%)\end{array}$ \\
\hline 0914 & 1 & 4' from lower pipe run, 4 ' from floor & 0.048 & 0.007 & 15 \\
\hline 0922 & II & $\begin{array}{l}4^{\prime} \text { from center of bagging operation, } 4^{\prime} \\
\text { from floor }\end{array}$ & 0.048 & 0.005 & 10 \\
\hline 0926 & III & Outdoors - $4^{\prime}$ from the large vacuum unit & 0.040 & 0.002 & 4 \\
\hline 0931 & IV & $\begin{array}{l}\text { Catwalk above pipe runs, } 10^{\prime} \text { above the } \\
\text { floor }\end{array}$ & 0.038 & 0.003 & 8 \\
\hline 0936 & 1 & $4^{\prime}$ from lower pipe run, $4^{\prime}$ from floor & 0.032 & 0.003 & 10 \\
\hline 0940 & II & $\begin{array}{l}4^{\prime} \text { from center of bagging operation, } 4^{\prime} \\
\text { from floor }\end{array}$ & 0.036 & 0.007 & 18 \\
\hline 0945 & III & Outdoors - 4 ' from the large vacuum unit & 0.038 & 0.004 & 11 \\
\hline
\end{tabular}




\section{APPENDIX B \\ MIE DATA RAM PARTICULATE MONITORING (BOA OPERATION)}

\begin{tabular}{|c|c|c|c|c|c|}
\hline TIME & STATION & LOCATION & $\begin{array}{l}\text { Average } \\
\text { Reading } \\
\left(\mathrm{mg} / \mathrm{m}^{3)}\right.\end{array}$ & $\begin{array}{l}\text { Maximum } \\
\text { reading } \\
\left(\mathrm{mg} / \mathrm{m}^{3}\right)\end{array}$ & $\begin{array}{l}\text { STEL } \\
\left(\mathrm{mg} / \mathrm{m}^{3}\right)\end{array}$ \\
\hline $\begin{array}{c}1455 \\
\text { June } \\
18\end{array}$ & 1 & $4^{\prime}$ from lower pipe run, $4^{\prime}$ from floor & 0.043 & $\mathrm{n} / \mathrm{a}$ & $\mathrm{n} / \mathrm{a}$ \\
\hline $\begin{array}{c}1430- \\
1458\end{array}$ & personal & $\begin{array}{l}\text { sampler attached to Abe Crowley, } \\
\text { pendant control operator }\end{array}$ & 0.067 & 1.302 & 0.069 \\
\hline $\begin{array}{c}1025 \\
\text { June } \\
19\end{array}$ & 1 & $\begin{array}{l}\text { typical operator position during cutting } \\
\text { head operation. }\end{array}$ & 0.101 & 0.332 & 0.074 \\
\hline 1035 & II & $\begin{array}{l}\text { typical operator position at bagging } \\
\text { operation }\end{array}$ & 0.095 & 0.123 & 0.074 \\
\hline $\begin{array}{l}1031- \\
1056 \\
\end{array}$ & Personal & $\begin{array}{l}\text { sampler placed on Abe Crowley during } \\
\text { operation }\end{array}$ & 0.102 & 0.485 & 0.108 \\
\hline \multicolumn{3}{|r|}{ Grand average } & 0.08 & & \\
\hline
\end{tabular}




\section{APPENDIX B \\ TOTAL AND RESPIRABLE DUST SAMPLING RESULTS}

\begin{tabular}{|c|c|c|c|}
\hline Sample Number & Location & $\begin{array}{l}\text { Total Mass } \\
\text { (mg) }\end{array}$ & $\begin{array}{l}\text { Results } \\
\text { (mg/m3) }\end{array}$ \\
\hline $\begin{array}{l}061797-\mathrm{CMU}- \\
001\end{array}$ & $\begin{array}{l}\text { Total dust - background sampling. On } \\
\text { top of water filtration unit ( } 45^{\prime \prime} \text { from } \\
\text { floor) in area of VecLoader }\end{array}$ & $<0.04$ & $<0.30$ \\
\hline $\begin{array}{l}061797-\mathrm{CMU}- \\
002\end{array}$ & $\begin{array}{l}\text { Total dust - background. CMU high } \\
\text { bay, } 36^{\prime \prime} \text { high on railing behind low } \\
\text { pipe system. }\end{array}$ & $<0.04$ & $<0.90$ \\
\hline $\begin{array}{l}061797-\mathrm{CMU}- \\
003\end{array}$ & Blank & $<0.04$ & $\mathrm{n} / \mathrm{a}$ \\
\hline $\begin{array}{l}061797-\mathrm{CMU}- \\
004\end{array}$ & $\begin{array}{l}\text { Respirable dust - background. Left } \\
\text { side of VecLoader. }\end{array}$ & $<0.04$ & $<0.05$ \\
\hline $\begin{array}{l}061797-\mathrm{CMU}- \\
005\end{array}$ & $\begin{array}{l}\text { Respirable dust - background. } \\
\text { CMU high bay, } 67 \text { " off ground to left } \\
\text { of low pipe rack. }\end{array}$ & $<0.04$ & $<0.05$ \\
\hline $\begin{array}{l}061997-C M U- \\
006\end{array}$ & Blank & $<0.04$ & $\mathrm{n} / \mathrm{a}$ \\
\hline $\begin{array}{l}061997-\mathrm{CMU}- \\
007\end{array}$ & Blank & $<0.04$ & $\mathrm{n} / \mathrm{a}$ \\
\hline $\begin{array}{l}061997-\mathrm{CMU}- \\
008\end{array}$ & $\begin{array}{l}\text { Respirable dust- during operation. } \\
\text { High bay area of left side of } \\
\text { VecLoader, } 60 \text { " off ground. }\end{array}$ & $<0.04$ & $<0.3$ \\
\hline $\begin{array}{l}061997-C M U- \\
009\end{array}$ & $\begin{array}{l}\text { Respirable dust - during operation. } \\
\text { On post immediately to left of } \\
\text { pipe/cutter head, } 66 " \text { off ground. }\end{array}$ & $<0.04$ & $<0.3$ \\
\hline $\begin{array}{l}061997-\mathrm{CMU}- \\
010\end{array}$ & VOIDED SAMPLE & $<0.04$ & $n / a$ \\
\hline $\begin{array}{l}061997-C M U- \\
011\end{array}$ & $\begin{array}{l}\text { Total dust - during operation. On top } \\
\text { of water filters in area of VecLoader }\end{array}$ & $<0.04$ & $<0.28$ \\
\hline $\begin{array}{l}\text { 061997-CMU- } \\
012\end{array}$ & Blank & $<0.04$ & $\mathrm{n} / \mathrm{a}$ \\
\hline $\begin{array}{l}061997-\mathrm{CMU}- \\
013\end{array}$ & $\begin{array}{l}\text { Total dust - during operation. Railing } \\
\text { immediately behind pipe where BOA } \\
\text { was removing insulation (approx. } 3 \\
\text { feet above ground). }\end{array}$ & $<0.04$ & $<0.28$ \\
\hline
\end{tabular}




\section{APPENDIX B \\ VENTILATION FLOW MEASUREMENTS}

\begin{tabular}{|c|l|c|}
\hline DATE AND TIME & \multicolumn{1}{|c|}{ LOCATION } & $\begin{array}{c}\text { AIR VELOCITY } \\
\text { (feet per minute) }\end{array}$ \\
\hline June 18/1006 & Station I - 4' from the cutting head & 30 \\
\hline June 18/1009 & $\begin{array}{l}\text { Near lower pipe run, directly above the } \\
\text { stairwell }\end{array}$ & $200-400$ \\
\hline June 18/1012 & $\begin{array}{l}\text { Near lower pipe run, directly above the } \\
\text { elevator shaft }\end{array}$ & 250 \\
\hline June 18/1510 & $\begin{array}{l}\text { Immediately outside the opening between } \\
\text { the cutter head cover and the pipe insulation } \\
\text { while main vacuum was operating }\end{array}$ & $200-300$ \\
\hline June 19/1015 & $\begin{array}{l}\text { Immediately outside the opening between } \\
\text { cutter head cover and pipe insulation when } \\
\text { only the small auxiliary vacuum was running }\end{array}$ & \\
\hline
\end{tabular}




\section{APPENDIX C \\ PENDANT CONTROL BUTTONS LAYOUT}

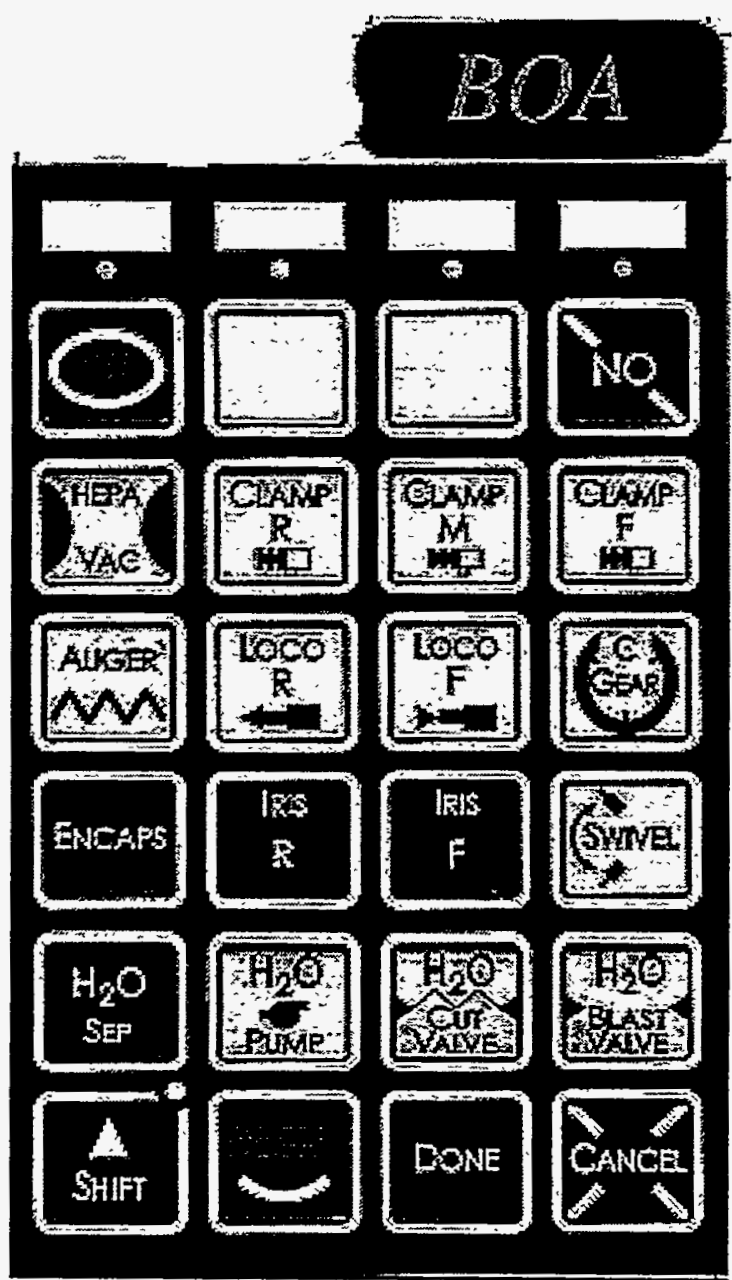




\section{APPENDIX D ACRONYMS}

$\begin{array}{lll}\text { ACGIH } & - & \text { American Conference of Governmental Industrial Hygienists } \\ \text { AIHA } & - & \text { American Industrial Hygiene Association } \\ \text { ANSI } & - & \text { American National Standards Institute } \\ \text { BOA } & - & \text { Big on Asbestos } \\ \text { CAS } & - & \text { chemical abstract system } \\ \text { cfm } & - & \text { cubic feet per minute } \\ \text { CFR } & - & \text { Code of Federal Regulations } \\ \text { CMU } & - & \text { Carnegie Mellon University } \\ \text { CV } & - & \text { coefficient of variation } \\ \text { DOE } & - & \text { Department of Energy } \\ \text { GFCl } & - & \text { ground fault circuit interrupter } \\ \text { EPA } & - & \text { Environmental Protection Agency } \\ \text { HAZCOM } & - & \text { Hazard Communication } \\ \text { HAZWOPER - } & \text { Hazardous Waste Operations and Emergency Response } \\ \text { HEPA } & - & \text { high efficiency particulate air filter } \\ \text { hZ } & - & \text { hertz } \\ \text { IR } & - & \text { infrared } \\ \text { LI } & - & \text { lifting index } \\ \text { MSDS } & - & \text { Material Safety Data Sheet } \\ \text { NFPA } & - & \text { National Fire Protection Association } \\ \text { NIOSH } & - & \text { National Institute of Occupational Safety and Health } \\ \text { OD } & - & \text { outside diameter } \\ \text { OENHP } & - & \text { Operating Engineers National Hazmat Program } \\ \text { OSHA } & - & \text { Occupational Health and Safety Administration } \\ \text { PEL } & - & \text { permissible exposure limit } \\ \text { PPE } & - & \text { personal protective equipment } \\ \text { RIA } & - & \text { Robotics Institute of America } \\ \text { RWL } & - & \text { recommended weight limit } \\ \text { SOP'S } & - & \text { standard operating procedures } \\ \text { STEL } & - & \text { short term exposure limits } \\ \text { TLV } & - & \text { threshold limit value } \\ \text { TSI } & - & \text { thermal system insulation } \\ \text { TWA } & - & \text { time weighted average } \\ & & \end{array}$




\section{CARNEGIE MELLON UNIVERSITY BOA TABLE OF CONTENTS}

ACKNOWLEDGEMENTS iii

EXECUTIVE SUMMARY iv

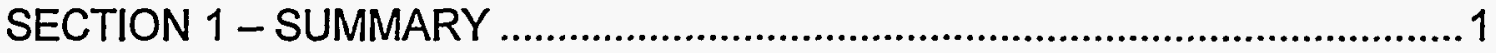

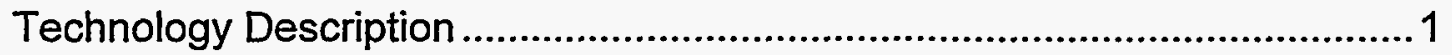

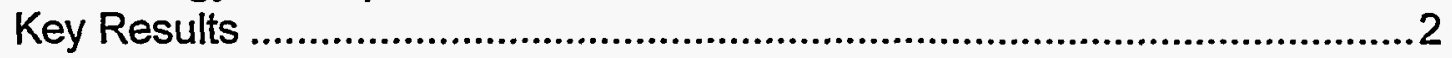

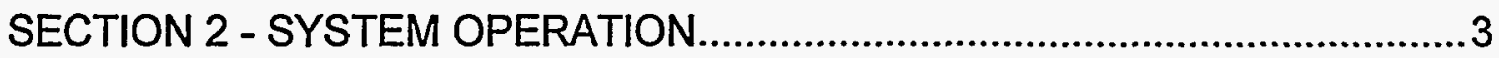

SECTION 3 - HEALTH AND SAFETY EVALUATION .................................... 5

General Health and Safety Concerns .......................................................5

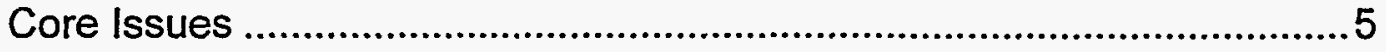

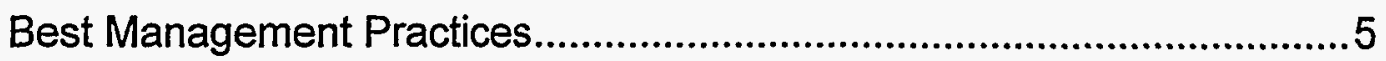

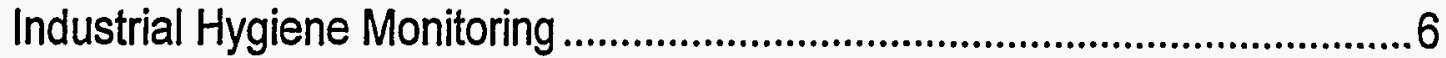

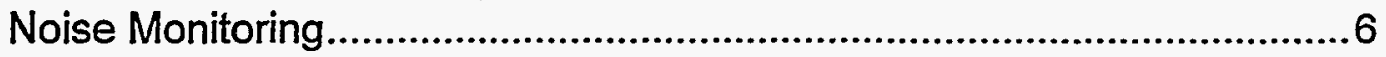

Evaluation of Airborne Particles ..............................................................6

Real Time MIE Data RAM Particulate Monitoring .......................................

Total and Respirable Dust Air Sampling................................................ 8

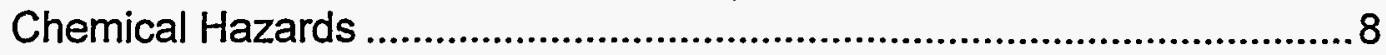

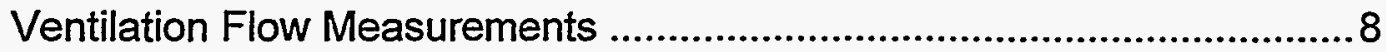

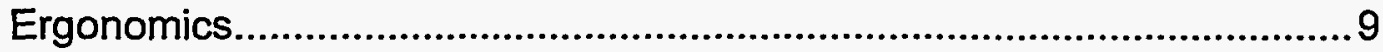

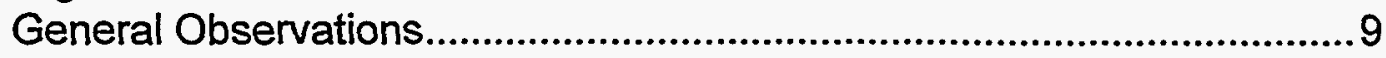

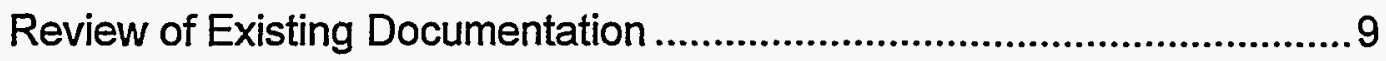

NIOSH Lifting Calculation ................................................................. 11

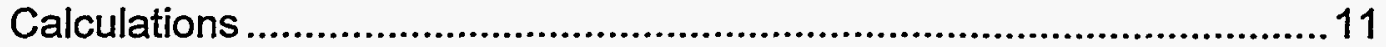

Software and Hardware Considerations ...................................................12

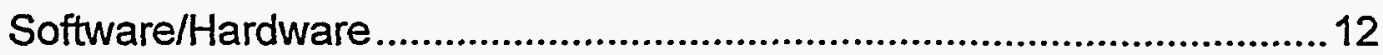

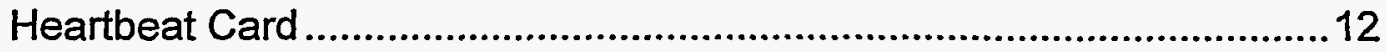

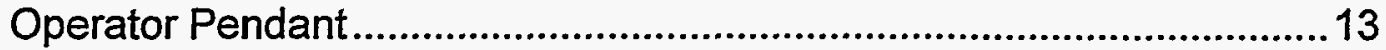

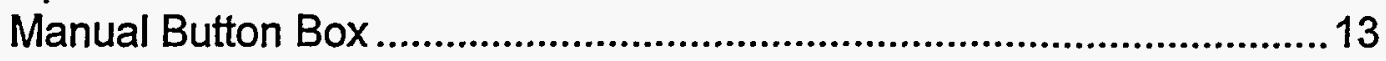

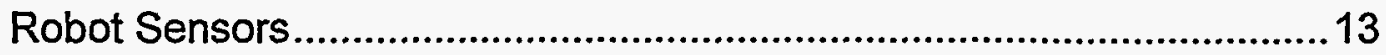

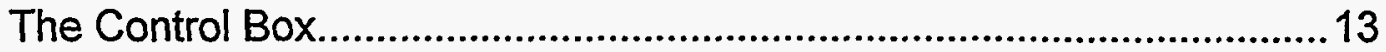

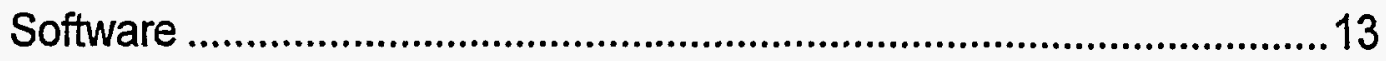

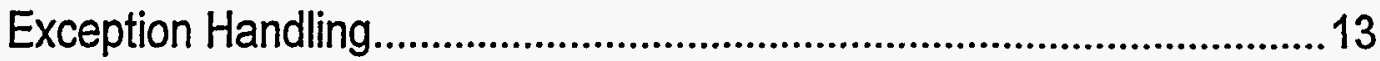

Computer Maintenance ..................................................................... 14

Modular Commercial Hardware ............................................................ 14 


\section{TABLE OF CONTENTS \\ (CONTINUED)}

Recommendations for Computer Operation ..............................................14

Human Factors Interface ...................................................................14

Technology Applicability ........................................................................ 16

SECTION 4 - EMERGENCY RESPONSE/PREPAREDNESS ........................ 16

SECTION 5 - REGULATORY POLICY ISSUES .......................................16

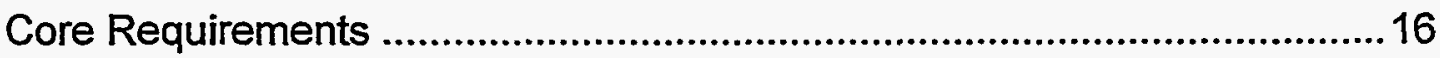

Technology Specific Requirements .....................................................17

Best Management Practices....................................................................... 18

Core Training Requirements .................................................................. 19

Technology Specific Training ................................................................19

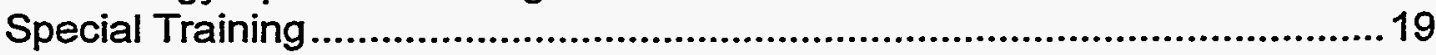

Best Management Practice Training ............................................................. 19

SECTION 6 - OPERATIONAL CONSIDERATIONS AND

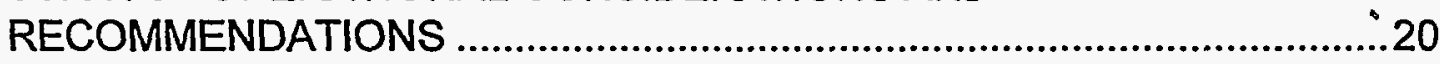

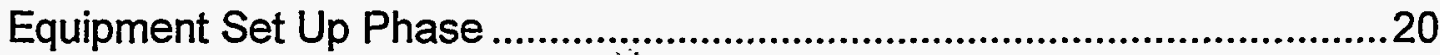

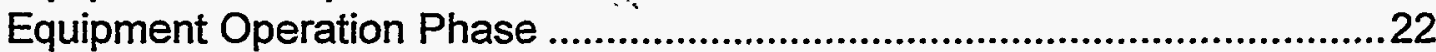

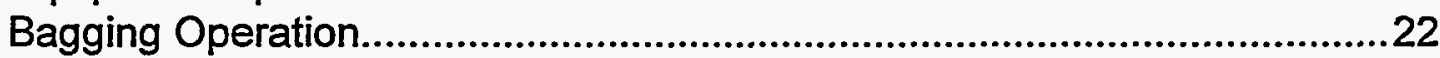

Maintenance and Decontamination Phase ...............................................23

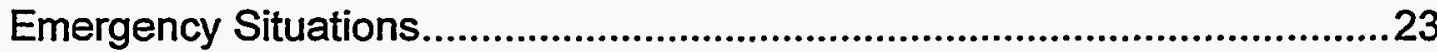

ADDENDUM

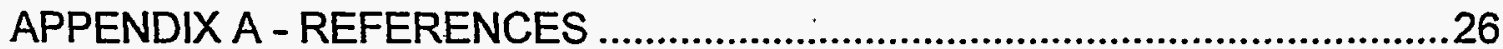

APPENDIX B - INDUSTRIAL HYGIENE DATA ............................................27

APPENDIX C - PENDANT CONTROL BUTTONS LAYOUT ..........................31

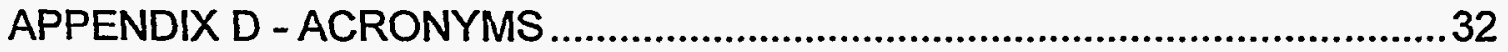




\section{ACKNOWLEDGEMENTS}

The human factors assessment of Carnegie Mellon University's BOA robotic system was conducted under support of the U.S. Department of Energy's Federal Energy Technology Center, under cooperative agreement DE-FC21-95MC32260 with the Operating Engineers National Hazmat Program. The Operating Engineers National Hazmat Program would like to thank the following people for their participation on the "research action team" and the professional expertise they provided for this assessment:

Team Member

Barbara McCabe

Patrick Bell

Robert Harrold

Randy Norris

Joe Byrd

Bruce Lippy

Tony Szwiliski

\section{$\underline{\text { Affiliation }}$}

Operating Engineers National Hazmat Program Operating Engineers National Hazmat Program Operating Engineers National Hazmat Program Operating Engineers Local Union Consultant to OENHP Consultant to OENHP (University of Maryland) Consultant to OENHP (Marshall University) 


\section{EXECUTIVE SUMMARY}

The BOA asbestos removal system designed by Carnegie Mellon University's (CMU) Robotics Institute was assessed for human factors by a team from the Operating Engineers National Hazmat Program. The team found that the system was generally well designed and incorporated many features that considered the protection of workers. The basic concept underlying the system represents the most important worker protection feature: remotely removing asbestos pipe insulation eliminates the use of glovebags, the standard abatement technique that requires working on ladders with arms constrained by a plastic bag while wearing respiratory protection and protective suits. Asbestos exposure and fall hazards are significant risks for workers using this standard technique. The BOA system is a major improvement in asbestos removal design. Not only does it remove asbestos insulation automatically, but the debris is cut into chunks and moved to a bagging machine under a strong vacuum. Prior to reaching the bagging operation, the material passes through a water separator which greatly reduces the weight of the debris and allows recirculation of water, after sufficient filtration. Additionally, the unit is capable of moving around pipe hangers and applying encapsulant to both cut edges of asbestos insulation. The unit also encapsulates the surface of the pipe after removal has taken place.

The use of encapsulant in the system means that operators need to wear gloves and eye protection whenever exposed to the liquid encapsulant, which is indicated as a skin and eye irritant in the Material Safety Data Sheet (MSDS).

Air sampling during the human factors assessment indicated that worker exposures may be kept low enough during normal operation of BOA to eliminate the need for respiratory protection. Currently, this is based on BOA removing calcium silicate insulation from pipe. Ventilation measurements documented strong air flow into the cutting head, between 500 and 1000 cubic feet per minute when the main vacuum was operating and between 200 to 300 cubic feet per minute when only the auxiliary vacuum was working. Given the high air flow into the cutter head, the low level of particle release is believable. Actual asbestos measurements from a field test will be critical, however.

Noise levels during operation of the unit were generally below the Occupational Safety and Health Administration (OSHA) $85 \mathrm{dBA}$ "action level" that would require a hearing conservation program. The large vacuum unit, however, was well over the OSHA level and had correctly been placed outdoors to limit exposure to personnel. It required almost no attention by workers, after being started.

The CMU Robotics Institute has not completed the minimal amount of documentation on the BOA system that is recommended by the Robotic Industries Association (RIA). 
Critical documents, such as standard operating procedures and maintenance procedures, will enlarge the understanding of worker risks and protection.

The computer hardware and software designed for the BOA system are robust and contain several key interlocks to protect operators. The software architecture is simple, straight-forward, yet provides the required functionality and exception handling necessary for a real-time system such as the BOA robot. "Fail Safe Status" occurs for system power failure and heartbeat loss. Operator Interaction is required for Emergency Stops (manual buttons) or operator actions from the Pendant keypad. System malfunctions occur from loss of vacuum, bumper activation on the robot, etc. The Feedback System Monitoring includes the status monitoring of limit switches on all system subsystems, motor current limits, activator positions, and water pressure and flow.

The primary missing item is diagnostic software to help a maintenance person locate faults within the system. An error log is provided that can be accessed from the system hard disk; however, this information is not organized is a manner which would be easy for maintenance to use. This is recommended before putting the system into full production.

Improvements in the ergonomic design of the operation are clearly possible. The work stations for several of the pieces of equipment involve awkward body positioning. During the set up phase, the connection of hoses and lines requires much bending over, while connecting the hoses and lines on the bagging unit requires reaching up over six feet. Similarly, connecting hoses to the large vacuum unit requires reaching approximately seven feet. Attaching the cutter head to elevated piping involves more awkward positions, including reaching out from an elevated manlift and working under the cutter head, both of which are serious safety hazards, in addition to ergonomic concerns. A calculation of the NIOSH Recommended Weight Limit for the bagging operation showed that the weight of the bags should be reduced from the present average of 48 pounds to approximately 30 pounds to avoid back stress that could lead to injuries. 


\section{CARNEGIE MELLON UNIVERSITY \\ BOA \\ HUMAN FACTORS ASSESSMENT}

\section{SECTION 1 - SUMMARY}

\section{TECHNOLOGY DESCRIPTION}

A team from the Operating Engineers National Hazmat Program (OENHP) conducted a human factors assessment of BOA, a robotic technology developed by CMU's Robotic institute. The main focus of the assessment was the human factors issues associated with the installation, operation, maintenance, and decontamination of this robotic equipment developed to remove asbestos insulation from pipe.

Many facilities throughout the Department of Energy (DOE) complex are slated for decontamination and decommissioning over the next several decades. Most of these facilities have asbestos-containing insulation on steam and process piping. Environmental Protection Agency (EPA) and Occupational Safety and Health Administration (OSHA) regulations require that this thermal system insulation (TSI) must be abated before the pipes can be dismantled. This will require abatement workers to handle a known carcinogen, removing the insulation primarily with glovebags that is an expensive and slow technique that presents potentially serious exposures to fall hazards, as well as ergonomic stressors. The projected abatement and disposal costs for TSl across the DOE complex is in the tens of millions of dollars with current practices.

The development of the CMU technology, called BOA, an automated pipe-insulation abatement system, represents a valuable effort to provide a robotic process that could remove workers from direct asbestos exposure and reduce abatement costs while meeting all federal and local regulations.

CMU, through the Robotic Institute's Field Robotics Center, has developed an automated asbestos pipe-insulation removal system called BOA. This system is a selfpropelled automated mini-enclosure, able to remove insulation from installed pipes, primarily of 4 " nominal outside diameter (OD). The system is designed for two operators, one at the abatement head and another at the cyclonic bagging station. Since the abatement head is its own enclosure there is no obvious need for further enclosures to be built, as long as there is no asbestos fiber released during operation. Additionally, operators may not need the respirators and protective garments required 
for glovebag removal, although there is not sufficient air monitoring data upon which to allow any reduction of protection at this point in time. This will need to be assessed further during actual asbestos insulation removal.

\section{KEY RESULTS}

The safety and health evaluation, during the human factors assessment, focused on: noise, dust concentrations, ergonomics, and computer software. Industrial hygiene sampling indicated that worker exposures may be kept low enough during normal operation of BOA to eliminate the need for respiratory protection or hearing protection around the cutting head and bagging operation. Ventilation measurements documented strong air flow into the cutting head when the main vacuum unit was operating and acceptable levels when only the auxiliary vacuum was working. Airborne particulate measurements using particle counting instruments showed a slight rise in dust particles over background levels during the operation of BOA, but the average of all the readings during operation was only 1.6 percent of the OSHA respirable dust standard. More reliable samples were collected by the approved NIOSH method and yielded results that were all below the laboratory's level of detection. Given the high air flow into the cutter head, the low level of particle release is believable. Actual asbestos measurements during field testing will be critical, however.

Noise levels from operation of the unit were generally below the OSHA $85 \mathrm{dBA}$ "action level" which would require a hearing conservation program. The large vacuum unit, however, was well over the OSHA "action level", as well as the permissible exposure limit (PEL) and had correctly been placed outdoors to limit exposure to personnel. It required almost no attention by workers after being started. Personal dosimetry measurements will be needed during actual BOA operation to ensure that worker noise levels are not above $85 \mathrm{dBA}$.

The computer hardware and software designed for the BOA system are robust and contain several key interlocks to protect operators. The software architecture is simple and straight-forward, yet provides the required functionality and exception handling necessary for a real-time system such as the BOA robot. Fail Safe Status occurs for system power failure and heartbeat loss. Operator Interaction is required for Emergency Stops (manual buttons) or operator actions from the Pendant keypad. The primary missing item is diagnostic software to help a maintenance person locate faults within the system.

Improvements in the ergonomic design of the operation are clearly possible. The work stations for several of the pieces of equipment involve awkward body positioning. During the set up phase, the connection of hoses and lines requires much bending over, while connecting the hoses and lines on the bagging unit requires reaching up over six feet. Similarly, connecting hoses to the large vacuum unit requires reaching approximately seven feet. Attaching the cutter head to elevated piping involves more awkward positions including reaching out from an elevated manlift and working under 
the cutter head, both of which are serious safety hazards. A calculation of the NIOSH RWL for the bagging operation showed that the weight of the bags should be reduced from the present average of 48 pounds to approximately 30 pounds to avoid back stress that could lead to injuries.

\section{SECTION 2 - SYSTEM OPERATION}

The BOA system is a major improvement in design for the removal of asbestos insulation from pipes. The system is a self-propelled automated mini-enclosure, able to remove insulation from installed pipes, primarily of 4 " outside diameter. The system is designed for two operators: one oversees the abatement head from a distance of 10 or

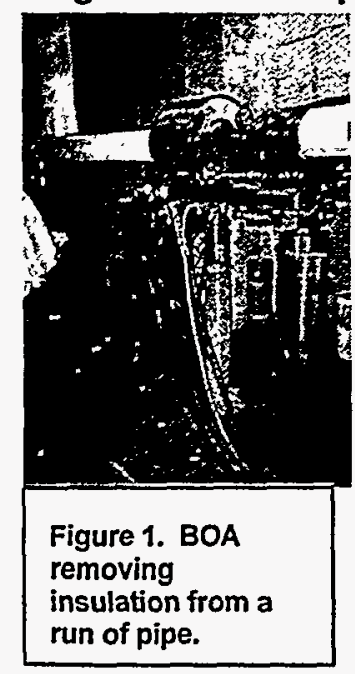

15 feet using a pendant control and the other bags the debris at a cyclonic bagging station that is attached by a vacuum hose to the cutting head. Since the abatement head is its own enclosure, there may be no need for further enclosures to be built. The system wets and removes asbestos insulation automatically, cutting the debris into consistent "chunks" and moving the waste under a strong vacuum to a bagging machine. Prior to reaching the bagging operation, the material passes through a water separator that greatly reduces the weight of the debris and allows recirculation of water, after sufficient filtration.

insulation from a run of pipe.

pipe insulation eliminates the use of glovebags, the standard abatement technique that requires working on ladders with arms constrained by a plastic bag while wearing respiratory protection and protective suits. Asbestos exposure and fall hazards are significant risks for workers with this standard technique.

BOA's abatement head, which weighs approximately 160 pounds, is clamped onto the pipe after positioning the unit with a jib-crane. A tether containing power, pressurized water, and encapsulant lines, as well as a 4-inch diameter vacuum hose is connected between the abatement head and the other pieces of equipment.

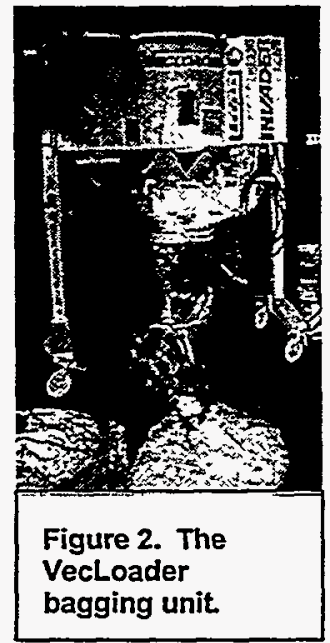
The tether is currently configured to allow up to 150 feet between the control-box and the abatement head. The abatement head removes asbestos with three omnidirectional specially designed endmill/water jet cutters that cut through metal jackets, cloth lagging, and insulation using a combination of mechanical cutters and high 
pressure water jets. The jets perform the final cuts so that the mechanical cutters never come in contact with the pipe surface.

An infrared light sensor and a bump sensor on the front of BOA will detect a hanger or other hindrance, stop, and prompt the operator. If it is a hanger, the operator can use the pendant control to initiate a sequence during which BOA will leave a small, encapsulated section of asbestos on both sides of the hanger, move past the hanger, and continue removing insulation. These small sections will have to be removed with glove bags. BOA cannot move around bends in the pipe and must be physically disengaged from the pipe and transported to the next straight run.

The other equipment that makes up the system includes a diesel-powered generator, a $1,000 \mathrm{cfm}$ industrial HEPA-filtered vacuum unit, a cyclonic waste-bagging system, and a water-separator system. A central controller box controls, coordinates, and monitors all system parameters. The only site-supplied requirements are tap-water (about 50 gallons per day) and a 110 VAC shore power to run the backup HEPA vacuum. The computer system constantly monitors a number of system parameters and shuts down the operation if it detects something outside acceptable bounds, such as a drop in pressure in the abatement head.

Several of these components were purchased commercially. The vacuum unit, called a VEC-Loader, is built by VEC, Inc. and was designed for vacuuming asbestos waste directly from an enclosed work area and into containers. The unit runs continually when $\mathrm{BOA}$ is in operation. The cyclonic bagger is also commercially available and is commonly used in the asbestos abatement industry. During the removal cycle, when sufficient insulation has been cut, the robot stops and the large vacuum is bypassed and an auxiliary vacuum is used to maintain negative pressure in the system while the materials are bagged. The operator must manually throw a lever to get the waste to drop out of the cyclonic bagger into a properly labeled asbestos bag. Once "bag-out" is completed, the system switches back to the large vacuum and the robot head begins a new removal cycle.

The high pressure water pump is a modified off-the-shelf unit that is standard in any industrial operation. The encapsulant system is a commercially available airless pump system that has been slightly modified for this operation. A commercially available penetrating encapsulant is used. The water separator is a unit that was custom built for the BOA operation. It removes all of the loose water that was not absorbed into the insulation, which keeps the weight (and cost) of disposal of the asbestos insulation much lower. The water is drawn through two filters before it is recycled for use by the system. 


\section{SECTION 3 - HEALTH AND SAFETY EVALUATION}

\section{GENERAL HEALTH AND SAFETY CONCERNS}

Personnel working with the BOA asbestos removal system need to be concerned with safety and health issues that may be divided into two categories. First, core issues are those that are based on current safety and health regulatory requirements. Second, best management practices are not regulatory requirements, but are key elements in preventing worker injury and illness on the job. Safety and health issues of concern with the BOA system included:

\section{Core Issues:}

- Tripping hazards - Although necessary, vacuum hoses, water lines, electrical cables, and encapsulant lines are tripping hazards. Therefore, the need for stringent housekeeping must be evaluated.

- Lockout/tagout - The user of the technology will need to develop a lockout/tagout program to assure there is not an accidental release of energy during maintenance/repair activities.

- Noise - BOA is acceptably quiet but the VEC-Loader vacuum unit exceeded the OSHA Noise standard. Hearing protection should be worn while working around this unit.

- Dust - The equipment did not generate visible dust during operation nor were significant amounts measured during operation. This is reasonable given the thorough wetting of insulation and the strong vacuum maintained during operation.

- Working at heights - The operation of BOA was much more hazardous during the removal of insulation located on elevated pipe sections.

\section{Best Management Practices:}

- Heat stress - The operator will potentially be subjected to an increase in heat stress if personal protective equipment (PPE), particularly disposable suits, is necessary. The individual removing filled bags from the bagging operation will be at more of a risk due to the increased activity level. The user will need to develop a heat stress program for the environment in which the technology is being used, taking into consideration any PPE that may need to be utilized.

- Ergonomics - There are several ergonomic concerns with the operation of BOA. During the equipment set up, particular care must be given to lifting large 
containers off of the truck. During setup there are hoses and cables that must be attached to the various pieces of the equipment which requires bending, twisting, kneeling, stooping, and wrist, hand, arm, shoulder, and back stress and abnormal positioning. In addition, the weight of the bags of asbestos should not exceed 30 pounds in order to avoid back injuries for the bagging operator.

Struck by hazards - The high pressure water lines have the potential to cause severe injury if their fittings were to fail. A safety line between the male and female end of the fittings would prohibit the line from becoming airborne. The accidental release of the cutting head during attachment to an overhead pipe could be fatal to workers underneath of the unit.

\section{INDUSTRIAL HYGIENE MONITORING}

\section{Noise Monitoring}

Noise monitoring was conducted with a Quest Technologies Model 2700 Sound Level Meter that was calibrated pre-and-post monitoring with a Quest Calibrator Model QC10.

Area noise monitoring was conducted during the operation of BOA and all associated equipment (vacuum unit, VecLoader, high pressure water pump, etc.). Readings ranged from 80-89 dBA inside the building and 96-103 dBA outside the building where the vacuum unit was located. These readings indicate noise to be a potential exposure problem during the operation of BOA. See Appendix B for specific locations and noise. levels for noise monitoring.

The noise levels generated and therefore, the noise levels the workers are exposed to will be dependent on several factors. This includes the placement of all the associated equipment (especially the vacuum unit) in relation to the cutting head, the position(s) where the operators need to be located (which is related to the placement of equipment), and the construction materials of the area where BOA is being used. The closer together the equipment must be and therefore, the closer the operators must be to it, the higher the noise levels/levels of exposure would be expected to be. The smaller the area in which BOA must operate and the more reverberation from construction materials in the area, the higher the noise levels/levels of exposure would be expected to be.

\section{Evaluation of Airborne Particles}

Calcium silicate pipe insulation was used, in lieu of asbestos during the human factors assessment. Calcium silicate is similar in texture but not nearly as fibrous as asbestos, consequently the fiber counting analytical procedure for asbestos (NIOSH Method 7400) was deemed to be inappropriate. Air samples were collected following NIOSH 
Methods 0500 and 0600 for gravimetric analysis of total dust and respirable dust, respectively. Samples were collected onto pre-weighed filters and sent for analysis to Galson Laboratories, an American Industrial Hygiene Association (AlHA) accredited lab. All samples were collected using MSA Escort Elf personal air sampling pumps. MSA cyclones were used for respirable dust sampling. The pumps were calibrated preand-post sampling with a BIOS DryCal-1 primary calibration source. Field blanks were collected on each day of sampling.

Additionally, real-time MIE personal/Data RAM model pDr-100 samplers were used to measure the concentration of airborne particulates. These photometric instruments provide an estimate of airborne mass based on particle counting and sizing.

Air sampling with both the personal air sampling pumps and the MIE Data RAM was conducted prior to the operation of BOA and during the operation of BOA. Since total and respirable dust were the analytes being monitored, this was done to account for any ambient airborne particulate that may have been present in the area where the BOA operation took place. The results were compared to the OSHA PEL and the American Conference of Governmental Industrial Hygienists (ACGIH) threshold limit value (TLV) of $15 \mathrm{mg} / \mathrm{m}^{3}$ for total dust and $5 \mathrm{mg} / \mathrm{m}^{3}$ for respirable dust and $10 \mathrm{mg} / \mathrm{m}^{3}$ for total dust and $3 \mathrm{mg} / \mathrm{m}^{3}$ for respirable dust, respectively.

\section{Real-Time MIE Data RAM Particulate Monitoring}

Background dust measurements were made one day prior to the operation of BOA. Up to 10 readings were taken at each station from which the mean, standard deviation, and coefficient of variation (CV) were determined. The CV was derived by dividing the mean into the standard deviation and then multiplying by 100 , to express the result as a percentage. The larger the CV, the greater the variation in the data. See Appendix B for air sampling data.

Dust measurements were also taken during the operation of BOA. During operation, exposures would be expected to be higher when the cutting head is actually engaged. Consequently, a maximum reading was taken at each work station. Similarly, the Short Term Exposure Limit (STEL) was recorded at each work station. See Appendix B for air sampling data.

The dust readings using the MIE personal/Data RAM samples prior to operation of BOA were all between 0.032 and $0.048 \mathrm{mg} / \mathrm{m}^{3}$. During operation, the results were higher: ranging from 0.043 to $0.102 \mathrm{mg} / \mathrm{m}^{3}$, with the highest readings obtained by hanging the samplers on the operator and bag-out worker. The average of all the exposures was $0.08 \mathrm{mg} / \mathrm{m}^{3}$. The standard deviation and coefficient of variation for these readings were calculated and are included in Appendix B. These statistical calculations indicate that the readings were very consistent which allows more confidence in the data. The OSHA PEL for total dust is $15 \mathrm{mg} / \mathrm{m}^{3}$ for respirable dust. 


\section{Total and Respirable Dust Air Sampling}

All of the mass measurements - both before and during operation of the BOA system were reported as below the level of quantification by the analytical laboratory. The differences reported below are due to the variations in air volumes collected. For example, the highest result, $<0.90 \mathrm{mg} / \mathrm{m}^{3}$, corresponded to the smallest air volume collected, 44.4 liters, after a pump failure. This result is well below the OSHA PEL. A complete air sampling plan for a site would need to be developed by all users of $B O A$. See Appendix B for sampling data.

\section{Chemical Hazards}

The only chemical that is used in the system, besides standard lubricants, is the encapsulant that is sprayed to seal asbestos insulation exposed during movement around hangers. The encapsulant is also sprayed onto the pipes to seal any fibers potentially left behind on the pipe. There are several different commercially-available encapsulants that can be used in this system, however; during the assessment CP-210 Chil-Abate ${ }^{\mathrm{TM}}$ by Childers Products $\mathrm{Co}$. was used. The MSDS for this product lists only one hazardous component: 1,2 Ethanediol, CAS Number 107-21-1. This chemical makes up only 1-5 percent of the product and has an OSHA PEL of 50 parts per million. The MSDS indicates that 1,2 Ethanediol may be an eye and skin irritant. Consequently, the manufacturer recommends that safety glasses or goggles and impermeable rubber 'gloves should be worn. Additionally, they recommend having an eye wash nearby. The product is not flammable or reactive. The MSDS for the encapsulant being used needs to be evaluated and PPE and monitoring needs must be established on a job-by-job basis.

\section{Ventilation Flow Measurements}

Ventilation flow measurements, into the cutting head of the BOA system, were made during the human factors assessment. Measurements were made with an Alanor Thermo Anemometer Model 8525. Additionally, ventilation smoke tubes were used to assess the air movement pattern(s) in the area of the cutting head.

Air flow immediately outside the opening between the cutter head cover and the pipe insulation while the main vacuum was operating averaged 500-1000 feet per minute. When only the auxiliary vacuum was operating, the air flow was 200-300 feet per minute. See Appendix B for flow measurements.

Smoke tube testing visually reinforced the data reported for air flow measurements. While operational, the cutter head is under strong negative pressure. Smoke released anywhere near the cutter head was quickly drawn into the unit, including when only the auxiliary vacuum was operating. 


\section{Ergonomics}

Through general observational techniques, the potential for ergonomic problems was evaluated during the human factors assessment. There is potential for muscle/back stress and/or injuries due to bending, twisting, and lifting associated with setup, operation, maintenance, and decontamination.

\section{General Observations}

- The work stations for several of the pieces of equipment involve awkward body positioning. During the set up phase, the connection of hoses and lines requires much bending over, while connecting the hoses and lines on the bagging unit requires reaching up over six feet. Similarly, connecting hoses to the large vacuum unit requires reaching approximately seven feet. Attaching the cutter head to elevated piping involves more awkward positions including reaching out from an elevated manlift and working under the cutter head, both of which are serious safety hazards, in addition to ergonomic stressors.

- In emergency situations, the emergency stop button on the electrical box will require reaching over considerably to shut down the operation.

- Some of the portable equipment is not ergonomically designed. The water pump has four wheels on it, for instance, but their positions are rigidly fixed so there is no way to steer the unit. The water filters are permanently affixed to a dolly that makes it easier to move the equipment. However, the load sets too far forward which puts significant stress on the back of the person pulling this unit back on the dolly to move it.

- The color coding that is used on the unit is helpful but does not conform to national standards nor does it seem particularly intuitive. The developer has marked in gold everything with moving parts that poses safety risks. All other parts are blue. The color coding for the hazardous parts is not easily recognized as indicating danger, which is a real concern considering the possibility of finger amputation by the BOA's

pipe clamping mechanism. Red would be much more effective than gold, and more warning stickers would be helpful.

- The icons used for the remote pendant are not intuitive and require serious training before an operator can effectively use the controls.

\section{Review of Existing Documentation}

The RIA has identified the following as important documents from the manufacturer of robotics systems. The following is information that was provided by Dr. Hagen Schempf concerning the availability of these documents. The software documentation was 
reviewed during this assessment and is discussed in greater detail under the software and hardware considerations section of this report.

\section{Document}

1. Function and location of all controls Robot specifications, including range and load capacity

3. Limiting device information

4. Number, location, and degree of adjustment of hard stops

5. Number and location of control reliable limiting means

6. Lifting procedures and precautions

7. Precautionary information

8. Operating instructions

9. Maintenance and repair information, including preventive maintenance schedules

10. Information required for installation

1.1. Special environmental requirements

12. Electrical requirements

13. Lockout procedures

14. Failure mode analysis information

15. Hazard analysis and description of all hazard controls

\section{Available}

Yes No N/A Under development

\begin{tabular}{|c|c|c|}
\hline 7 & 凶 & 口 \\
\hline & $\begin{array}{l}\square \\
\square\end{array}$ & $\begin{array}{l}\text { 口 } \\
\text { ■ }\end{array}$ \\
\hline & 凶 & $\square$ \\
\hline & $\begin{array}{l}\square \\
\square \\
\text { 区 } \\
\square\end{array}$ & $\begin{array}{l}\text { 囚 } \\
\square \\
\square \\
\square\end{array}$ \\
\hline
\end{tabular}

$\square \quad$ 口 $\square$

$\square \quad \square \quad \square \quad$ 口

$\square \square \cdot \square \quad \square$

冈日吕口

口回吕吕

口 $\square \quad \square \quad$ 口

$\square \quad \square \quad \square \quad$ 口

The OENHP assessment of Type III, robotic technologies requires the following be reviewed in addition to the previous list:

Document

1. Training manuals and training requirements

2. Health and safety plan

3. Job Safety Analyses

4. Operations Manual

5. Maintenance Manual

6. Software listing

\section{Available}

Yes No N/A Under development

$\begin{array}{llll}\square & \otimes & \square & \square \\ \square & \square & \square & \square \\ \square & \square & \square & \square \\ \square & 凶 & \square & \square \\ \square & \square & \square & \square \\ \square & \square & \square & \square\end{array}$




\section{NIOSH Lifting Calculation}

$\mathrm{NIOSH}$ has developed an equation for determining the RWL which is defined for a specific set of task conditions as the weight of the load that nearly all healthy workers could perform over a substantial period of time without an increased risk of developing lifting-related lower back pain. The RWL is based on a multiplicative model that provides a weighting for each of six task variables. The weightings are expressed as coefficients that serve to decrease the load constant, which represent the maximum recommended load to be lifted under ideal conditions. The RWL is defined by the following equation:

\section{$R W L=L C \times H M X V M \times D M \times A M \times F M \times C M$}

Where:

\begin{tabular}{|l|l|l|l|l|}
\hline Name & Abbrev. & Formula & $\begin{array}{l}\text { Raw data } \\
\text { from BOA }\end{array}$ & $\begin{array}{l}\text { Multiplier } \\
\text { Determination }\end{array}$ \\
\hline Load Constant & LC & $\mathrm{n} / \mathrm{a}$ & $\mathrm{n} / \mathrm{a}$ & 51 lbs. (given) \\
\hline Horizontal Multiplier & $\mathrm{HM}$ & $(10 / \mathrm{H})$ & 9 inches & 1.0 \\
\hline Vertical Multiplier & VM & $1-(.0075 \mid \mathrm{V}-30 /)$ & 32 inches & 1.0 \\
\hline Distance Multiplier & $\cdot \mathrm{DM}$ & $.82+(1.8 / \mathrm{D})$ & 22 inches & .90 \\
\hline Asymmetric Multiplier & AM & $1-(.0032 \mathrm{~A})$ & 45 degrees & .86 \\
\hline Frequency Multiplier & $\mathrm{FM}$ & $\begin{array}{l}\text { Designation of Long duration } \\
\text { task from Table 5 in NIOSH } \\
\text { text }\end{array}$ & $\begin{array}{l}1 \text { lift every 10 } \\
\text { minutes } \\
(0.1 \text { lift/min.) }\end{array}$ & .85. \\
\hline Coupling Multiplier & CM & $\begin{array}{l}\text { Designation of Poor from } \\
\text { Table 6 }\end{array}$ & V>30 & .90 \\
\hline
\end{tabular}

\section{CALCULATIONS:}

$$
\begin{aligned}
& R W L=L C \times H M \times V M \times D M \times A M \times F M \times C M \\
& R W L=52 \times 1.0 \times 1.0 \times .90 \times .86 \times .85 \times .90 \\
& R W L=30.2 \text { lbs. }
\end{aligned}
$$

$\mathrm{NIOSH}$, in its guidance documents points out that, "it is likely that lifting tasks with a lifting index $(\mathrm{LI})>1.0$ poses an increased risk for lifting-related low back pain for some fraction of the workforce. Hence, the goal should be to design all lifting jobs to achieve a $\mathrm{Ll}$ of 1.0 or less...experts agree that nearly all workers will be at an increased risk of a work-related injury when performing highly stressful lifting tasks (i.e., lifting tasks that would exceed a $L I$ of 3.0)." Calculations for the bagging operation show a $L I$ of 1.6.

1 U.S. Department of Health and Human Services, Public Health Service, Applications Manual for the Revised NIOSH Lifting Equation, DHHS (NIOSH) Publication No. 94-110, January 1994, pg. 35. 
Calculations further indicate that the waste bags should be kept to approximately 30 pounds.

$$
\begin{aligned}
\text { Lifting Index } & =\text { load weight/Recommended Weight Limit } \\
& =48.7 / 30.2 \\
& =1.6
\end{aligned}
$$

\section{SOFTWARE AND HARDWARE CONSIDERATIONS}

The BOA system has considerable fail-safe systems built into its operation but few are mechanical interlocks. The majority is software interlocks that exist in the computer programs designed for the system, not in mechanical interlocks that are routinely found in industry. The software/hardware was assessed to determine the robustness of the fail-safe computer interlocks.

The following resources were part of the computer software evaluation:

- listing of software program code;

- discussions with Brian Chemel (programmer); and

- observations during assessment operations of the robot.

The computer system (in the final version) will be an embedded system contained in the system Control Box. Boot up operations will be initiated in firmware by the operator using the Pendant, so that an external computer terminal is not necessary for operation. The boot up firmware was not employed with the system used for the assessment ; an external computer terminal was used for boot-up operation and to log operational status during system activity. This "log" information will be put on the embedded hard disk drive in the final version. An operator (or maintenance person) will be able to access this information by externally connecting a terminal.

\section{Hardware/Software}

The computer hardware implementation uses a modular, plug-in $486 / 33 \mathrm{PC}$ with $4 \mathrm{M}$ RAM, 2M EPROM, ADC board, DAC board, a special Heartbeat board, and servo amplifier circuitry. All components are commercially available with the exception of the Heartbeat board and amplifiers.

Heartbeat Card: This performs a "dead-man" switch function. Control inputs to this card monitor various system operations which provide a "heartbeat" clock $(20 \mathrm{~Hz}$ update clock) to keep the system active and enabled. Any malfunction in the software or hardware results in an irregular "heartbeat" which disables all system components in a fail-safe mode. When a single-axis failure occurs (jammed pipe clamp, etc.), the system 
can be re-started by operator action. When two failures occur sequentially the system shuts down, and a re-boot is necessary to restart the system. The E-Stop buttons located on several system components (pendant, control box, etc.) activate a heartbeat failure.

Operator Pendant: This commercial unit is environmentally sealed from dust, etc. Programming an EPROM customizes the unit to a unique application. BOA pendant control consists of simple, single actions, i.e. open clamp, close clamp. See Appendix $\mathrm{C}$ for Layout of Pendant Control Buttons. Full control by the operator is via this pendant. The pendant has a message display panel which displays operational and fault information to the operator. It does not provide a complete diagnostic message but simply states the actions required or the current status of the system.

Manual Button Box: This unit provides simple controls and power to the robot, if the BOA unit has to be removed from the pipe due to computer system failure. The normal input connections are disconnected and the Button Box provides the basic functions to unclamp the robot so that it can be moved to another location for maintenance purposes.

Robot Sensors: The BOA robot has a bumper tactile sensor and a pipe hanger detection infrared (IR) sensor.

The Control Box: This is a centrally located, portable unit that interconnects input power and all electrical and control signals/cables for the BOA system components. The computer system is housed in this Control Box. Input power requirements for the system are $208 \mathrm{v}$ ac, 3-ph, 50 -amp. A separate $115 \mathrm{v}$ ac, 10 -amp power input is required for the HEPA pony vacuum unit used in emergency situations. This power input is intentionally separated from the main system power for safety reasons (if main power fails, the HEPA unit will remain active.)

Software: The software architecture is simple, straight-forward, yet provides the required functionality and exception handling necessary for a real-time system such as the $\mathrm{BOA}$ robot. It is written in Borland $\mathrm{C}++$. At the highest level, a Planning Module plans and controls operations for two basic operational modes: Manual and Automatic. Once the system is in the Automatic mode, it must be terminated by operator action or by a system fault. The lowest level uses system interrupts.

Exception Handling: The system "exceptions" are organized as follows: Fail Safe Status, Operation Interaction Required, System Malfunction, and Feedback System Monitoring. Fail Safe Status occurs for system power failure and heartbeat loss. Operator Interaction is required for Emergency Stops (manual buttons) or operator actions from the Pendant keypad. System Malfunctions occur from loss of vacuum, bumper activation on robot, etc. The Feedback System Monitoring includes the status monitoring of limit switches on all system subsystems, motor current limits, activator positions, and water pressure and flow. 
Computer Maintenance: Access to the computer is at the Control Box. The only other computer component is the Operator Pendant. Except for the lack of diagnostic software, this system should be relatively easy to maintain by anyone trained in computer maintenance. The system is an embedded system. An external terminal may be connected for maintenance purposes (read out the system log, run diagnostic programs if/when available, etc.) The software is presented in good format and is well documented with appropriate comments. It is easy to follow by someone knowledgeable in programming.

Modular Commercial Hardware: Modular commercial hardware simplifies system maintenance. Several special cards would have to be built for spare parts.

\section{Recommendations for Computer Operation:}

- The primary missing item is diagnostic software to help a computer maintenance person locate faults within the system. An error log is provided that can be accessed from the system hard disk; however, this information is not organized in a manner that would be easy for maintenance to use. All the "hooks" are there for providing these diagnostic tools. This would be recommended before the system went into full production use.

- Diagnostic messages at the Operator Pendant could be improved to provide more explicit information.

- The exception handling design and implementation appears to be adequate to provide fail safe systems under any unusual failure within the software and/or hardware.

- System valves and motors fail in a "safe" deactivated condition. For example, if power or computer failure occurs, the robot will remain securely clamped to the pipe and requires manual power to be applied to move it.

- The heartbeat card is an effective monitoring tool for hardware and software and shuts down the system should failures occur.

\section{HUMAN FACTORS INTERFACE}

The computer system responsible for operating BOA provides an important human factors interface. A Heartbeat Card in the system basically performs a dead-man switch function. Control inputs to this card monitor various system operations which provide a "heartbeat" clock ( $20 \mathrm{~Hz}$ update clock) to keep the system active and enabled. Any malfunction in the software or hardware results in an irregular "heartbeat" which disables all system components in a fail-safe mode. When a single-axis failure occurs 
(jammed pipe clamp, etc.), the system can be re-started by operator action. When two failures occur sequentially the system shuts down, and a re-boot is necessary to restart the system. The E-Stop buttons located on several system components (pendant, control box, etc.) activates a heartbeat failure.

System operation from the pendant is simple and straight forward. The Operator Pendant is a commercial unit that is environmentally sealed from dust, etc.

Programming an EPROM customizes the unit to a unique application. The BOA pendant control consists of simple, single actions, i.e. open clamp, close clamp. Full control by the operator is via this operator pendant. The pendant has a message display panel which displays operational and fault information to the operator. It does not provide a complete diagnostic message but simply states the actions required or the current status of the system.

The Manual Button Box provides simple controls and power to the robot, if the unit has to be removed from the pipe due to computer system failure. The normal input connections are disconnected and the Button Box provides the basic functions to unclamp the robot so that it can be moved to another location for maintenance purposes. BOA has a bumper tactile sensor and a pipe hanger detection IR sensor. The Control Box is a centrally located, portable unit that interconnects input power and all electrical and control signals/cables for the BOA system components. The computer system is housed in this Control Box. Input power requirements for the system are $208 \mathrm{v}$ ac, 3-ph, 50-amp. A separate 115v ac, 10-amp power input is required for the HEPA unit used in emergency situations. This power input is intentionally separated from the main system power for safety reasons (if the main power fails, the HEPA unit will remain active.)

The software architecture is simple, straight-forward, yet provides the required functionality and exception handling necessary for a real-time system such as the BOA robot. It is written in Borland $\mathrm{C}++$. At the highest level, a Planning Module plans and controls operations for two basic operational modes: Manual and Automatic. Once the system is in the automatic mode, it must be terminated by operator action or by a system fault. The lowest level uses system interrupts.

For computer maintenance, access to the computer is at the Control Box. The only other computer component is the Operator Pendant. Except for the lack of diagnostic software, this system should be relatively easy to maintain by anyone trained in computer maintenance. The system is an embedded system. An external terminal may be connected for maintenance purposes (read out the system log, run diagnostic programs if/when available, etc.) The software is presented in good format and is well documented with appropriate comments. It is easy to follow by someone knowledgeable in programming. 


\section{TECHNOLOGY APPLICABILITY}

On observation the technology did not generate visible dust and air monitoring did not show a significant dust level. Noise measurements were also acceptable for the new technology. The need to work only on 4" O.D. pipe runs that do not have many bends limits the applicability of the technology. The time needed to physically move the head around a pipe bend may negate the savings associated with the unit automatically operating on a straight run.

\section{SECTION 4 - EMERGENCY RESPONSE/PREPAREDNESS}

Emergency response and emergency preparedness must be part of every hazardous waste site safety and health plan. The possibility of a medical emergency due to an accident resulting from the operation of BOA is credible enough to require contingency planning. Operators should have sufficient first aid materials on site to deal with injuries resulting from falls from heights, lacerations or amputations from the clamping mechanism, and cuts or contusions from high pressure water lines.

All workers on site must be trained to operate the emergency shut off controls at the pendant and the control box. Additionally, they should be trained to handle the medical emergencies above.

The BOA system, however, does not pose the risk of fire, explosion, or chemical release that would threaten outside responders like Emergency Medical Services that may arrive at the site.

\section{SECTION 5 - REGULATORY/POLICY ISSUES}

Regulations that apply to this technology may be divided into four categories. First, core requirements are those regulations that would apply to any hazardous waste work site, regardless of the type of job. Second, technology-specific requirements are those regulations that apply due to the specific technology being used. Third, special requirements are standards and policies that are specific to the technology itself, and are required by reference in a regulation. Fourth, best management practices are not required but are recommended by organizations such as the American National Standards Institute (ANSI), NIOSH, DOE, National Fire Protection Association (NFPA), etc. These regulations/standards may include, but not be limited to, the following:

\section{Core Requirements:}

OSHA 29 CFR 1926.25 Housekeeping

OSHA 29 CFR 1910.141 Sanitation (1910.141(a)(3) covers housekeeping) 
OSHA 29 CFR 1926 Subpart Z Toxic and Hazardous Substances

OSHA 29 CFR 1910 Subpart Z Toxic and Hazardous Substances

OSHA 29 CFR 1926.59 Hazard Communication

OSHA 29 CFR 1910.1200 Hazard Communication

OSHA 29 CFR 1926.64 Process Safety Management of Highly Hazardous Chemicals

OSHA 29 CFR 1910.119 Process Safety Management of Highly Hazardous Chemicals

- OSHA 29 CFR 1926.65 Hazardous Waste Operations and Emergency Response

OSHA 29 CFR 1910.120 Hazardous Waste Operations and Emergency Response

Occupational Safety and Health Act 1970(5)(a)(1) General Duty Clause

EPA 40 CFR 61.145 National Emissions Standards for Hazardous Air Pollutants, Asbestos

- EPA 40 CFR 763.92 Toxic Substance Control Act, Asbestos Hazard Emergency Response Act

\section{Technology Specific Requirements:}

- OSHA 29 CFR 1926.1101 Asbestos

OSHA 29 CFR 1910.1001 Asbestos

OSHA 29 CFR 1926 Subpart L Scaffolding

- OSHA 29 CFR 1910.28 Safety Requirements for Scaffolding

- OSHA 29 CFR Subpart N Cranes, Derricks, Hoists, Elevators, and Conveyors

- OSHA 29 CFR 1910 Subpart O Machinery and Machine Guarding

- OSHA 29 CFR 1910.147 The Control of Hazardous Energy (Lockout/Tagout)

OSHA 29 CFR 1926.52 Occupational Noise Exposure 


\section{OSHA 29 CFR 1910.95 Occupational Noise Exposure}

OSHA 29 CFR 1926.103 Respiratory Protection

OSHA 29 CFR 1910.134 Respiratory Protection

OSHA 29 CFR 1926.102 Eye and Face Protection

OSHA 29 CFR 1910.133 Eye and Face Protection

OSHA 29 CFR 1926.28 Personal Protective Equipment

OSHA 29 CFR 1910.132 Personal Protective Equipment

OSHA 29 CFR 1910.132 General Requirements (Personal Protective Equipment)

OSHA 29 CFR 1926.23 First Aid and Medical Attention

OSHA 29 CFR 1910.151 Medical Services and First Aid

OSHA 29 CFR 1910.1000 Toxic and Hazardous Substances

Best Management Practices:

- ACGIH Threshold Limit Values for Chemical Substances and Physical Agents and Biological Exposure Indices

NIOSH Revised Lifting Equation, 1994

- Association for Robotics in Hazardous Environments "Guidelines for Procurement Specifications for Remote and Robotic Systems and Equipment to Operate in Hazardous Environments" RHE H01.01-1996

- Robotic Industries Association, R15.06 Safety Requirements Draft 10

- NIOSH "Safe Maintenance Guidelines for Robotic Workstations," DHHS (NIOSH) Publication No. 88-108, March 1988.

NIOSH "Elements of Ergonomics Programs, A Primer Based on Workplace Evaluations of Musculoskeletal Disorders" March 1997 


\section{Training Requirements}

In addition to the above regulations and policies, it is imperative that all workers have appropriate and adequate training for the task and associated safety and health conditions. Training that would be required may be divided into four categories. Core training is that which is required for anyone entering a hazardous waste site to perform work, regardless of the type of job. Technology specific training is that training that is specific to the technology and required by safety and health standards. Special training is that which is specific to the technology to assure the worker is adequately trained for the task but is not necessarily required by safety and health standards. Best management practices are trainings that while not mandated by health and safety standards, provide information and knowledge to the worker that will allow the worker to perform the job safely. Training to be applied for BOA may include but not be limited to:

\section{Core Training Requirements:}

\section{$\checkmark \quad$ HAZWOPER}

$\checkmark \quad$ HAZCOM

\section{Technology Specific Training:}

- Scaffolding

- Asbestos worker

- Respiratory Protection

$\checkmark \quad$ Hearing Conservation

- Personal Protective Equipment

- Lockout/Tagout

\section{Special Training:}

- Job specific training for equipment operation

\section{Best Management Practice Training:}

- Ergonomics (proper lifting, bending, stooping, kneeling)

- Heat stress (learning to recognize signs and symptoms) 
- CPR/First Aid/Emergency Response/Bloodborne Pathogens

- Electrical Safety

- Crane/Hoisting Safety

- Hand Signal Communication

- Construction Safety (OSHA 500) and or General Industry Safety (OSHA 501)

\section{SECTION 6 - \\ OPERATIONAL CONSIDERATIONS AND RECOMMENDATIONS}

Recommendations made here for improved worker safety and health take into consideration that during the human factors assessment, the insulation BOA removed was calcium silicate. Assumptions made regarding asbestos will need to be confirmed at a later date when BOA is used to remove asbestos insulation.

\section{Equipment Set Up Phase}

- The vacuum, air, and water hoses needed to operate the BOA range in diameter from less than an inch to up to 5 inches and pose a significant tripping hazard. Given their integral role in the system, they can not be eliminated or easily re-engineered.

- Less cluttered deployment and better marking would be helpful. Good housekeeping practices are essential.

- The hooking of lines requires poor posture - stooping and also overhead reaching that can cause back problems, as well as stress/injury to knees, shoulders, arms, and neck. Ergonomic training to include proper lifting techniques is indicated.

- The cyclonic bagger (VecLoader) was purchased commercially. It has wheels that are only 32 inches apart while the top of the unit is also 32 inches wide. It is easy to rock the unit and, if placed on uneven ground, could pose a serious flipping hazard. The wheels should be at least 6 more inches apart. Operating procedures should not allow the unit to be placed on uneven ground.

- The water pump's wheels are fixed which makes it impossible to steer the unit without lifting it at some point - a serious stressor for the back. Re-engineering the wheels to allow movement necessary for steering would alleviate this concern. 
- The adapter that was designed for the end of the crane to lift the BOA cutting head out of its container uses clamps to secure the head during lifting. The design of these clamps does not prevent an accidental release. A heavier clamping mechanism with a locking device would help to prevent this.

- During the assessment, the crane for lifting the cutter head was mounted on a scissors man lift and held in place by C-clamps, a temporary solution. Additionally, the crane was positioned such that the operators had to hang over the man lift in order to make the connections. Using a manlift with an $8^{\prime} \times 10^{\prime}$ platform and the crane bolted in the center would allow operators to make the connections without hanging out of the lift, or working under the cutter head, which could disconnect and fall. Even with an ideal setup for a scissor lift, it means that placing the abatement head at a height requires the operation of three sets of controls: the lift, the crane on the lift, and the pendant for the abatement head. Considering a system that allows hoisting the unit in place with a pulley or some sort of ratcheting apparatus might be more appropriate.

- In moving the abatement head from the crane up to the pipe, or changing from the jack to crane, there needs to be some way to secure the head to the jack. During the demonstration it was setting on a block of wood. Any serious movement could cause this to fall.

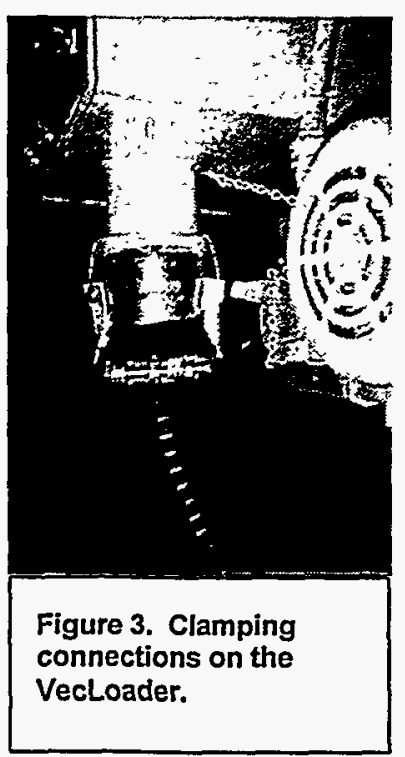

- The safety caps for the bagging unit are hanging on a chain at a height of nearly 6 feet. This means that hooking up the hoses requires working at a difficult height. The arrangement with hooking the clamps mean that fingers could be pinched. SOP's, which require the use of a platform to reach the connection, would help alleviate the height problem. The clamps need to be labeled as pinch points. 


\section{Equipment Operation Phase}

- The clamps that hold the abatement head to the pipe cannot be stopped in mid-cycle and the force of these clamps can sever a finger.

- The operator, if using the pendant control with both hands, would be guarded according to OSHA machine guarding requirements but there is a real danger to others performing maintenance or repair and additional guarding or at least additional warnings would be appropriate.

- When the high pressure water pump changes from spraying to cutting, or from cutting to spraying, the two 3 -inch hoses jerk as

the pressure changes. If the hoses released they could whip and hurt someone before the system was shut down. Adding safety straps to the connectors would significantly reduce this possibility.

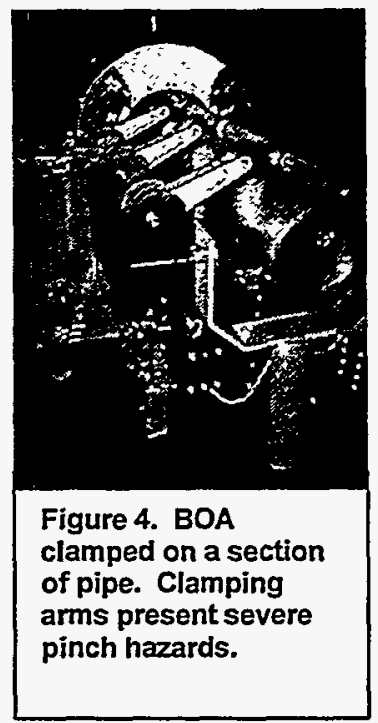

- The high pressure water pump has a cover that eliminates the possibility of hands being caught in the in-running nip points caused by the moving belt. There were several occasions when the pump was operated without the cover in place. An interlock that does not allow the pump to operate without the cover or a permanent guard inside the cover for the belt, would eliminate the possibility of serious injury to fingers.

- The cutter operates with high pressure water jets that can cut through metal and, therefore, flesh. However, the possibility of the jets coming on accidentally is quite low because with the unit open, the vacuum sensor would measure insufficient vacuum and not allow water to flow. This sensor operates quickly: within a half a second. A redundant interlock system that does not allow the water jets to spray when the abatement head is open would provide additional safety measures.

- The large vacuum unit should be operated outdoors and, if operated indoors, needs to have its diesel fumes exhausted outside and should be positioned to reduce noise exposure as much as possible. All noise readings for the vacuum unit exceeded the OSHA PEL level and would require hearing protection if workers needed to be in the area. Additionally, the exhaust of air from this unit could contain asbestos fibers if the filters are not properly placed - another reason to continue to operate outdoors.

\section{Bagging Operation}

- The BOA system abatement head automatically stops cutting after a certain number of oscillations of the locomotor. The cuttings are then sent to the bagging operation. 
The weight of materials being bagged can be standardized by the number of oscillations. During the human factors assessment, the setting was too high, according to the results of the NIOSH lifting calculation performed. The adjustments should be made for future work and incorporated into the SOP's.

- After the debris is deposited into the plastic bag, the operator had to manually twist the bag before sealing it with duct tape. This put additional stress on the operator. Some sort of "lazy Susan" apparatus for the bag to rest on could relieve this stress. In addition, a "lazy Susan" with wheels would provide a method for moving the bag to the waste collection area.

\section{Maintenance and Decontamination Phase}

- The abatement head is designed to provide a water wash of the inside of the head and then vacuum the residue away automatically. Any form of manual decontamination is not currently recommended. A visual inspection showed that materials did remain in the cutter head after the water wash. These materials could become dry after residing in the head in between removal jobs, releasing asbestos fibers when the abatement head is opened. Many asbestos abatement contracts require that the contractor not bring any equipment onto the job site that is contaminated. The current method for decontamination of the BOA head may not meet these requirements. A more complete flushing method may be needed.

- If cutting heads need to be changed after removal of the insulation has begun, the residue around the heads could become airborne. Additionally, the heads are sharp and should be handled with gloves to prevent cuts.

- Maintenance work on the abatement head will require a special work bench. The abatement head would be precariously balanced on a flat table. The bench should also be adjustable to prevent maintenance workers from having to bend over or assume abnormal or awkward positions.

\section{Emergency Situations}

- BOA has capabilities for alerting operators to emergency situations. There is a box near the cutting head that flashes with a bright strobe light whenever the head reaches an obstruction. The system automatically stops abatement and proceeds to encapsulate exposed surfaces.

- There is an emergency stop button on the electrical box that shuts down everything. There is also an emergency button on the pendant control unit. This provides the operator with the ability to immediately shut down the system. A vacuum is maintained in the system throughout any emergency shutdown. Even if the main vacuum unit goes down, the auxiliary HEPA vacuum will operate. 


\section{ADDENDUM}

On August 28, 1997, BOA was demonstrated on an outdoor pipe run located at the K25 facility at the Oak Ridge site. During the demonstration, calcium silicate insulation was removed from an out-of-doors pipe rack that was approximately 6 feet off of the ground. BOA was operated for approximately $30-45$ minutes. Changes that had been made since the human factors assessment covered by this report were evaluated during the demonstration.

During the current demonstration, the industrial hygiene department at Oak Ridge conducted air sampling for total dust. Information received from them indicates that the dust levels were below the level of detection.

When the human factors assessment of BOA was conducted at the Carnegie Mellon facility in June 1997, there were safety and health concerns associated with the use of a manlift with a jib-crane to lift the cutter head to an elevated pipe rack and with the clamps used to hold the cutter head onto the jib-crane. During the Oak Ridge demonstration, the jib-crane was attached to the forks of a forklift that was used to lift the cutter head to the pipe rack. The jib-crane was attached to the forks with large cclamps. There is concern that these c-clamps may not be tightened enough by hand, they may come loose during the lift, or they may be bumped and loosened before the lift is even started. This could present the opportunity for the entire structure (jib-crane and cutter head) to fall from the forks of the forklift as the move and lift are being made. If either or both fell and struck a worker, severe injury or a fatality are credible results. A better method would be to design equipment specifically for attaching the jib-crane to the forks of the forklift.

The clamps used to hold the head of the jib-crane (which then holds the cutter head) to the arm are not very substantial, nor did they have a locking mechanism to assure they would stay closed. There was concern during the human factors assessment that these could break and or easily be bumped and open. These same clamps with one modification were used during the Oak Ridge demonstration. The clamping mechanism itself had a wire secured around it. This wire would not allow the clamp to open or if it did open, the wire would hold the head to the arm until it could be placed in a safe position and repaired. There is still concern that the wire would not hold and something more substantial with a higher load rating would need to be used. It is also recommended that the clamps themselves be changed and a clamp with a higher load rating and a safety latching system built in be used.

One of the ergonomic concerns associated with the bagging operation had been addressed and on observation appeared to have greatly lessened the ergonomic stressors discussed in this report. The original concern was the bending and lifting the operator had to do to manually lift and twist the bag of waste before duct taping it shut. 
During the demonstration a "lazy-Susan" type of device with wheels was used, as recommended in this report. The bag was located on this device so that once the waste was dumped into the bag, the operator could turn the "lazy-Susan" without lifting the bag, tape the bag closed, remove the device with the bag on it to the waste accumulation area, and remove the bag from the device. This was a far superior method from an ergonomic standpoint for bagging and waste removal. Two further recommendations are made to further improve this operation: (1) attach an adjustable handle to the "lazy-Susan" to avoid having to bend over to push it out from under the bagging unit and to the waste accumulation site; and (2) use a mechanical materials handling device to remove the bag of waste from the "lazy-Susan". Both of these would continue to reduce ergonomic stressors (and therefore, injury) placed on the back.

Additionally, it is recommended that when BOA is used to remove asbestos insulation, air monitoring for asbestos should be conducted before the system is approved for use without worker respiratory protection and other associated PPE. 


\section{APPENDIX A \\ REFERENCES}

Occupational Safety and Health Standards for General Industry, 29 CFR Part 1910, Occupational Safety and Health Administration United States Department of Labor, 1995

Occupational Safety and Health Standards for the Construction Industry, 29 CFR Part 1926, Occupational Safety and Health Administration United States Department of Labor, 1995

Threshold Limit Values (TLVs) for Chemical Substances and Physical Agents and Biological Exposure Indices (BEls), American Conference of Governmental Industrial Hygienists, 1995-1996

U.S. Department of Health and Human Services, Public Health Services, Applications Manual for the Revised NIOSH Lifting Equation, DHHS (NIOSH) Publication No. 94110, January 1994

U.S. Department of Health and Human Services, Public Health Service, Center for Disease Control and Prevention, The NIOSH compendium of hearing protection devices, October 1994

Guidelines for Hazard Evaluation Procedures, Battelle Columbus Division, The Center for Chemical Process Safety, American Institute of Chemical Engineers, New York, 1985 
APPENDIX B

REAL-TIME MIE DATA RAM PARTICULATE MONITORING (PRE-BOA OPERATION)

\begin{tabular}{|c|c|c|c|c|c|}
\hline TIME & STATION & LOCATION & $\begin{array}{l}\text { Average } \\
\text { Reading } \\
\left(\mathrm{mg} / \mathrm{m}^{3}\right)\end{array}$ & $\begin{array}{l}\text { Standard } \\
\text { Deviation }\end{array}$ & $\begin{array}{l}\mathrm{CV} \\
(\%)\end{array}$ \\
\hline 0914 & 1 & $4^{\prime}$ from lower pipe run, 4 ' from floor & 0.048 & 0.007 & 15 \\
\hline 0922 & II & $\begin{array}{l}4^{\prime} \text { from center of bagging operation, } 4 \text { ' } \\
\text { from floor }\end{array}$ & 0.048 & 0.005 & 10 \\
\hline 0926 & III & Outdoors - $4^{\prime}$ from the large vacuum unit & 0.040 & 0.002 & 4 \\
\hline 0931 & IV & $\begin{array}{l}\text { Catwalk above pipe runs, } 10^{\prime} \text { above the } \\
\text { floor }\end{array}$ & 0.038 & 0.003 & 8 \\
\hline 0936 & 1 & $4^{\prime}$ from lower pipe run, 4 ' from floor & 0.032 & 0.003 & 10 \\
\hline 0940 & II & $\begin{array}{l}4^{\prime} \text { from center of bagging operation, } 4^{\prime} \\
\text { from floor }\end{array}$ & 0.036 & 0.007 & 18 \\
\hline 0945 & III & Outdoors $-4^{\prime}$ from the large vacuum unit & 0.038 & 0.004 & 11 \\
\hline
\end{tabular}




\section{APPENDIX B \\ MIE DATA RAM PARTICULATE MONITORING (BOA OPERATION)}

\begin{tabular}{|c|c|l|c|c|c|}
\hline TIME & STATION & \multicolumn{1}{|c|}{ LOCATION } & $\begin{array}{c}\text { Average } \\
\text { Reading } \\
\left(\mathrm{mg} / \mathrm{m}^{3}\right)\end{array}$ & $\begin{array}{c}\text { Maximum } \\
\text { reading } \\
\left(\mathrm{mg} / \mathrm{m}^{3}\right)\end{array}$ & $\begin{array}{c}\text { STEL } \\
\left(\mathrm{mg} / \mathrm{m}^{3}\right)\end{array}$ \\
\hline $\begin{array}{c}1455 \\
\text { June } \\
18\end{array}$ & 1 & $4^{\prime}$ from lower pipe run, 4' from floor & 0.043 & $\mathrm{n} / \mathrm{a}$ & $\mathrm{n} / \mathrm{a}$ \\
\hline $\begin{array}{c}1430 \\
1458\end{array}$ & personal & $\begin{array}{l}\text { sampler attached to Abe Crowley, } \\
\text { pendant control operator }\end{array}$ & 0.067 & 1.302 & 0.069 \\
\hline $\begin{array}{c}1025 \\
\text { June } \\
19\end{array}$ & $\mathrm{I}$ & $\begin{array}{l}\text { typical operator position during cutting } \\
\text { head operation. }\end{array}$ & 0.101 & 0.332 & 0.074 \\
\hline $\begin{array}{c}1035 \\
1031- \\
1056\end{array}$ & Personal & $\begin{array}{l}\text { typical operator position at bagging } \\
\text { operation }\end{array}$ & 0.095 & 0.123 & 0.074 \\
\hline \multicolumn{2}{|l|}{ sampler placed on Abe Crowley during } \\
\hline
\end{tabular}




\section{APPENDIX B}

TOTAL AND RESPIRABLE DUST SAMPLING RESULTS

\begin{tabular}{|c|c|c|c|}
\hline Sample Number & Location & $\begin{array}{l}\text { Total Mass } \\
\text { (mg) }\end{array}$ & $\begin{array}{l}\text { Results } \\
\left(\mathrm{mg} / \mathrm{m}^{3}\right)\end{array}$ \\
\hline $\begin{array}{l}061797-\mathrm{CMU}- \\
001\end{array}$ & $\begin{array}{l}\text { Total dust - background sampling. On } \\
\text { top of water filtration unit ( } 45^{\prime \prime} \text { from } \\
\text { floor) in area of VecLoader }\end{array}$ & $<0.04$ & $<0.30$ \\
\hline $\begin{array}{l}061797-\mathrm{CMU}- \\
002\end{array}$ & $\begin{array}{l}\text { Total dust - background. CMU high } \\
\text { bay, } 36^{\prime \prime} \text { high on railing behind low } \\
\text { pipe system. }\end{array}$ & $<0.04$ & $<0.90$ \\
\hline $\begin{array}{l}061797-\mathrm{CMU}- \\
003\end{array}$ & Blank & $<0.04$ & $\mathrm{n} / \mathrm{a}$ \\
\hline $\begin{array}{l}061797-\mathrm{CMU}- \\
004\end{array}$ & $\begin{array}{l}\text { Respirable dust - background. Left } \\
\text { side of VecLoader. }\end{array}$ & $<0.04$ & $<0.05$ \\
\hline $\begin{array}{l}061797-\mathrm{CMU}- \\
005\end{array}$ & $\begin{array}{l}\text { Respirable dust - background. } \\
\text { CMU high bay, } 67 " \text { off ground to left } \\
\text { of low pipe rack. }\end{array}$ & $<0.04$ & $<0.05$ \\
\hline $\begin{array}{l}061997-\mathrm{CMU}- \\
006\end{array}$ & Blank & $<0.04$ & $\mathrm{n} / \mathrm{a}$ \\
\hline $\begin{array}{l}061997-C M U- \\
007\end{array}$ & Blank & $<0.04$ & $\mathrm{n} / \mathrm{a}$ \\
\hline $\begin{array}{l}061997-C M U- \\
008\end{array}$ & $\begin{array}{l}\text { Respirable dust- during operation. } \\
\text { High bay area of left side of } \\
\text { VecLoader, } 60^{\prime \prime} \text { off ground. }\end{array}$ & $<0.04$ & $<0.3$ \\
\hline $\begin{array}{l}061997-\mathrm{CMU}- \\
009\end{array}$ & $\begin{array}{l}\text { Respirable dust - during operation. } \\
\text { On post immediately to left of } \\
\text { pipe/cutter head, } 66^{\prime \prime} \text { off ground. }\end{array}$ & $<0.04$ & $<0.3$ \\
\hline $\begin{array}{l}061997-\mathrm{CMU}- \\
010\end{array}$ & VOIDED SAMPLE & $<0.04$ & $\mathrm{n} / \mathrm{a}$ \\
\hline $\begin{array}{l}061997-\mathrm{CMU}- \\
011\end{array}$ & $\begin{array}{l}\text { Total dust - during operation. On top } \\
\text { of water filters in area of VecLoader }\end{array}$ & $<0.04$ & $<0.28$ \\
\hline $\begin{array}{l}061997-\mathrm{CMU}- \\
012\end{array}$ & Blank & $<0.04$ & $\mathrm{n} / \mathrm{a}$ \\
\hline $\begin{array}{l}061997-\mathrm{CMU} \\
013\end{array}$ & $\begin{array}{l}\text { Total dust - during operation. Railing } \\
\text { immediately behind pipe where BOA } \\
\text { was removing insulation (approx. } 3 \\
\text { feet above ground). }\end{array}$ & $<0.04$ & $<0.28$ \\
\hline
\end{tabular}




\section{APPENDIX B \\ VENTILATION FLOW MEASUREMENTS}

\begin{tabular}{|c|l|c|}
\hline DATE AND TIME & \multicolumn{1}{|c|}{ LOCATION } & $\begin{array}{c}\text { AIR VELOCITY } \\
\text { (feet per minute) }\end{array}$ \\
\hline June 18/1006 & Station I - 4' from the cutting head & 30 \\
\hline June 18/1009 & $\begin{array}{l}\text { Near lower pipe run, directly above the } \\
\text { stairwell }\end{array}$ & $200-400$ \\
\hline June 18/1012 & $\begin{array}{l}\text { Near lower pipe run, directly above the } \\
\text { elevator shaft }\end{array}$ & 250 \\
\hline June 18/1510 & $\begin{array}{l}\text { Immediately outside the opening between } \\
\text { the cutter head cover and the pipe insulation } \\
\text { while main vacuum was operating }\end{array}$ & $200-300$ \\
\hline June 19/1015 & $\begin{array}{l}\text { Immediately outside the opening between } \\
\text { cutter head cover and pipe insulation when } \\
\text { only the small auxiliary vacuum was running }\end{array}$ & \\
\hline
\end{tabular}




\section{APPENDIX C \\ PENDANT CONTROL BUTTONS LAYOUT}

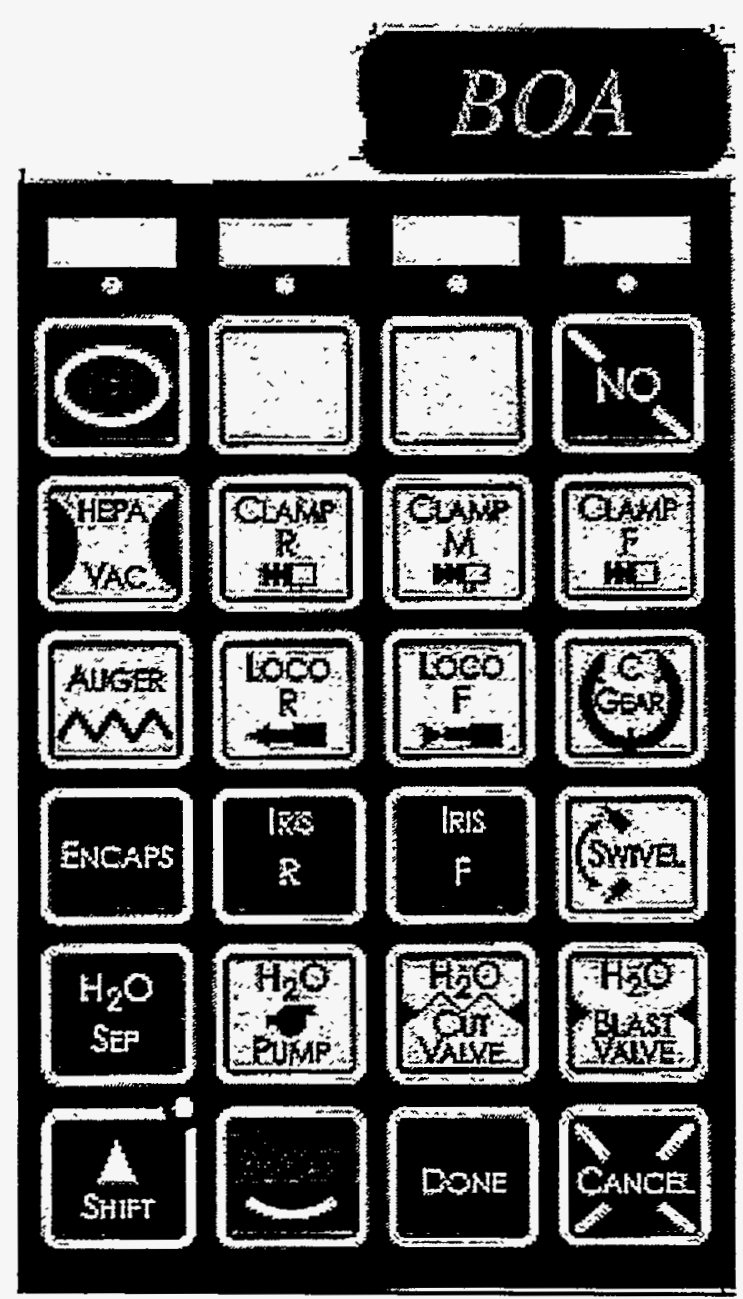




\section{APPENDIX D ACRONYMS}

$\begin{array}{lll}\text { ACGIH } & - & \text { American Conference of Governmental Industrial Hygienists } \\ \text { AIHA } & - & \text { American Industrial Hygiene Association } \\ \text { ANSI } & - & \text { American National Standards Institute } \\ \text { BOA } & - & \text { Big on Asbestos } \\ \text { CAS } & - & \text { chemical abstract system } \\ \text { cfm } & - & \text { cubic feet per minute } \\ \text { CFR } & - & \text { Code of Federal Regulations } \\ \text { CMU } & - & \text { Carnegie Mellon University } \\ \text { CV } & - & \text { coefficient of variation } \\ \text { DOE } & - & \text { Department of Energy } \\ \text { GFCl } & - & \text { ground fault circuit interrupter } \\ \text { EPA } & - & \text { Environmental Protection Agency } \\ \text { HAZCOM } & - & \text { Hazard Communication } \\ \text { HAZWOPER - } & \text { Hazardous Waste Operations and Emergency Response } \\ \text { HEPA } & - & \text { high efficiency particulate air filter } \\ \text { hZ } & - & \text { hertz } \\ \text { IR } & - & \text { infrared } \\ \text { LI } & - & \text { lifting index } \\ \text { MSDS } & - & \text { Material Safety Data Sheet } \\ \text { NFPA } & - & \text { National Fire Protection Association } \\ \text { NIOSH } & - & \text { National Institute of Occupational Safety and Health } \\ \text { OD } & - & \text { outside diameter } \\ \text { OENHP } & - & \text { Operating Engineers National Hazmat Program } \\ \text { OSHA } & - & \text { Occupational Health and Safety Administration } \\ \text { PEL } & - & \text { permissible exposure limit } \\ \text { PPE } & - & \text { personal protective equipment } \\ \text { RIA } & - & \text { Robotics Institute of America } \\ \text { RWL } & - & \text { recommended weight limit } \\ \text { SOP's } & - & \text { standard operating procedures } \\ \text { STEL } & - & \text { short term exposure limits } \\ \text { TLV } & - & \text { threshold limit value } \\ \text { TSI } & - & \text { thermal system insulation } \\ \text { TWA } & - & \text { time weighted average } \\ & & \end{array}$




\section{UNIVERSITY OF SOUTH CAROLINA CYBERMOTION, INC. A ROBOTIC INSPECTION EXPERIMENTAL SYSTEM (ARIES) TABLE OF CONTENTS}

ACKNOWLEDGEMENTS iii

EXECUTIVE SUMMARY iv

SECTION 1 SUMMARY 1

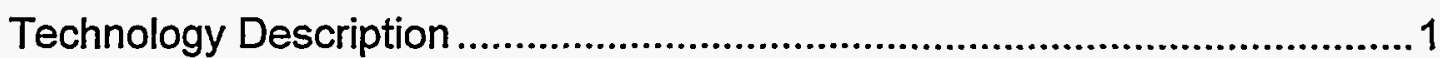

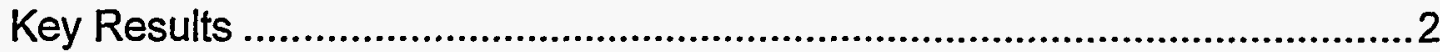

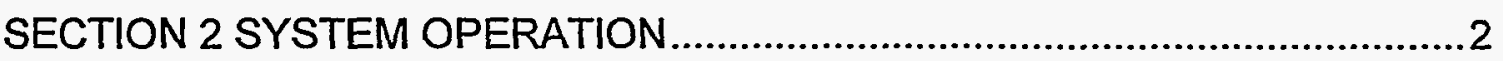

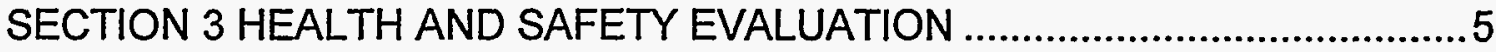

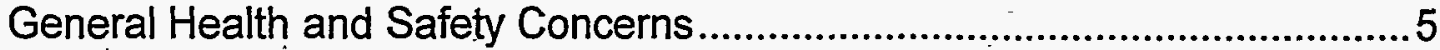

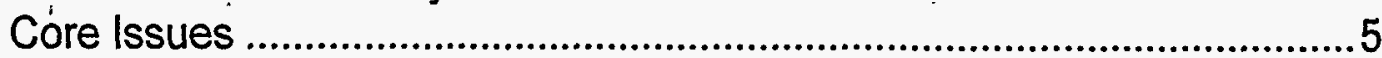

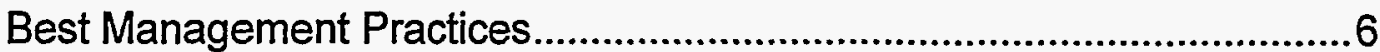

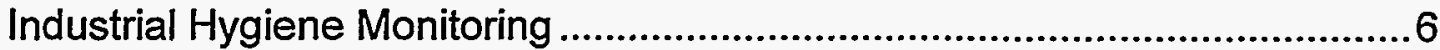

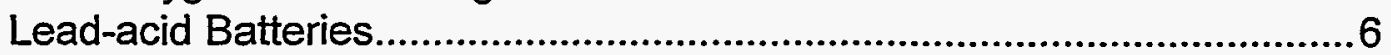

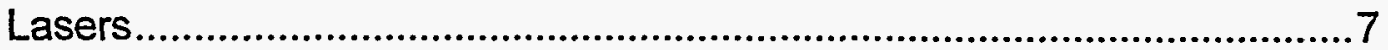

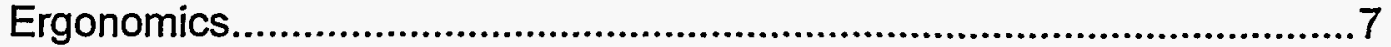

Review of Existing Documentation ............................................................. 8

Software and Hardware Considerations .....................................................

Human Factors Interface ....................................................................... 10

Technology Applicability .......................................................................12

SECTION 4 EMERGENCY RESPONSE/PREPAREDNESS ........................14

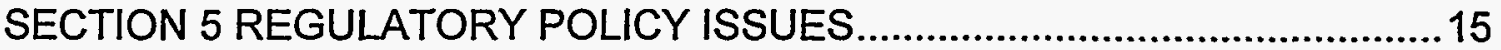

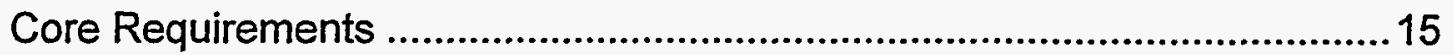

Technology Specific Requirements .........................................................16

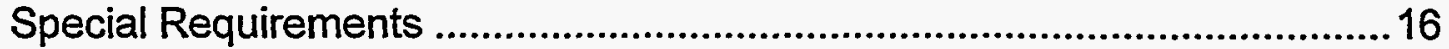

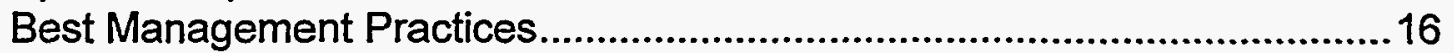

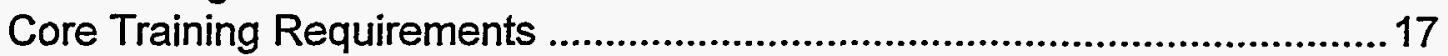

Technology Specific Training ................................................................... 17 


\section{TABLE OF CONTENTS (CONTINUED)}

Special Training

SECTION 6 OPERATIONAL CONSIDERATIONS AND

RECOMMENDATIONS

APPENDIX A - REFERENCES

APPENDIX B - ACRONYMS 


\section{ACKNOWLEDGEMENTS}

The human factors assessment of Cybermotion, Inc.'s A Robotic Inspection Experimental System (ARIES), was conducted under support of the U.S. Department of Energy's Federal Energy Technology Center, under cooperative agreement DE-FC21$95 \mathrm{MC} 32260$ with the Operating Engineers National Hazmat Program. The Operating Engineers National Hazmat Program would like to thank the following people for their participation on the "research action team" and the professional expertise they provided for this assessment:

Barbara McCabe

Pat Bell

Robert Harrold

David Mullins

Tony Szwiliski

Aktar Lodger

Tracy Smith
Operating Engineers National Hazmat Program Operating Engineers National Hazmat Program Operating Engineers National Hazmat Program Operating Engineers Local Union 132

Contractor to OENHP (Marshall University) Contractor to OENHP (Marshall University) Contractor to OENHP (Marshall University) 


\section{EXECUTIVE SUMMARY}

The ARIES robotic drum inspection robot designed by Cybermotion, Inc. was assessed for "human factors" by a team from the Operating Engineers National Hazmat Program. ARIES was developed for the Department of Energy (DOE) to remove the worker from the potentially hazardous environment encountered during the routine inspection of drums used to store radioactive waste. There are currently over 315,000 drum equivalents of Mixed, Tru-Mixed, and Low-Level waste accumulated at DOE sites. Mixed waste, due to its hazardous constituents, is covered under the Resource Conservation and Recovery Act (RCRA) regulations which outline a requirement for a weekly inspection of drums and facilities. In addition, DOE and Environmental Protection Agency (EPA) requirements mandate regular inspections.

At the present time, workers walk through the aisles where the drums are stored and visually inspect the drums for discoloration, paint blisters, dents, bulging, and rusting. This is a less than efficient method to conduct inspections and creates the potential to expose workers to radioactive waste. The robot will roam the aisles of 55-gallon drums, stacked three high, making decisions about the surface condition of the drums and maintaining a database of information about each drum. The robot will locate and identify each drum, characterize relevant surface features, and update a database containing inspection information. A camera positioning system positions the vision camera and any other required instrumentation packages (bar-code reader, etc.) to perform the inspection process for each drum. It is anticipated that the mobile robot system will improve the quality of inspection and generate required reports in addition to relieving workers from potential low-level radioactive exposure and contamination hazards. Workers will be required for computer operations, maintenance of the system and its components, and decontamination, when necessary.

The robot itself does not generate any airborne hazards that require exposure monitoring. Exposure monitoring requirements will be dependent on the environment where ARIES is operating. This will need to be determined by the site characterization and air monitoring plan.

The use of sealed lead-acid batteries to power the robot presents an exposure potential for workers. Under normal circumstances there should not be any exposure to the hazardous constituents of the battery but the potential for exposure to lead and lead contaminated sulfuric acid must be realized and proper precautions must be used. This may include handling the batteries utilizing personal protective equipment (PPE), when appropriate, training personnel in the hazards associated with lead-acid batteries, and proper storage and waste disposal. Additionally, there is the possibility of the production of hydrogen gas during the charging of lead-acid batteries. Due to the flammable and explosive properties of hydrogen, this needs to be taken into consideration when the location of the charging station is chosen. 
ARIES uses a Class IIlb (less than) $100 \mathrm{~mW} 600-1550 \mathrm{~mm}$ wave length diode laser. The laser is mounted on the mast and is used in the laser-based lidar navigation beacon system. Direct viewing as well as diffuse reflection of the beam of a Class IIlb laser such as the one used on ARIES is hazardous to the eye, especially to the retina. The laser should never be viewed directly or with any type of telescopic device.

Ergonomic stressors are associated with the crating, uncrating, unloading, and loading of the components for ARIES. Of particular concern is the robot mast. The mast weighs approximately 300 pounds. This has the potential to cause severe back injury to workers from lifting, bending, and carrying the mast. A crate or container or a transport vehicle needs to be developed that will allow the mast to be lifted, carried, and set on the robot base strictly by mechanical means, such as a forklift.

Cybermotion has not completed the minimal amount of documentation on ARIES that is recommended by the Robotic Industries Association (RIA). Critical documents, such as standard operating procedures (SOP's) and maintenance procedures, will enlarge the understanding of worker risks and protection.

The computer system used to operate the robot and the associated software does not distinguish between types of users or levels of security levels. Three user levels are recommended: 1 . the expert, who is the person that knows the details of the operation of the robot, its programming, and the internal hardware; 2 . the programmer, who is the person that programs the aisle path, location of the fiduciaries, etc.; and 3. the operator, who will start the robot operation for each mission, after which the robot will perform its tasks. Additionally, analysis, design, testing, and other appropriate architecture diagrams and documentation need to be developed for the internals of the Site Manager software.

During the human factors assessment, the collision avoidance system was assessed. It was found that the system works adequately as long as the obstacle is not too short or too far off to the side. It needs to be assured that workers in the area are aware of the "blind spots" for the collision avoidance system and that they take appropriate precautions.

There are decontamination issues with ARIES that may keep it from being "clean" enough to be removed from the area. Areas of concern on the base include the cooling fan for the on board computers and the access doors for areas such as the on board computers and the batteries. Due to the design of the mast and its camera payload arm, it appears to be virtually impossible to decontaminate this section of the robot. Water cannot be used to decontaminate this part of the robot because of all of the open electrical connections and wiring. Where the wiring, chains, and belts run through conduit, the conduit is an open design. 
The robot has a current limit and stall servo kickout feature if it runs into an object and cannot continue forward. It does not have a similar feature for tipping avoidance. The center of gravity for the robot is not known and therefore, there is not enough information to determine when the robot could tip and thereby cause injury to workers or damage to the drums. The center of gravity needs to be calculated and a stall servo kickout feature for angle of operation needs to be incorporated. 


\section{UNIVERSITY OF SOUTH CAROLINA CYBERMOTION, INC. A ROBOTIC INSPECTION EXPERIMENTAL SYSTEM (ARIES)}

\section{SECTION 1 - SUMMARY}

\section{TECHNOLOGY DESCRIPTION}

A team from the Operating Engineers National Hazmat Program (OENHP) conducted a human factors assessment of A Robotic Inspection Experimental System (ARIES ${ }^{1}$ ), a robotic technology developed by Cybermotion, Inc. The main focus of the assessment was the human factors issues associated with the installation, operation, maintenance, and decontamination of this robotic equipment developed to inspect drums.

Currently, there are over 315,000 drum equivalents of Mixed, TRU-Mixed, and LowLevel waste accumulated at Department of Energy (DOE) sites. Most of this waste is stored above ground in drums or other containers stacked in rows in warehouses at DOE facilities. Mixed waste, due to its hazardous constituents, is covered under the Resource Conservation and Recovery Act (RCRA) regulations which outline a requirement for a weekly inspection of drums and facilities. In addition, DOE and Environmental Protection Agency (EPA) requirements mandate regular inspections.

The development of a mobile robot system, such as ARIES, for the automation of visual inspection provides several benefits. These benefits include a decreased risk, a decreased radiation dose to workers, and increased consistency of inspections.

The mobile robot inspection system, ARIES, has been developed for the DOE to remove workers from the potentially hazardous environment encountered during the routine inspection of drums used to store radioactive waste. The robot will roam the three-foot wide aisles of 55-gallon drums, stacked three high, making decisions abut the surface condition of the drums and maintaining a database of information abut each drum.

\footnotetext{
'ARIES is the commercialized product of a three-phase contract, No. DE-AC21-92MC29115, awarded by FETC to SCUREF (South Carolina Universities Research and Educational Foundation). This project team involved the University of South Carolina, Clemson University, and Cybermotion, Inc.
} 
The robot system will locate and identify each drum, characterize relevant surface features (such as paint blisters, dents, rusted areas, etc.), and update a database

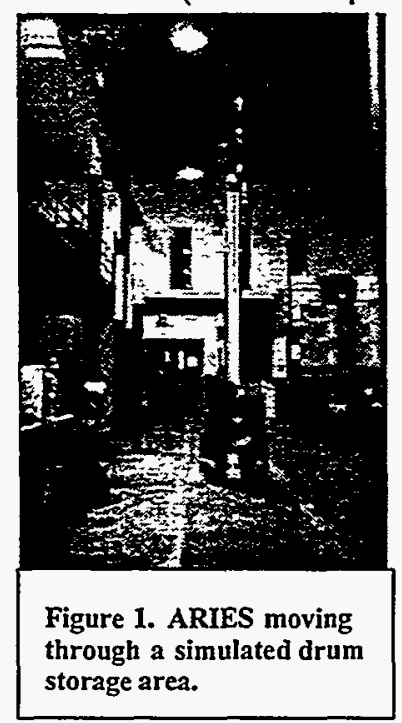
containing inspection information. A camera positioning system (CPS) positions the vision camera and any other required instrumentation packages (bar-code reader, etc.) to perform the inspection process for each drum. It is anticipated that this mobile robot system, based on a commercial mobile platform, will improve the quality of inspection, generate required reports, and relieve workers from potential low-level radioactive exposure and contamination hazards. Workers will be required for computer operations, maintenance of the system and its components, and decontamination, when necessary.

\section{KEY RESULTS}

The safety and health evaluation during the human factors assessment found several areas of concern. These areas, which will be discussed in detail in later sections of this report, include issues related to ergonomics, laser hazards, tripping hazards, fall-fromabove hazards, struck-by hazards, electrical hazards, and decontamination of the system.

\section{SECTION 2 - SYSTEM OPERATION}

The mobile robot inspection system, ARIES, has been developed for the DOE to remove workers from the potentially hazardous environment encountered during the routine inspection of drums used to store radioactive waste. The robot will roam the three-foot wide aisles of 55-gallon drums, stacked three high, making decisions about the surface condition of the.drums and maintaining a database of information about each drum. The robot system will locate and identify each drum, characterize relevant surface features (such as paint blisters, dents, rusted areas, etc.), and update a database containing inspection information. The CPS positions the vision camera and any other required instrumentation packages (bar-code reader, etc.) to perform the inspection process for each drum. It is anticipated that this mobile robot system, based on a commercial mobile platform, will improve the quality of inspection, generate required reports, and relieve workers from potential low-level radioactive exposure and contamination hazards. Workers will be required for computer operations, maintenance of the system and its components, and decontamination, when necessary. 
Cybermotion developed a new version of their commercial Navmaster Series vehicle for ARIES. The robot consists of a 6 -wheeled K3A mobile platform, a compact subturret, a sonar (sound navigation and ranging) imaging system, a laser-based lidar (light detection and ranging) navigation beacon system, and a camera positioning system. It has a sonar imaging system used in navigation and collision avoidance and an automatic docking/charging system. Drum-referencing algorithms and camerapositioning algorithms have been included in the primitive instruction set for the robot. The vehicle for the mobile autonomous robot is commercially available, and is capable of unsupervised navigation in a variety of semi-structured environments. The robot's navigation is based on "SynchroDrive," a patented design that utilizes concentric shafts to distribute drive and steering power to the six wheels simultaneously. This gives the vehicle an ability to dead-reckon its navigation with good accuracy to any given locale

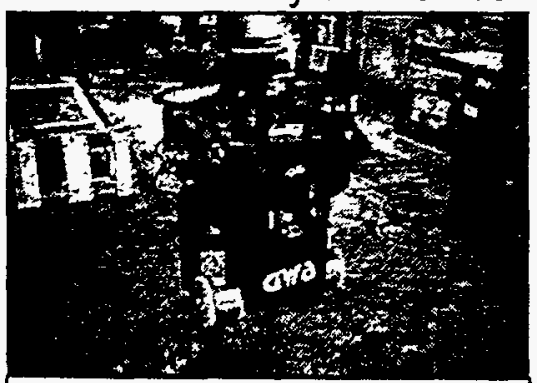

Figure 2. The 6-wheeled K3A subturret. over rough and dynamic indoor terrain. The K3A platform is equipped with several onboard and offboard computers. The navigation computer is located in the vehicle base and manages the drive and steering functions. The collision avoidance computer resides in the movable turret and oversees the data acquisition from eight ultrasonic transducers (also located in the turret).

ARIES uses a virtual path concept in which only a limited amount of information needs to be provided to the control computer in order to get the vehicle moving. Low-level, sensor and computing hardware. The vehicle updates its estimated position in a Cartesian coordinate plane with every 0.07 inches that it travels regardless of how locomotion is obtained. While navigating a path, the PID drive and steering controllers are initiated every 0.1 seconds to correct any perceived errors accumulated as the vehicle travels. Referencing instructions provide dynamic navigational corrections to the vehicle by referencing the system to walls, halls, doorways, etc.

The additional special computer systems for ARIES consist of an onboard management system and an offboard supervisory system. The onboard system, housed in the robot subturret, provides control of the inspection processes and manages other onboard activities. Low-level primitive instructions used by the drum navigation algorithms have been added to the instruction set of the K3A. The onboard computers are essentially transparent to the operator during autonomous operations. Standard UNIX workstations are used for the offboard supervisory computers. The software is written to be portable across most UNIX systems and currently runs on Silicon Graphics, DEC, $H P$, and Sun workstations. Silicon Graphics systems are used for development purposes and some 3-D features require this system for acceptable performance. Provisions have been made for alternative representations in other systems. The offboard system provides three primary functions: (i) functional compatibility with the PC-based software provided by Cybermotion for control and programming of the basic 
robot, (ii) programming tools for creating the mission program, and (iii) the ability to monitor and control the robot during the inspection process. An assembler for the virtual path language of the robot has been provided. This assembler operates in the DOS and UNIX environment. The offboard computers are used by operators for mission setup, monitoring, and control when human interaction is necessary.

Offboard computers networked via wireless Ethernet with onboard computers provide the high-level planning, monitoring, reporting, and general supervision of ARIES. Multiple control and monitoring stations may be employed. Planning the inspection task (the mission) begins with the implementation of a world representation of the robot's environment (the Robot World).

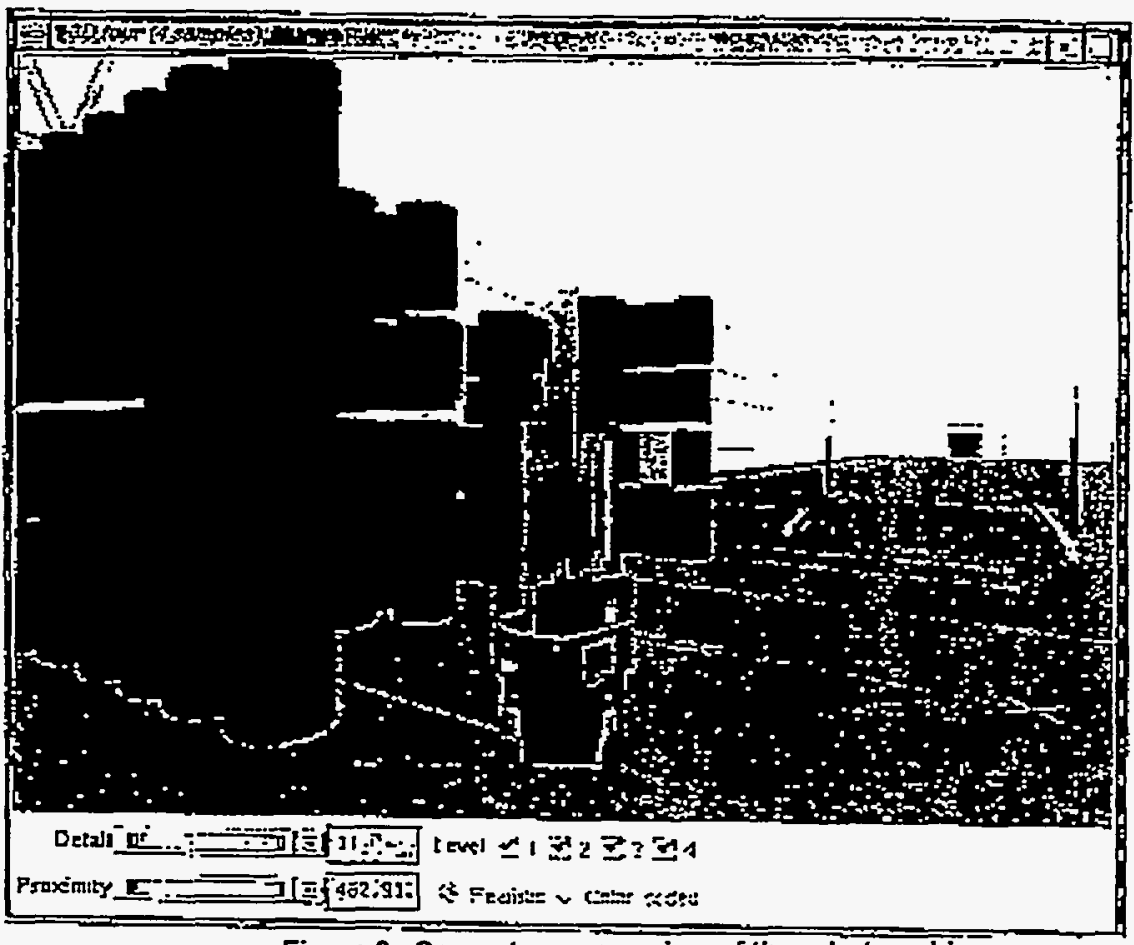

Figure 3. Computer screen view of the robot world.

A path planner automatically generates robot path programs for user-specified paths, based on the site description contained in the robot world. The mission program, used to control the inspection process, is downloaded from the offboard system to the onboard computer where it is executed. The offboard systems may be used to monitor and control the system during the inspection process.

The mission represents the system description of the tasks to be performed by the robot. The mission is created by the Site Manager (mission planning), down-loaded to the robot (mission assignment), and executed by the onboard Mission Controller. The Site Manager may be used off-line to plan and create a mission or on-line to control 
and/or monitor the operation of the robot. It is the user's primary access to the system at the task level. The Mission Controller is charged with the task of carrying out the mission. It is a peer of the Site Manager in that it receives the mission from the Site Manager. However, it is primarily a real-time program, since it directly controls the robot during the survey. The mission consists of (i) the mission script, a high-level description of the mission used by the onboard Mission Controller; (ii) the Path Library, a set of path programs that may be used to travel between the nodes included in the survey area; and (iii) a local copy of the drum list.

The mobile platform transports an inspection application payload that includes a mechanical fixed-mast deployment system, the CPS. The inspection payload consists of color and black and white cameras, bar-code scanner, and strobe lighting. For the drum inspection process, at each stack of drums (three drums in height) the CPS deploys the inspection module at various heights on the drums required by the vision system. A major component of the inspection module is the vision system. It is used to analyze the drums' external and visible conditions and to determine their structural integrity. The overall function of the vision module is to locate suspect drums and to report their condition. Once drums have been located by the robot's navigation system, visual assessment of drum condition is primarily an autonomous assessment of visible and quantifiable surface characteristics. The visible surface blemishes which indicate the possibility of drum failure are rust patches of approximately $0.5 \times 0.5$ inch size and paint blisters indicating internal surface rust. These inspection criteria were developed for ARIES by a task specific work group of the DOE Mixed Waste Focus Area (MWFA).

\section{SECTION 3 - HEALTH AND SAFETY EVALUATION}

\section{GENERAL HEALTH AND SAFETY CONCERNS}

Personnel where ARIES is being used need to be concerned with safety and health issues. Issues that personnel need to be cognizant of may be divided into two categories. Core issues are those that are based on current safety and health regulatory requirements. Best management practices are related to issues that are not based on current safety and health regulations but are key elements in preventing worker injury and illness on the job.

Safety and health issues of concern with ARIES included:

\section{Core Issues:}

Tripping hazards - The fiduciaries used for robot navigation are tripping hazards. In addition, they are easily moved, by tripping on them, which could cause navigational problems for the robot. 
Electrical hazards - There are electrical hazards associated with the charging station and the lead-acid batteries. Proper lockout/tagout procedures need to be applied before any maintenance activities are performed.

\section{Best Management Practices:}

Laser - There are hazards associated with the Class llib laser used on ARIES.

Tipping hazards - There is the potential for the robot to tip and fall on or strike personnel or strike a drum of waste.

Fall-from-above hazards - There is the potential for fall-from-above hazards from the robot striking an object and knocking it onto personnel or other drums.

Struck-by hazards - There is potential for struck-by hazards from the robot running into personnel in the area as well as running into other objects which may then become a struck-by hazard for personnel.

Ergonomics - There is the potential for severe back injury during the loading and unloading of the ARIES system from the transport vehicle. This will be discussed in greater detail in the Industrial Hygiene section of this report.

\section{INDUSTRIAL.HYGIENE MONITORING}

Exposure monitoring requirements will be dependent on the environment where ARIES is operating. This will be determined by the site characterization and air monitoring plan. There are however, areas of concern that are directly related to ARIES itself. This includes lead-acid batteries, lasers, and ergonomics.

\section{Lead-acid Batteries}

The batteries used to power the base of the robot are 12 volt $85 \mathrm{amp}$. sealed lead-acid. Under normal circumstances there should not be any exposure to the hazardous constituents of the battery but the potential for exposure to lead and lead contaminated sulfuric acid must be realized and proper precautions must be used. Proper precautions may include handling the batteries utilizing personal protective equipment (PPE), when appropriate, training personnel in the hazards associated with lead-acid batteries, and proper storage and waste disposal. In 1985, the EPA declared lead-acid batteries to be hazardous waste. Therefore, these batteries must be disposed of using the proper procedures for the disposal of hazardous waste. The lead-acid batteries need to be stored in a water tight, impermeable, curbed surface area. Additionally, there is the possibility of the production of hydrogen gas during the charging of leadacid batteries. Due to the flammable and explosive properties of hydrogen, this needs 
to be taken into consideration when the location of the charging station is chosen. There should be no open flame or external ignition sources in the area of the charging station.

\section{Lasers}

Lasers are classified to describe the capabilities of the laser system to produce injury to personnel. This classification rates lasers from Class I lasers (no harm) to Class IV lasers. ARIES uses a Class IIlb (less than) $100 \mathrm{~mW} 600-1550 \mathrm{~mm}$ wavelength diode laser. The laser is mounted on the mast and is used in the laser-based light detection and ranging (lidar) navigation beacon system. Direct viewing as well as diffuse reflections of the beam of the Class Illb laser used on ARIES is hazardous to the eye, in particular to the retina. The laser should never be viewed directly or with any type of telescopic device. Persons working in an area where there is the potential to be in direct view or reflected view of the laser beam need to use goggles developed specifically for laser use. In addition, all persons working with or performing any type of maintenance activities on the laser must be trained in laser safety.

\section{Ergonomics}

General observational techniques were used to assess the ergonomic stressors associated with ARIES. The observations included:

- The robot, including the base with subturret and mast, and the associated system components must be loaded and unloaded from the transport vehicle. The base of the robot with the subturret can be manually "walked" off of or on to the vehicle but the mast and all other components must be hand-carried. The main concern is the mast. The mast, which weighs approximately 300 pounds, is contained in a wooden crate-like structure which is used to carry it. Although there are handles located on the crate for carrying, there is a great potential for severe back injury and/or injury to the shoulders/arms/hands from workers having to lift and carry this amount of weight. A crate or container or a transport vehicle needs to be developed that will allow the mast to be lifted and carried strictly by mechanical means, such as a forklift.

There is also the potential for ergonomic stressors to the back and shoulders/arms/hands from lifting and carrying other system components. Placing these components on pallets to facilitate lifting and moving them with a forklift would alleviate many of these stressors.

- Uncrating/crating the mast may require bending, lifting, stooping, and/or kneeling. These activities increase the ergonomic stressors placed on the back, legs, knees, shoulders, and arms. Additionally, uncrating/crating requires the crate to be 
disassembled from around or assembled around the mast. This requires removing/placing of screws and nails, which at times are in difficult to reach locations. Bolts with wing nuts would be easier to reach and maneuver. A system that would allow the crate be raised and/or lowered would eliminate the need for all of the bending, stooping, kneeling.

\section{REVIEW OF EXISTING DOCUMENTATION}

The Robotic Industries Association (RIA) has identified the following as important documents from the manufacturer. The following review was conducted during the human factors assessment of ARIES.

\section{Document}

1. Function and location of all controls

2. Robot specifications, including range and load capacity

3. Limiting device information

4. Number, location, and degree of adjustment of hard stops

5. Number and location of control reliable limiting means

6. Lifting procedures and precautions

7. Precautionary information

8. Operating instructions

9. Maintenance and repair information, including preventive maintenance schedules

10. Information required for installation

11. Special environmental requirements

12. Electrical requirements

13. Lockout procedures

14. Failure mode analysis information $\bigotimes$

15. Hazard analysis and description of all hazard controls

\section{Available}

Yes No N/A Under development

冈

囚 $\quad \square \quad \square$

区

凶

冈 $\quad \square \quad \square$

凶

冈

凶

$\begin{array}{llll}\square & 凶 & \square & \square \\ 凶 & \square & \square & \square \\ \square & 凶 & \square & \square \\ \square & 凶 & \square & \square \\ \square & 凶 & \square & \square\end{array}$

区

The OENHP evaluations of Type III, robotic technologies requires the following be reviewed in addition to the previous list. 
1. Training manuals and training requirements

2. Health and safety plan

3. Job Safety Analysis

4. Operations Manual

5. Maintenance Manual

6. Software listing

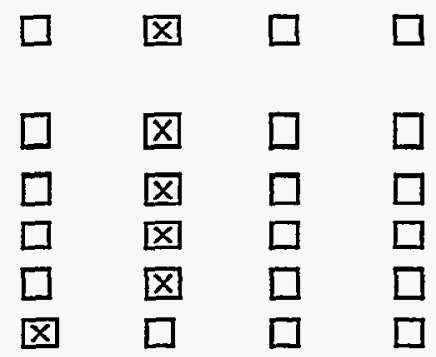

\section{SOFTWARE AND HARDWARE CONSIDERATIONS}

During the human factors assessment, the software and hardware required for the operation of ARIES was assessed. The following comments and recommendations are made with regard to this:

- From the perspective of software usage, it was evident that three types of users will exist for the system: (1) the expert, who is the person that knows the details of the operation of the robot, its programming and the internal hardware. This may be a representative of the developer; (2) the programmer, who is the person that programs the aisle paths, location of the fiduciaries, etc. This person must have the knowledge (training) required to use the "Site Manager" and other software provided by the developer to program the path and normal.operational features of the robot. This person may have limited knowledge of the internal workings of the robot, internal programming details such as UNIX codes; and (3) the operator, who will start the robot operation for each mission, after which the robot will perform its tasks. If the robot stalls, the operator would take it out to a safe location and report the incident to the supervisor. The operator would not be required to have any knowledge of the software/hardware aspects of the robot.

The programs (Site Manager) did not distinguish between users and there was not any "levels of security " feature in the software. This would allow anyone logging into the system to have access to all features with the possibility of someone changing/modifying data inadvertently. This could lead to the robot functioning differently than expected and the results could lead to events with the potential for causing accidents and worker injury. It is recommended that the different user levels be defined, either as above or otherwise, and appropriate levels of security be provided for each.

- During the human factors assessment, the Site Manager was demonstrated to the research action team. It was evident that many of the features of the user interface were not very "user friendly". For example, the process of entering the robot path points and fiducial points, the inability to see the path sequence, and the inability to conduct a simulated (computer generated) run. Due to this, several tasks conducted 
by the user (programmer level, as described above), were tedious. As a result of this tedium, there is the potential for the user to make mistakes, resulting in a possible incorrect path for the robot, resulting in a safety/hazard situation. It is recommended that a careful analysis of the user interface be conducted to increase its "user-friendliness" from an operational perspective.

- The robot has internal default values, such as motor speed, which can be set using the software, Site Manager. However, Site Manager does not provide an easy way to either view the default settings or modify them. This may cause incorrect paths for the robot which may result in safety/hazard situations. It is recommended that the software be programmed to allow viewing of the appropriate robot default settings and/or modifications.

- During the human factors assessment, it was indicated that the robot hardware, through its internal software, has many "lockout" features and is not dependent on external software for safety lockouts. Some of these features were demonstrated during the human factors assessment, stalling when encountering an object too small for the sonar to recognize but too large for the robot to go over and speed control during path movements. Other lockout features need to be assessed before ARIES is deployed at a facility.

- During the human factors assessment, it was indicated that there has not been any analysis, design, testing, or other architecture diagrams and documentation conducted for the internals of the Site Manager software. It is recommended that design and testing documentation be created for future use.

\section{HUMAN FACTORS INTERFACE}

From the perspective of software usage and the human interface with the operation of ARIES, three levels of users have been identified and suggested by the current human factors assessment. The three suggested levels are (1) the expert who knows the details of the operation of the robot, its programming, and the internal hardware; (2) the programmer who programs the aisle paths, location of the fiduciaries, etc.; and (3) the operator who starts the robot operation for each mission.

The Site Manager software, which was demonstrated during the human factors assessment, was not considered to be very "user friendly". For example, the process of entering the robot path and fiducial points, the inability to see the path sequence, and the inability to conduct a simulated run prior to the actual event increased the level of difficulty of using the software to operate ARIES. In addition, this caused several of the tasks to be tedious. This tedium increases the potential for the user to make mistakes which could result in a safety/hazard situation. 
An additional area of concern with the system software and human factors interface issues involves the analysis, design, testing, and architecture diagrams and documentation. These have not been developed and there is concern that this could lead to human error which may result in a safety/hazard situation.

ARIES is capable of being manually controlled should the need arise. A manual control pendant can be attached to the base of the robot which is then controlled by a "joy-stick" type control lever. This is a basic operation for moving the robot forward/backward/side-to-side in case of computer operation shutdown. An issue of importance for manual operation is that the sonar capabilities for sensing obstructions in its path is disabled. The operator manually moving ARIES needs to be aware of this and take proper precautions to not run into anyone or anything. The operator must assure he/she has clear visibility of the robots path as it is being removed from one area to another area. Additionally, it may be necessary for the operator to enter the area where ARIES has stopped. This area may be contaminated and therefore, the operator will need to enter utilizing the proper PPE. This has the potential to cause a decrease in visibility due to the use of a full face respirator and a decrease in dexterity and tactile sensation due to the use of radiation/chemical protective gloves. This needs to be taken into consideration and proper precautions used. If ARIES is used in an area where the site characterization has shown chemical protective garments, including gloves to be necessary upon entering the area, consideration should be given to a design change for the manual operating pendant. This should include a larger "joystick" control to accommodate the decrease in dexterity and tactile sensation caused by wearing the gloves.

Several maintenance tasks were conducted during the human factors assessment. This included changing the filter on the charging station, changing the prong on the charging station, and changing the lead-acid batteries in the robot base. These activities were conducted with the operator wearing no gloves (Level D protection), gloves commonly used with an Anti-C (radiation protection) ensemble, and gloves commonly used with a Level $B$ (chemical protection) ensemble. Changing the filter on the charging station and changing the lead-acid batteries was not a problem with any of these types of protection. Although changing the lead-acid batteries was not difficult, there were other concerns. These concerns were with electrical hazards and ergonomics which will be discussed in greater detail in other sections of this report. Changing the prong on the charging station was difficult without any gloves and with the Anti-C gloves, and impossible with the Level B gloves. The space to reach into to unscrew the nuts (which were small) is very tight. This, in addition to the decrease in manual dexterity and tactile sensation, made the task impossible. Replacing the nuts with a wing-nut would make the task easier regardless of the type of glove that must be worn. 


\section{TECHNOLOGY APPLICABILITY}

ARIES' mission involves navigating through narrow aisles (typically 36 inches) to inspect drums stacked three high. This does not allow much room for collision avoidance maneuvers. Collision with an object has the potential to stall or tip the robot or the robot may run over the object. This in and of itself, the robot striking a drum or the object striking a drum, has the potential to cause a release and therefore, a spill and/or exposure to contaminants. Additionally, injury may be caused by workers being struck by falling objects.

During the human factors assessment the collision avoidance capabilities of ARIES were assessed by placing objects of various size and shape in the robot's path. The collision avoidance was assessed in both the manual mode and autonomous mode of operation. The objects placed in the path and the robot's reaction to these during autonomous operation are as follows:

\begin{tabular}{|c|c|c|}
\hline Object & Object Dimensions & $\therefore$ Robot Action \\
\hline traffic cone & $3^{\prime}$ high with $16^{\prime \prime}$ wide base & saw the cone and stopped \\
\hline delineator pole & $3^{\prime} 9^{\prime \prime}$ high with $4 \frac{1}{2}{ }^{n} \times 6^{\prime \prime}$ base & saw the delineator and stopped \\
\hline wooden peg & $6^{\prime \prime}$ high & hit and pushed \\
\hline brick (lying flat) & $23 / 16^{\prime \prime} \times 7^{n} \times 3 \frac{1}{2 n}$ & hit and stalled \\
\hline delineator pole base & $41 / 2^{n} \times 6^{\prime \prime}$ & hit and stalled \\
\hline $\begin{array}{l}\text { delineator pole (sticking } \\
\text { perpendicularly into aisle } \\
\text { at } 38^{\prime \prime} \text { from floor) }\end{array}$ & & did not see, ran into \\
\hline legal pad & $81 / 2^{n} \times 11 \frac{134^{n}}{11 / 2} 2^{n}$ & did not see, ran over \\
\hline wooden base & $1 / 2 n$ high & hit and stalled \\
\hline brick (standing on end) & $23 / 16^{\prime \prime} \times 7^{\prime \prime} \times 3 \frac{1 / 2 "}{2}$ & hit, pushed brick over then stalled \\
\hline $\begin{array}{l}\text { moving man (Level A suit } \\
\text { on overhead crane) }\end{array}$ & & stopped, did not hit \\
\hline
\end{tabular}

When ARIES came upon an obstacle which it could see (was located by the sonar), it immediately stopped and beeped a warning to indicate that it had stopped. If the obstacle was removed within an appropriate period of time, ARIES would continue along its path, as previously programmed. If the obstacle was not removed within the designated period of time, ARIES would not continue and had to be manually moved back to its starting location (in this case the charging station) before it could continue on its mission. Manual removal requires a worker, utilizing the appropriate PPE, to enter 
the hazardous area to retrieve the robot using the tether line. The ability to re-start the robot to continue along its path from the operator's station would eliminate the need for a worker to enter the hazardous area.

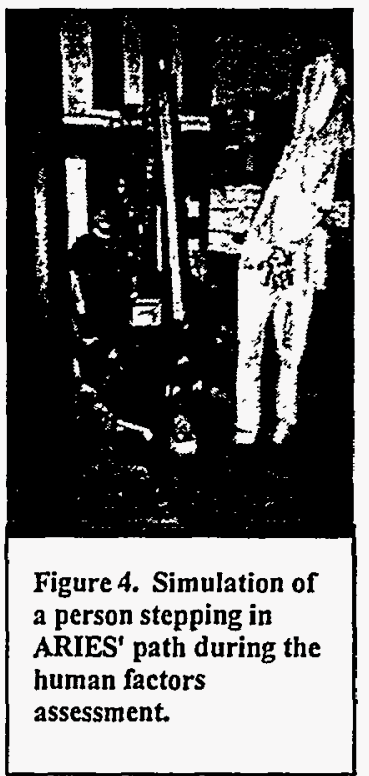

When ARIES came upon an obstacle it could not see (was not located by the sonar), one of two results occurred: (1) the robot ran into the obstacle and stalled or (2) it ran over the obstacle. If ARIES stalled, it would not continue and had to be manually moved back to its starting location (in this case the charging station) before it could continue on its mission. Manual removal would present the concerns discussed above. If the obstacle was small enough that the robot did not stall, it ran over it. There is concern in that this presents the potential for the robot to run over things such as the foot of a worker.

An additional concern is that when the robot does not see an obstacle and runs into it, the robot may attempt to go over the obstacle which could cause the robot to tip. Although there is a feature to set the drive on the robot to avoid the robot attempting to continue, there is still concern for two reasons: (1) the center of gravity of the robot is not known; and (2) there is no stall out feature based on the robot angle of operation. That is, the robot will continue regardless of the angle at which it is climbing. The robot tipping could result in severe injury if it were to fall on or strike a worker. Additional problems could be caused if the robot tipped and knocked over a drum and caused a spill. This has the potential to expose workers to a variety of contaminants. In addition, workers would have to enter the area to clean up the spill. The robot may also become contaminated which presents additional problems which will be discussed in a later section of this report.

Another situation which causes concern for creating a tipping hazard, is an obstacle sticking out at a height above the ground whereby it hits the mast of the robot. The sonar would not "see" an obstacle at that height and the robot would continue until it ran into the obstacle. If the robot continues forward and the obstacle did not move the robot may tip until it falls over. Again, since the center of gravity is not known, it is not possible to determine at what angle the robot will tip.

During the human factors assessment, several substances were spilled on the floor directly in ARIES' path. This was done to determine if a spill occurred and ARIES ran through it, if it would hang-up and burn out the motor or if it would stall out due to the current limit and stall servo kickout features. Water, oil (vegetable oil), a water and oil combination, and a water, oil, liquid soap combination were spilled. ARIES did not have any difficulty navigating through any of the spills. ARIES' ability to navigate through thicker and more slippery spills needs to be evaluated at a later date. 
Decontamination of the base of the robot may be difficult, particularly for radiation contamination. The main areas of concern on the base of the robot are the cooling fan for the on board computer and the access doors for areas such as the on board computer and the batteries. Filtering the air being pulled into the on board computer area by the cooling fan would prevent contamination from getting inside the robot. It needs to be assured that the access doors are sealed to prevent any contamination from getting inside the robot.

Due to the design of the mast and its camera payload arm, it appears to be virtually impossible to decontaminate this section of the robot. Water cannot be used to decontaminate this part of the robot due to all of the open electrical connections and wiring. Where the wiring, chains, and belts run through conduit, the conduit is an open design. Consideration needs to be given to enclosing the electronics, wiring, camera payload and associated components to enable decontamination to take place.

\section{SECTION 4 - EMERGENCY RESPONSE/PREPAREDNESS}

Emergency response and preparedness must be part of every hazardous waste site health and safety plan (HASP). During normal operation of ARIES there is no indication for any out of the ordinary emergencies. However, emergency situations could arise if there were problems such as ARIES tipping or running into something that could potentially be knocked over and spill. This would then require emergency response activities to be put into motion.

All workers must be trained to operate the emergency shut off controls located on ARIES and the manual pendant control. Additionally, they need to be trained to handle any emergencies that may occur in the area where they are operating ARIES.

One concern is that the operator located at the operation station may be out of "line of sight" with ARIES and not be able to see where the robot is or what it is doing in realtime. An emergency situation may occur and not be realized until someone enters the area. This could be remedied by installing a real-time video camera on ARIES that would provide visual feedback to the operator as to ARIES' location and the present operational conditions at any point in time.

Electrical hazards and the potential for leaking lead-acid batteries are the two main concerns for responders to an emergency involving ARIES. A complete shutdown of the system and the use of the proper PPE may be necessary before responding to such an emergency. 


\section{SECTION 5 - REGULATORY/POLICY ISSUES}

Regulations that apply to this technology may be divided into four categories. First, core requirements are those regulations that would apply to any hazardous waste work site, regardless of the type of job. Second, technology-specific requirements are those regulations that apply due to the specific technology being used. Third, special requirements are standards and policies that are specific to the technology itself, and are required by reference in a regulation. Fourth, best management practices are not required but are recommended by organizations such as the American National Standards Institute (ANSI), the National Institute of Occupational Safety and Health (NIOSH), DOE, National Fire Protection Association (NFPA), etc. These regulations/standards may include, but not be limited to, the following:

\section{CORE REQUIREMENTS:}

- OSHA 29 CFR 1926.25 Housekeeping

- OSHA 29 CFR 1910.141 (a)(3) covers housekeeping

- OSHA 29 CFR 1926 Subpart Z Toxic and Hazardous Substances

- OSHA 29 CFR 1910 Subpart Z Toxic and Hazardous Substances

$\checkmark \quad$ OSHA 29 CFR 1926.59 Hazard Communication

- OSHA 29 CFR 1910.1200 Hazard Communication

OSHA 29 CFR 1926.64 Process Safety Management of Highly Hazardous Chemicals

OSHA 29 CFR 1910.119 Process Safety Management of Highly Hazardous Chemicals

- OSHA 29 CFR 1926.65 Hazardous Waste Operations and Emergency Response

OSHA 29 CFR 1910.120 Hazardous Waste Operations and Emergency Response

- Occupational Safety and Health Act 1970(5)(a)(1) General Duty Clause 


\section{TECHNOLOGY SPECIFIC REQUIREMENTS:}

- OSHA 29 CFR 1910.147 The Control of Hazardous Energy (Lockout/Tagout)

- OSHA 29 CFR 1926.102 Eye and Face Protection

- OSHA 29 CFR 1910.133 Eye and Face Protection

- OSHA 29 CFR 1910.1000 Toxic and Hazardous Substances

- OSHA 29 CFR 1926 Subpart K Electrical

- OSHA 29 CFR 1910 Subpart S Electrical

- OSHA 29 CFR 1926.54 Non-ionizing Radiation

- OSHA 29 CFR 1910.97 Non-ionizing Radiation

- OSHA 29 CFR 1926.602 Material Handling Equipment

- OSHA 29 CFR 1910.178 Powered Industrial Trucks

\section{SPECIAL REQUIREMENTS:}

- ANSI B56.1-1969, Safety Standards for Powered Industrial Trucks

\section{BEST MANAGEMENT PRACTICES:}

- ACGIH Threshold Limit Value for Chemical Substances and Physical Agents and Biological Exposure Indices

- ANSI 136.1-1993 Safe Use of Lasers

- Association for Robotics in Hazardous Environments "Guidelines for Procurement Specifications for Remote and Robotic Systems and Equipment to Operate in Hazardous Environments" RHE01.01-1996

- Robotics Industries Association, R15.06 Safety Requirements Draft 10

- NIOSH "Safe Maintenance Guidelines for Robotic Workstations", DHHS (NIOSH) Publication No. 88-108, March 1988 
- NIOSH "Elements of Ergonomics Programs, A Primer Based on Workplace Evaluations of musculo-skeletal Disorders" March 1997

\section{TRAINING REQUIREMENTS:}

In addition to the above regulations and policies, it is imperative that all workers have appropriate and adequate training for the task and associated safety and health conditions. Training that would be required may be divided into four categories. Core training is that which is required for anyone entering a hazardous waste site to perform work, regardless of the type of job. Technology specific training is that training that is specific to the technology and required by safety and health standards. Special training is that which is specific to the technology to assure the worker is adequately trained for the task but is not necessarily required by safety and health standards. Best management practices are training that while not mandated by health and safety standards, provide information and knowledge to the worker that will allow the worker to perform the job safely. Training to be applied for ARIES may include but not be limited to:

\section{Core training requirements:}

HAZWOPER (Hazardous Waste Operations and Emergency Response)

- HAZCOM (Hazard Communication)

Technology Specific training:

- Personal Protective Equipment

Lockout/Tagout

$\checkmark \quad$ Radiation Worker II (due to the environment where ARIES is scheduled to be operated)

\section{Special training:}

- Job specific training for equipment operation

\section{Best Management Practice training:}

Ergonomics (proper lifting, bending, stooping, kneeling, arm-hand vibration)

- CPR/First Aid/Emergency Response/Bloodborne Pathogens 


\section{$-\quad$ Electrical Safety}

- Laser Safety

Fork Lift Training

- Hand Signal Communication

- Construction Safety (OSHA 500) and or General Industry Safety (OSHA 501)

\section{SECTION 6 - OPERATIONAL CONSIDERATIONS AND RECOMMENDATIONS}

- The fiduciaries used for robot navigation are tripping hazards. In addition, they are easily moved, by tripping on them, which could cause navigational problems for the robot. Marking the base of the fiduciary with a brighter color (they are black) would make it more noticeable to anyone walking by. In addition, weighting the base of the fiducial so it will not move so easily when it is bumped would help with the navigational problems that could be created.

- There are electrical hazards associated with the charging station, the lead-acid batteries, and the computer components in the base of the robot. The probe on the charging station carries a low voltage and could cause a mild shock if touched while the robot is docking. During maintenance the energized circuit could result in severe injury or death. The probe needs to be labeled as an electric shock hazard and proper lockout/tagout techniques must be used during maintenance activities.

When changing the lead-acid batteries in the base of the robot, there is the potential for sparking from the battery wire accidentally coming into contact with the frame of the base. This could result in a shock and/or burn hazard to the worker. An electrical disconnect would alleviate this problem.

Reaching into the energized computer components may cause an electrical shock. The computer drawer cover needs to be labeled as an electrical hazard. SOP's to include lockout/tagout procedures to be used when maintenance must be performed needs to be developed.

The laser used on ARIES in the laser-based lidar navigation beacon system is a Class IIlb. Direct viewing as well as diffuse reflections of the beam of a Class Illb laser is hazardous to the eye, in particular the retina. Anyone working in the area where there is the potential to direct or reflected view of the laser beam needs to 
use goggles developed specifically for laser use. In addition, all persons working with or performing any type of maintenance activities on the laser must be trained in laser safety.

Tipping is a concern with the robot. There are two major concerns associated with tipping, the first being that when the robot does not see an obstacle and runs into it, the robot may attempt to go over the obstacle which could cause the robot to tip. Although there is a feature to set the drive on the robot to avoid attempting to continue, there is still concern for two reasons: (1) the center of gravity of the robot is not known and (2) there is no stall out feature based on the robot angle of operation. That is, the robot will continue regardless of the angle at which it is climbing. The robot tipping could result in severe injury if it were to fall on or strike a worker. Additional problems could be caused if the robot tipped and knocked over a drum and caused a spill. This has the potential to expose workers to a variety of contaminants. In addition, workers would have to enter the area to clean up the spill. The robot may also become contaminated which presents additional problems which will be discussed in a later section of this report.

The second situation which causes concern for creating a tipping hazard, is an obstacle sticking out at a height above the ground, therefore, it hits the mast of the robot. The sonar would not "see" an obstacle at that height and the robot would continue until it ran into the obstacle. If the robot continues forward and the obstacle did not move the robot may tip until it falls over. Again, since the center of gravity is not known, it is not possible to determine at what angle the robot will tip.

It is recommended that the center of gravity for the robot be calculated so the angle of tipping required for the robot to fall over will be known. This would then allow the robot to be programmed that when it reaches a certain angle (less than the tipping angle), it will stall and not continue forward until it tips.

Two types of hazardous situations that may be caused by the robot are fall-fromabove hazards and struck-by hazards. There is the potential for fall-from-above hazards if the robot strikes an object and knocks it onto personnel. There is also the potential for struck-by hazards if the robot runs into personnel in the area as well as running into other objects which may then become a struck-by hazard for personnel.

Ergonomics during unloading and loading of the ARIES system is of major concern. The robot, including the base with subturret and mast, and the associated system components must be unloaded from and loaded onto the transport vehicle. The base of the robot with the subturret can be manually "walked" off of or on to the vehicle but the mast and all other components must 
be hand-carried off of or on to the vehicle. The main concern is the mast. The mast which weighs approximately 300 pounds is contained in a wooden cratelike structure that is used to carry it. Although there are handles located on the crate for carrying, there is a great potential for severe back injury and/or injury to the shoulders/arms/hands from workers having to lift and carry this amount of weight. A crate or container or a transport vehicle needs to be developed that will allow the mast to be lifted and carried strictly by mechanical means, such as a forklift.

There is also potential for ergonomic stressors to the back and shoulders/arms/hands from lifting and carrying other system components. Placing these components on pallets to facilitate lifting and moving them with a forklift would alleviate many of these stressors.

Uncrating/crating the mast may require bending, lifting, stooping, and/or kneeling. These activities increase the ergonomic stressors placed on the back, legs, knees, shoulders, and arms. Additionally, uncrating/crating requires the crate to be disassembled from around or assembled around the mast. This requires removing/placing of screws and nails, which at times are in difficult to reach locations. Bolts with wing nuts would be easier to reach and maneuver. A system that would raise and/or lower the crate would eliminate the need for all of the bending, stooping, kneeling.

ARIES is capable of being manually controlled should the need arise. A manual control pendant can be attached to the base of the robot which is then controlled by a "joy-stick" type of control lever. During manual operation, sonar (obstacle avoidance capabilities) are inoperable and the operator must have a clear "line of sight". This is of concern because since the aisles for which the ARIES mission is slated are only 36 inches wide. This requires the operator to manually remove ARIES by walking behind or in front of it. When walking behind ARIES vision may be totally or partially obscured. When walking in front of ARIES the operator must walk backwards and cannot see where he/she is going. Both of these situations have the potential to result in injury to the operator and/or to others in the area. It is recommended that SOP's for the manual removal of ARIES be developed to include the operator checking the path for obstacles before ARIES is moved and notifying others in the area that ARIES is being manually moved so they will stay clear of the path. An alarm (different from the stalled/stopped alarm) would also be useful for notifying other personnel in the area. The operator should never walk backwards while manually moving ARIES.

The front bumper of the base of the robot is large enough that someone could stand on it, although it is not designed for this purpose. Stepping on the bumper could cause the robot to tip which could result in personal injury or drums being 
knocked over and spilled or damaged. It is recommended that a "no step" label be placed on the bumper.

- The probe on the charging station sticks out and could easily be run into. This may injure the person and/or break the probe. It is recommended that the probe

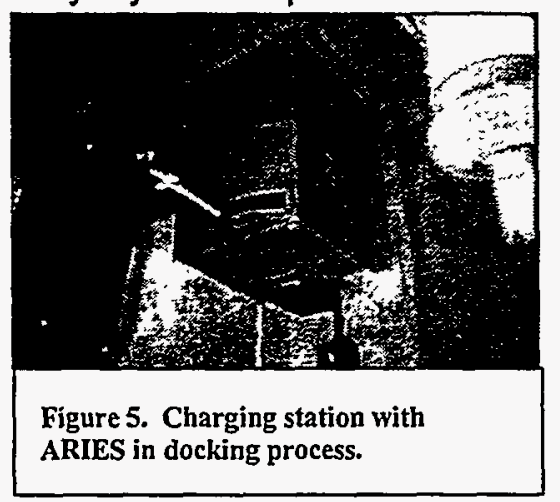
be brightly colored or a brightly colored marker be placed on it so it is more easily seen. Additionally, the charging station should be place well out of the flow of traffic areas. The charging station area could also be marked off so workers could not get close enough to it to come into contact with the probe.

The lead-acid batteries have the potential to create a toxicity/corrosion hazard should they leak. The batteries need to be properly stored and disposed of in accordance with all applicable regulations. If a spill should occur, it needs to be cleaned up immediately. All personnel working with the batteries need to be trained to use them and informed of their potential hazards.

The recharging of lead-acid batteries produces hydrogen gas which has the potential to result in an explosion. It is recommended that "no smoking" signs be posted within 50 feet of the charging station and that the charging station not be placed in the vicinity of any potential ignition sources.

When changing the lead acid batteries in the base of the robot, there is the potential for accidental sparking from the battery wires contacting the frame. There needs to be an electrical disconnect to prevent this from happening.

- The robot is able to move and navigate with the arm, which carries the camera payload, of the mast extended. Fully extended the arm can reach $3^{\prime} 8^{\prime \prime}$ from

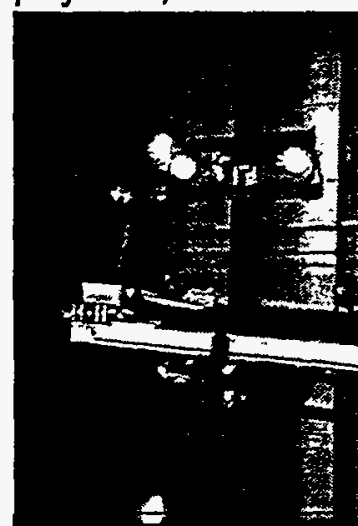

Figure 6. ARIES mast with arm fully extended. center. This will change the center of gravity and may make the robot more unstable. Consideration needs to be given to programming an interlock into the system so the robot cannot move as long as the arm is extended. Additionally, the robot would have to be manually moved with the arm extended if it were to fail in that position. This is due to the fact that failure of autonomous control does not provide a mechanism to retract the arm. If the robot were to be manually moved in this position there is the potential for the arm to hit a drum and knock it over. A mechanism for 
manual retraction of the arm needs to be developed.

- The robot, in particular the mast section of the robot, contains a lot of wiring and small delicate connections. These small connections and the tight areas where they are contained will make it very difficult to perform any maintenance/repair if gloves are required due to the contaminated environment. This area would also be very difficult to decontaminate to move the robot to a clean area for maintenance/repair. Consideration needs to be given to enclosing these areas so they could be easily decontaminated which would make it possible to do maintenance/repair without gloves or other PPE.

- Due to its height (which is approximately 11 feet), there is the potential for the mast to contact overhead hazards. All overhead hazards need to be taken into consideration when programming the robot. Operators should be trained to be aware of the environment in which the robot is operating and to always be looking for changes and new hazards that may necessitate changes in the program. A real-time video camera attached to ARIES would aid the operator's ability to monitor the environment. 


\section{APPENDIX A REFERENCES}

American National Standards Institute, American National Standard for the Safe Use of Lasers: ANSI Z 136.1 (1993), Laser Institute of America, New York, NY (1993)

Occupational Safety and Health Standards for General Industry, 29 CFR Part 1910, Occupational Safety and Health Administration United States Department of Labor, 1995

Occupational Safety and Health Standards for the Construction Industry, 29 CFR Part 1926, Occupational Safety and Health Administration United States Department of Labor, 1995

U.S. Department of Health and Human Services, Public Health Services, Applications Manual for the Revised NIOSH Lifting Equation, DHHS (NIOSH) Publication No. 94110, January 1994 


\section{APPENDIX C ACRONYMS}

$\begin{array}{lll}\text { ACGIH } & - & \text { American Conference of Governmental Industrial Hygienists } \\ \text { ANSI } & - & \text { American National Standards Institute } \\ \text { ARIES } & - & \text { A Robotic Inspection Experimental System } \\ \text { CFR } & - & \text { Code of Federal Regulations } \\ \text { CPS } & - & \text { camera positioning system } \\ \text { DOE } & - & \text { Department of Energy } \\ \text { EPA } & - & \text { Environmental Protection Agency } \\ \text { HASP } & - & \text { Health and Safety Plan } \\ \text { HAZCOM } & - & \text { Hazard Communication } \\ \text { HAZWOPER } & - & \text { Hazardous Waste Operations and Emergency Response } \\ \text { LIDAR } & - & \text { light detection and ranging } \\ \text { MM } & - & \text { millimeter } \\ \text { MW } & - & \text { milliwatt } \\ \text { MWFA } & - & \text { Mixed Waste Focus Area } \\ \text { NFPA } & - & \text { National Fire Protection Association } \\ \text { NIOSH } & - & \text { National Institute of Occupational Safety and Health } \\ \text { OENHP } & - & \text { Operating Engineers National Hazmat Program } \\ \text { OSHA } & - & \text { Occupational Safety and Health Administration } \\ \text { PPE } & - & \text { personal protective equipment } \\ \text { RCRA } & - & \text { Resource Conservation and Recovery Act } \\ \text { RIA } & - & \text { Robotics Industries Association } \\ \text { SOP's } & - & \text { standard operating procedures } \\ \text { TRU } & - & \text { transuranic }\end{array}$

